UNIVERSIDADE DE SÃO PAULO

INSTITUTO DE PSICOLOGIA

DEPARTAMENTO DE PSICOLOGIA EXPERIMENTAL

FERNANDA HELENA RIBEIRO CUTRIM

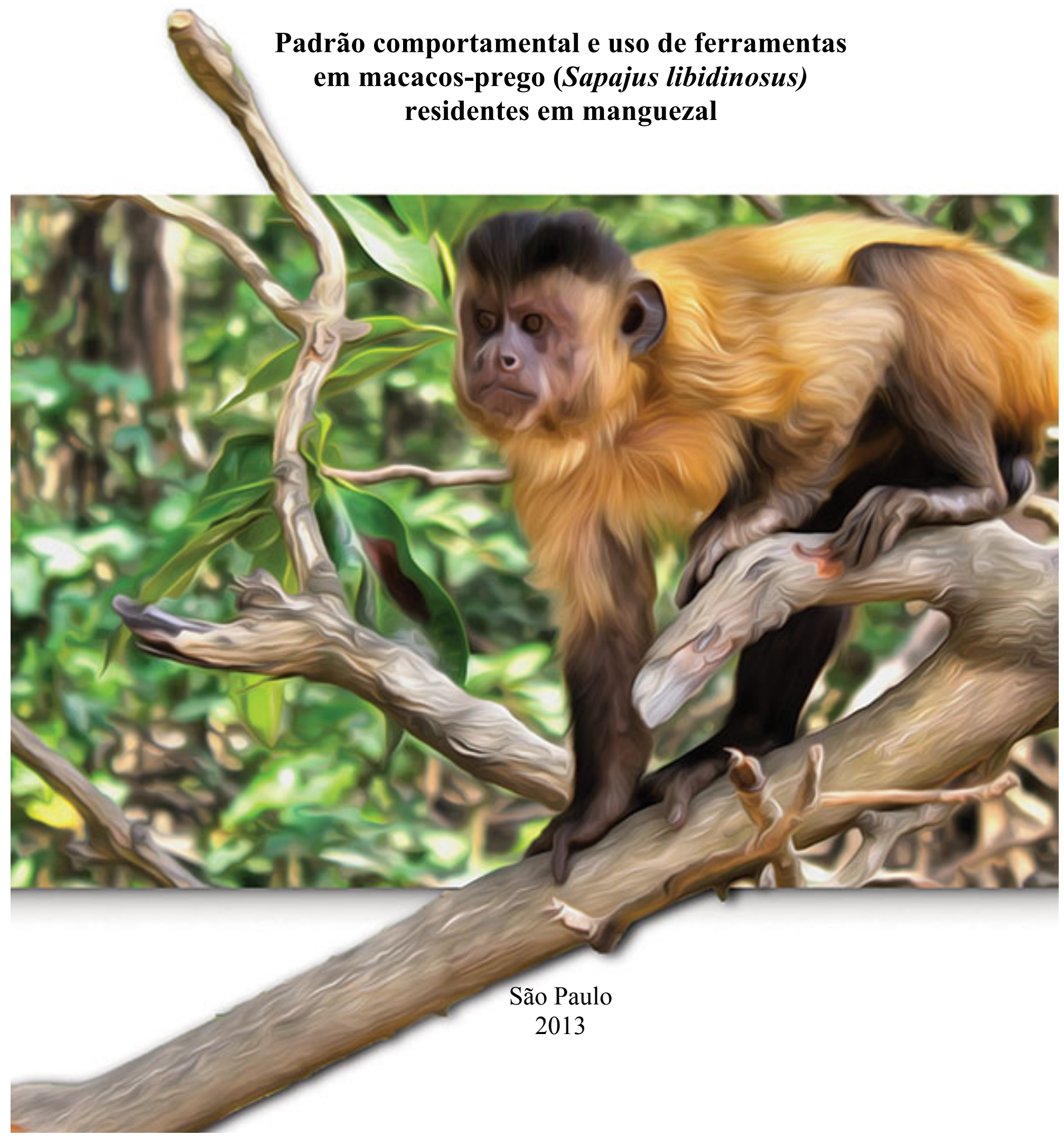




\section{Padrão comportamental e uso de ferramentas em macacos-prego (Sapajus libidinosus) residentes em manguezal}

(Versão corrigida)

Tese apresentada ao Instituto de Psicologia da Universidade de São Paulo, como parte dos requisitos para a obtenção do título de Doutor em Psicologia

Área de concentração: Psicologia Experimental

Orientadora: Prof ${ }^{a}$ Dra. Patrícia Izar 
Cutrim, Fernanda Helena Ribeiro.

Padrão comportamental e uso de ferramentas em macacos-prego (Sapajus libidinosus) residentes em manguezal / Fernanda Helena Ribeiro Cutrim; orientadora Patrícia Izar. -- São Paulo, 2013.

$114 \mathrm{f}$.

Tese (Doutorado - Programa de Pós-Graduação em Psicologia. Área de Concentração: Psicologia Experimental) - Instituto de Psicologia da Universidade de São Paulo.

1. Macacos-prego 2. Dieta 3. Utilização de ferramentas 4. Comportamento alimentar animal 5. Ecossistemas de Mangue I. Título. 
Nome: Cutrim, Fernanda Helena Ribeiro

Título: Padrão comportamental e uso de ferramentas em macacos-prego (Sapajus libidinosus) residentes em manguezal

Tese apresentada ao Instituto de Psicologia da Universidade de São Paulo, como parte dos requisitos para a obtenção do título de Doutor em Psicologia.

Aprovado em:

Banca Examinadora

Prof. (a) Dr. (a):

Instituição:

Assinatura:

Prof. (a) Dr. (a):

Instituição:

Assinatura:

Prof. (a) Dr. (a):

Instituição:

Assinatura:

Prof. (a) Dr. (a):

Instituição:

Assinatura:

Prof. (a) Dr. (a):

Instituição:

Assinatura: 
Aos meus pais, Frederico e Sylvia, com todo o meu amor e gratidão, por me encaminharem na vida com tanta dignidade e não medirem esforços para que eu alcançasse os meus sonhos. 


\section{AGRADECIMENTOS}

Esses quatro anos de caminhada foram de muito estudo, dedicação, abdicação e, por que não, de superação? Mas, sozinha eu não teria chegado até aqui! Por isso, quero agradecer neste momento de muita alegria a todos que contribuíram na construção dessa tese.

Agradeço a Deus, pela força e amparo diante de todas as dificuldades que passei, principalmente quando me via solitária em campo e durante a árdua tarefa de me dividir entre a tese e meu compromisso com minhas aulas e alunos.

Aos meus queridos pais, Sylvia e Frederico, pelo amor, carinho, apoio incondicional nas minhas decisões e encorajamento. À mamãe, pelos ensinamentos, amizade, por entender minha vida de bióloga e por me inspirar a seguir a docência. Ao meu pai, em especial, por todo o esforço e colaboração nos meus estudos, por ter sonhado junto comigo esse passo que hoje se concretiza e, jamais esquecerei, por ter se aventurado no manguezal atrás dos macacos. Eu amo especialmente vocês!

Ao meu irmão, Frederico Jorge, pela amizade, descontração e por ter me incentivado a buscar o doutorado na USP. Obrigada, amore!

Ao Daniel, pelo amor, zelo, apoio, paciência e toda a ajuda, principalmente no campo (nunca imaginei que um publicitário paulista toparia se "embrenhar" na lama e raízes dos mangues atrás de macacos!). Você me surpreende e ter você ao meu lado, ainda que distante, me faz muito feliz! Eu te amo!

Aos meus familiares, Cutrim e Ribeiro, pelo apoio e carinho de sempre!

À professora Dra ${ }^{\mathrm{a}}$. Patrícia Izar, um agradecimento especial, primeiramente por ser um exemplo de pesquisadora competente que me inspirou a estudar os macacos-prego e por aceitar me orientar; pelo entendimento e confiança quando passei a me dividir entre o doutorado e o trabalho, pelos conhecimentos passados e acima de tudo pela orientação, mesmo que à distância, e ajuda ao longo de todo esse processo.

A todas as pessoas que me ajudaram em Barreirinhas e região. Principalmente, ao Nalberto, Ana e família por me acolherem como filha nas suas casas em Vassouras e no Morro do Boi. Agradeço à Ana por ter cuidado de mim, sempre com uma refeição deliciosa ao final de cada dia de trabalho (sinto saudade do robalo na brasa, dos camarões e claro, da farofinha) e pelas conversas prazerosas. Ao Nalberto, pela ajuda no manguezal, por me ensinar como andar na lama sem afundar muito, por me tirar dos "apuros" com as cobras, jacarés, maribondos e com a travessia dos igarapés, sem contar as conversas de mateiro e 
pescador! Ao Marcílio, pela presteza e ajuda no meu deslocamento de barco entre Barreirinhas e Vassouras ou Morro do Boi e por terra até São Luís.

A todos que tentaram me acompanhar no manguezal, mas que por algum motivo não puderam dar continuidade ao longo do trabalho: Nalberto, Nauro, Domingos, Fabrício, Tinho, Zé, Bernardo (vulgo "Lacira") e Nadson. A ajuda de vocês foi muito importante, mas constatamos que seguir macaco-prego em manguezal não é para qualquer um!

À professora Briseida Resende e Michele Verderane, por participarem da minha banca de qualificação e pelas contribuições altamente relevantes para este trabalho.

Aos professores do Departamento pelas informações compartilhadas nas disciplinas da Pós-Graduação que colaboraram para o meu crescimento profissional.

Aos meus colegas da pós pelas conversas e troca de experiências durante meu curto período em São Paulo. Em especial à Priscila Suscke por também ter dividido toda a angústia de ter o auxílio financeiro aprovado e os contratempos do trabalho de campo! E a Laura Stobaüs pelas conversas, companhia durante as disciplinas e ajuda imprescindível quando o tempo esfriava na capital paulista e eu não levava casaco!

Aos meus colegas do Instituto Federal do Maranhão, Campus Bacabal, pela compreensão quando eu não pude dar o meu máximo. Agradeço aos professores Reinaldo Cruz e Maron Stanley pelo entendimento da importância da qualificação dos docentes da Instituição e pela flexibilidade, sempre ajustando minhas atividades docentes com as do doutorado. Agradeço também à Cláudia Mendes, pela ajuda e revisão do abstract.

Aos meus amigos, pelo apoio e entendimento da minha reclusão social.

À Fundação de Amparo à Pesquisa do Estado de São Paulo (FAPESP) pelo apoio financeiro necessário ao desenvolvimento do projeto de pesquisa e ao Conselho Nacional de Desenvolvimento Científico e Tecnológico (CNPq) pela concessão da bolsa de estudos durante o primeiro ano de curso.

E, aos queridos macacos-prego, seres fundamentais para a realização desse trabalho, por me encantar e me ensinar durante todo esse processo. 


\section{RESUMO}

Cutrim, F. H. R. (2013). Padrão comportamental e uso de ferramentas em macacos-prego (Sapajus libidinosus) residentes em área de manguezal. Tese de Doutorado, Instituto de Psicologia, Universidade de São Paulo, São Paulo.

A eficiência dos macacos-prego (gênero Sapajus) em uma ampla variedade de ambientes é resultado de sua flexibilidade, oportunismo e adaptabilidade. Esses primatas demonstram padrões de forrageio complexos, exploram manualmente vários estratos do habitat à procura de presas escondidas e apresentam técnicas de forrageio distintas, mostrando-se eficientes no uso de ferramentas para a obtenção de alimento. Embora poucos estudos abordem primatas não-humanos que vivem em manguezais, sabe-se que neste tipo de habitat existem registros do uso de ferramentas de quebra para acessar recursos animais encapsulados. A presente pesquisa é pioneira no estudo da ecologia e do uso de ferramentas em macacos-prego que habitam ambientes fragmentados, com variações sazonais de maré e de recursos alimentares. Os objetivos deste trabalho foram (1) investigar o orçamento de atividade e a dieta de um grupo de macacos-prego (S. libidinosus) residentes em manguezal, avaliando a influência dos fatores ambientais e da disponibilidade de recursos e (2) analisar, sob a perspectiva das hipóteses da necessidade e da oportunidade o uso de ferramentas por esse grupo, estimando a densidade dos sítios de quebra e sua frequência de uso. $\mathrm{O}$ estudo foi realizado no fragmento de manguezal Morro do Boi (MB), localizado nos Pequenos Lençóis Maranhenses (Barreirinhas), litoral leste do Maranhão, entre setembro de 2011 e março de 2013. Os resultados mostraram que a oferta de alimento encapsulado (caranguejo) no MB não sofreu grande variação ao longo do período da pesquisa e seguiu o padrão encontrado para os manguezais brasileiros situados na zona equatorial, enquanto que a oferta dos recursos vegetais (flores) foi influenciada pelo regime de chuvas e umidade, apresentando-se maior no período chuvoso. O orçamento de atividade foi semelhante ao de algumas populações de macacos-prego selvagens, embora a pequena e fragmentada área de vida e a alta de densidade de indivíduos possam ter influenciado os padrões de forrageio e deslocamento, que se apresentaram diferentes de populações em condições ecológicas e demográficas distintas. $\mathrm{O}$ uso do solo no $\mathrm{MB}$ apesar de ter sido mais frequente que o de populações de floresta úmida foi inferior ao dos macacos-prego do Cerrado/Caatinga, podendo ser um reflexo de fatores como a variação das marés, que limita o tempo de uso desses estratos para o forrageio e o consumo de itens encapsulados com ferramentas de quebra. A dieta se assemelhou a de primatas que vivem em manguezal, com o predomínio de recursos vegetais do mangue. A inclusão de crustáceos e moluscos se deu de forma oportunista, na maré baixa, sendo o caranguejo o item com maior frequência nos sítios de quebra. Os demais recursos por serem menores e menos energéticos do que os caranguejos tiveram maior frequência de quebra no período seco, se apresentando como recursos alternativos utilizados para complementar a dieta. As estratégias de forrageio apresentadas pelos indivíduos do MB confirmam a flexibilidade e adaptabilidade dos macacos-prego e contribuem para o aumento do conhecimento da espécie em um ambiente com limitações de espaço e condições ecológicas sazonais.

Palavras-chave: Orçamento de atividade, dieta, uso de ferramentas, macacos-prego, Sapajus libidinosus, manguezal. 


\begin{abstract}
Cutrim, F. H. R. (2013). Behavioral pattern and tools use in living capuchin monkeys (Sapajus libidinosus) in mangrove. Doctoral Thesis, Institute of Psychology, University of São Paulo, São Paulo.
\end{abstract}

The efficiency of capuchin monkeys (genus Sapajus) in a wide variety of environments is the result of their flexibility, adaptability and opportunism. These primates demonstrate complex patterns of foraging; explore various strata manually in order to look for hidden prey and also they have distinct foraging techniques, showing efficiency at using tools to obtain food. Although few studies approach non-human primates that live in mangroves, it is known in this habitat many records of tool use cracking to access encapsulated animals. This research is pioneer due to the lack of information on the ecology and tool use in capuchin monkeys that inhabit fragmented environments with tidal and seasonal variations of food resources. Our aims were (1) investigating the activity budget and diet of a capuchin monkeys ( $S$. libidinosus) group which live in mangrove estimating whether environmental factors and availability of resources influence in the activity budget and diet and (2) analyzing, from the perspective of the necessity and opportunity hypotheses, the behavioral expression about tool use by this group, estimating the density of tool use in the sites and the frequency of using. The study was conducted at Morro do Boi (MB) fragment's mangrove located on the Lençóis Maranhenses (Barreirinhas), east coast of Maranhão, between September 2011 and March 2013. The results showed that the supply of encapsulated food (crab) in MB did not have a significant variation over the study period and followed the pattern found in the Brazilian mangroves located in the equatorial zone, while the supply of plant resources (flowers) was influenced by rainfall and humidity, being higher in the rainy season. The found activity budget was similar to that one in some populations of wild capuchin monkeys, although small and fragmented home range and high density of individuals may have influenced patterns of foraging and locomotion, which showed different of populations in distinct ecological and demographic conditions. Although the ground use in $\mathrm{MB}$ was more common than in populations of rainforest, it was lower than in Cerrado/Caatinga areas, it may be a reflection of factors such as tidal range, which limits the use of these substrates for foraging and eating encapsulated items with cracking tools. The diet was similar to that one from other primates that live in mangroves, with the predominance of the mangrove plant resources. Consumption of crustaceans and mollusks occurred opportunistically after the low tide, and the crab was the most frequently consummated item in the sites. Regarding to the other resources, the fact of being smaller and less energetic than the crabs they had a higher frequency of breaks in the dry season, presenting themselves as alternative resources used to supplement the diet. The foraging strategies presented by individuals in MB confirm the flexibility and adaptability of capuchin monkeys and contribute to the increasing knowledge of the species in an environment with limited space and seasonal ecological conditions.

Keywords: Activity budget, diet, tools use, capuchin monkeys, Sapajus libidinosus, mangrove. 


\section{LISTA DE FIGURAS}

\section{CAPÍTULO I - Introdução Geral}

Figura 1. Localização da área de estudo. (A) Fragmento de manguezal (Morro do Boi) onde o grupo de estudo reside nos Pequenos Lençóis Maranhenses, Barreirinhas - MA.

Figura 2. Área de estudo. Vista externa (A) e interna (B) do fragmento de manguezal Morro do Boi, Pequenos Lençóis Maranhenses, Barreirinhas -MA.

\section{CAPÍTULO II - Orçamento de atividades e dieta de um grupo de macacos-prego (Sapajus libidinosus) residentes em área de Manguezal no Maranhão}

Figura 1. Disponibilidade mensal de caranguejo (Ucides cordatus) por metro quadrado na área de uso do grupo de macacos-prego (S. libidinosus) do Morro do Boi, no período de setembro de 2011 a março de 2013.

Figura 2. Disponibilidade mensal de flor de Rhizophora mangle por metro quadrado na área de uso do grupo de macacos-prego (S. libidinosus) do Morro do Boi, no período de março de 2012 a março de 2013

Figura 3. Dados climáticos da Estação Farol Preguiças correspondentes ao período de setembro de 2011 a março de 2013.

Figura 4. Correlação de Spearman significativa e positiva entre precipitação e disponibilidade de flor (Rhizophora mangle) no Manguezal do Morro do Boi. 44

Figura 5. Correlação de Spearman significativa e positiva entre umidade e disponibilidade de flor (Rhizophora mangle) no Manguezal do Morro do Boi.

Figura 6. Orçamento de atividades - REP: repouso; DESL: deslocamento; FOR: forrageio; ING VEG: ingestão vegetal; ING ANI: ingestão animal; INT SOC: interação social; OUT: outros - do grupo Morro do Boi, no período de setembro de 2011 a março de 2013. 46

Figura 7. Orçamento de atividades - REP: repouso; DESL: deslocamento; FOR: forrageio; ING VEG: ingestão vegetal; ING ANI: ingestão animal; INT SOC: interação social; OUT: outros - do grupo Morro do Boi, no período de setembro de 2011 a março de 2013.

Figura 8. Orçamento de atividades em relação à classe de idade dos macacos-prego ( $S$. libidinosus) do Morro do Boi, no período de setembro de 2011 a março de 2013 (REP: repouso; DESL: deslocamento; FOR: forrageio; ING VEG: ingestão vegetal; ING ANI: ingestão animal).....

Figura 9. Interações sociais do grupo Morro do Boi no período de setembro de 2011 a março de 2013 
Figura 10. Percentual de interações sociais no grupo Morro do Boi no período de setembro de 2011 a março de 2013.

Figura 11. Uso dos diferentes estratos da floresta de mangue pelos macacos-prego ( $S$. libidinosus) do Morro do Boi no período de setembro de 2011 a março de 2013....................52

Figura 12. Diferentes estratos utilizados pelos macacos-prego (S. libidinosus) do Morro do Boi durante o período de setembro de 2011 a março de 2013. (A) e (B) Uso de estratos com altura superior a 5 metros. (C) e (D) Uso de estratos com altura abaixo de 5 metros, exceto solo. (E) Uso do solo como estrato..... 53

Figura 13. (A) e (B). Fêmea de macaco-prego (S. libidinosus) do grupo Morro do Boi forrageando no solo do manguezal em busca de caranguejo.

Figura 14. Itens da dieta dos macacos-prego (S. libidinosus) do Morro do Boi no período de setembro de 2011 a março de 2013. (A) Propágulo de Avicennia germinans.(B) Fruto de Avicennia germinans.

Figura 15. Itens da dieta dos macacos-prego (S. libidinosus) do Morro do Boi no período de setembro de 2011 a março de 2013. (A) Flor de Rhizophora mangle. (B) e (C) Propágulos de Rhizophora mangle. (D) Detalhe da ponta da raiz de Rhizophora mangle. 55

Figura 16. Itens da dieta dos macacos-prego (S. libidinosus) do Morro do Boi no período de setembro de 2011 a março de 2013. (A) Murici (Byrsonima crassifolia). (B) Guajiru (Chrysobalanus icaco).

Figura 17. Itens da dieta dos macacos-prego (S. libidinosus) do Morro do Boi no período de setembro de 2011 a março de 2013. (A) e (B) Caranguejo (Ucides cordatus). (C) Turu (Teredo sp.). (D) Gastrópode (Neritina sp.). (E) Bivalves e gastrópodes................................ 56

Figura 18. Forrageio e alimentação de invertebrado (lagarta) por um indivíduo de $S$. libidinosus do Morro do Boi. (A) Forrageio. (B) Captura da lagarta (em detalhe no centro do círculo vermelho). (C) Manuseio da lagarta. (D) Ingestão da lagarta......

Figura 19. Fezes com vestígios dos alimentos consumidos pelos macacos-prego ( $S$. libidinosus) do Morro do Boi. (A) Caranguejo. (B) e (C) Frutos de Avicennia germinans......

Figura 20. Tipos de alimentos ingeridos pelos macacos-prego (S. libidinosus) do grupo Morro do Boi no período de setembro de 2011 a março de 2013. 58

Figura 21. Tipos de alimentos ingeridos pelos macacos-prego (S. libidinosus) do grupo Morro do Boi nas estações seca e chuvosa no período de setembro de 2011 a março de 2013. 58 


\section{CAPÍTULO III- Uso de ferramentas por macacos-prego (Sapajus libidinosus) em Manguezal no Maranhão: evidências indiretas e caracterização dos sítios de quebra}

Figura 1. Evidências do uso de ferramentas por macacos-prego ( S. libidinosus) do Morro do Boi. (A) Ocorrência de fragmentos das carapaças de caranguejos nas bigornas e (B) nos pedaços de pau utilizados como martelos. 81

Figura 2. Vestígios de caranguejo com quebra recente. (A) cefalotórax superior intacto. (B) e (C) resíduos das carapaças de caranguejos quebradas com martelo. Destaque em círculo para a marca das mãos do macaco-prego (S. libidinosus) 81

Figura 3. Tipos de bigorna utilizadas pelos macacos-prego (S. libidinosus) do Morro do Boi no período de março de 2012 a março de 2013.

Figura 4. Caracterização dos sítios de quebra encontrados no Morro do Boi no período de março de 2012 a março de 2013: tipos de bigorna. (A) Bigorna do tipo tronco caída no chão (detalhe do martelo em cima da bigorna). (B) Bigorna do tipo raiz (Sítio com 3 (três) martelos, no detalhe).

Figura 5. Caracterização das bigornas (altura e diâmetro) quanto ao tipo tronco e raiz utilizadas pelos macacos-prego (S. libidinosus) do Morro do Boi no período de março de 2012 a março de 2013.

Figura 6. Caracterização das bigornas quanto ao substrato utilizadas pelos macacos-prego $(S$. libidinosus) do Morro do Boi no período de março de 2012 a março de 2013. (A) Substrato liso. (B) Substrato rugoso. As setas indicam a presença de caranguejos quebrados. 85

Figura 7. Bigorna de Rhizophora mangle do tipo raiz com substrato reto e rugoso utilizada pelos macacos-prego (S. libidinosus) do Morro do Boi no período de março de 2012 a março de 2013. Em vermelho destacam-se o martelo utilizado e os fragmentos das carapaças dos caranguejos que foram quebrados.

Figura 8. Caracterização dos sítios de quebra quanto ao tipo de alimento quebrado/extraído pelos macacos-prego (S. libidinosus) do Morro do Boi no período de março de 2012 a março de 2013.

Figura 9. (A) Sítio de quebra com vestígios de quebra de caranguejo (Ucides cordatus) no Manguezal Morro do Boi em 2013. (B) Tamanho médio dos cefalotórax dos caranguejos encontrados intactos nos sítios de quebra.

Figura 10. (A) Sítio de quebra com vestígios das conchas de gastrópodes (Neritina sp.) no manguezal Morro do Boi em 2012. (B) Tamanho médio dos gastrópodes encontrados nos sítios de quebra.

Figura 11. Número de sítios com vestígios de quebra de alimentos encapsulados no Morro do Boi no período de março de 2013 a março de 2013. 
Figura 12. Tipo de alimento encapsulado encontrado nos sítios de quebra nas estações seca e chuvosa no Manguezal do Morro do Boi no período de março de 2012 a março de 2013.

Figura 13. Localização dos sítios de quebra no fragmento de manguezal do Morro do Boi. Os sítios numerados de 1 a 4 foram os que apresentaram vestígios de uso durante todos os meses. Os dois sítios representados por bandeiras vermelhas apresentaram vestígios de quebra, porém nenhum martelo foi encontrado no local

Figura 14. (A) e (B). Sítio de quebra com localização à margem de um igarapé (ao fundo) que foi abandonado pelos macacos-prego (S. libidinosus) do Morro do Boi provavelmente pelas pertubações causadas por seres humanos no meio do estudo. 
CAPÍTULO II - Orçamento de atividades e dieta de um grupo de macacos-prego (Sapajus libidinosus) residentes em área de Manguezal no Maranhão

Tabela 1. Categorias comportamentais registradas pelo método de varredura no grupo de macacos-prego (S. libidinosus) do Morro do Boi no período de setembro de 2011 a março de 2013. 40

Tabela 2. Valores de Mann-Whitney para o orçamento de atividades do grupo Morro do Boi, no período de setembro de 2011 a março de 2013. REP: repouso; DESL: deslocamento; FOR: forrageio; ING VEG: ingestão vegetal; ING ANI: ingestão animal; INT SOC: interação social

Tabela 3. Valores de Mann-Whitney para o orçamento de atividades nas estações seca e chuvosa do grupo Morro do Boi, no período de setembro de 2011 a março de 2013.

Tabela 4. Valores de Mann-Whitney para os tipos de interações sociais nas estações seca e chuvosa do grupo Morro do Boi, no período de setembro de 2011 a março de 2013.

CAPÍTULO III- Uso de ferramentas por macacos-prego (Sapajus libidinosus) em Manguezal no Maranhão: evidências indiretas e caracterização dos sítios de quebra

Tabela 1. Caracterização das bigornas e martelos utilizados pelos macacos-prego ( $S$. libidinosus) do Morro do Boi para a extração de itens animais encapsulados no período de março de 2012 a março de 2013 


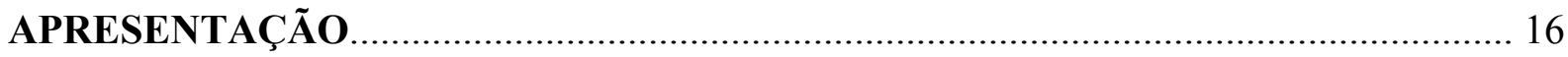

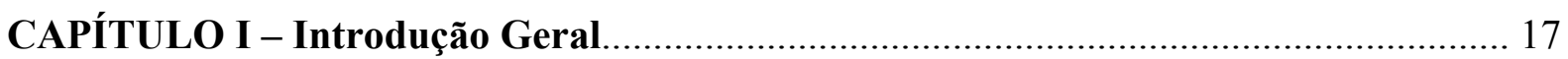

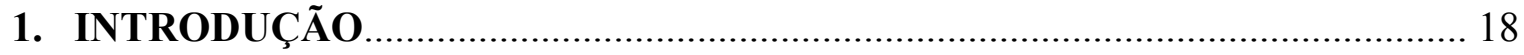

1.1.Ecologia de primatas e flexibilidade comportamental....................................... 18

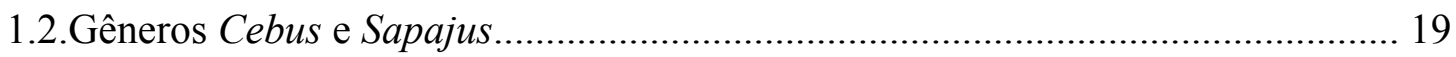

1.2.1. Taxonomia, distribuição, dieta e flexibilidade comportamental............... 19

1.2.2. Uso de ferramentas nos macacos-prego................................................. 22

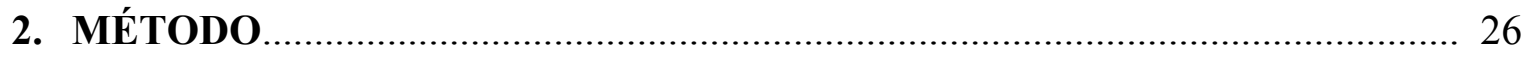

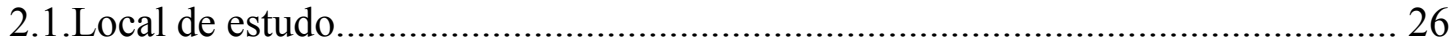

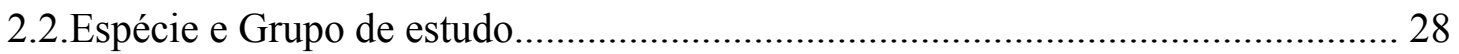

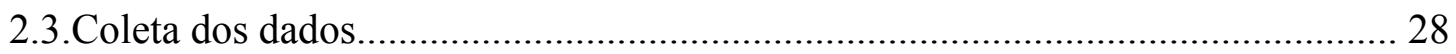

CAPÍTULO II - Orçamento de atividades e dieta de um grupo de macacos-prego (Sapajus libidinosus) residentes em área de Manguezal no Maranhão........................... 30

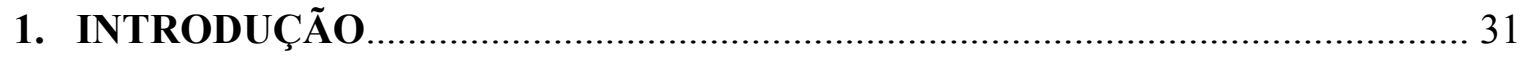

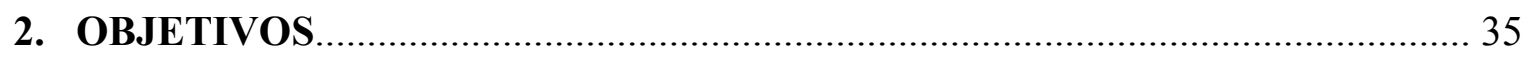

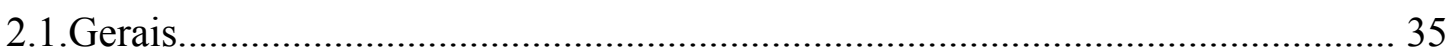

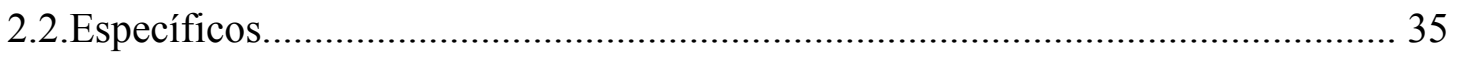

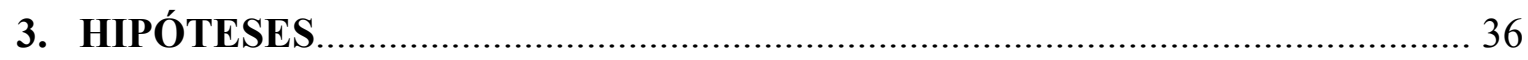

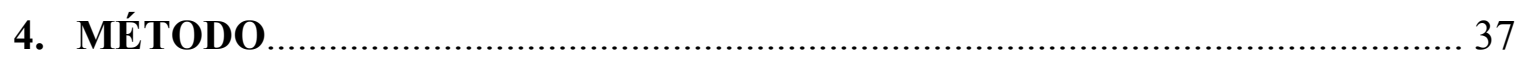

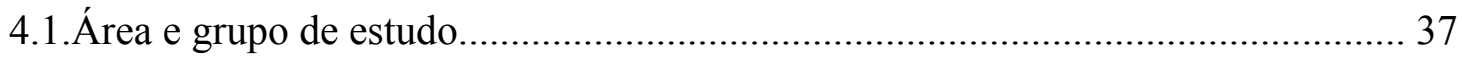

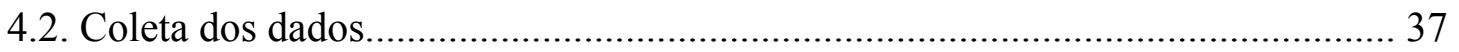

4.2.1. Disponibilidade de alimento e Clima.................................................... 37

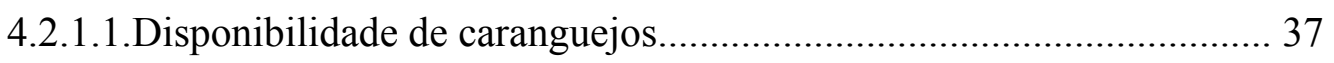

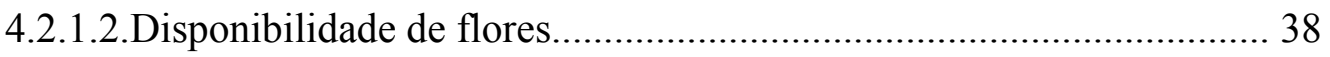

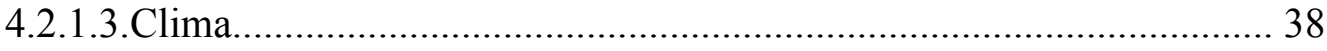

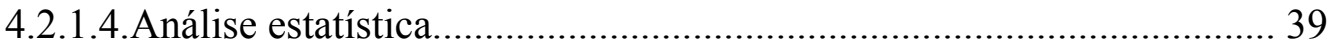




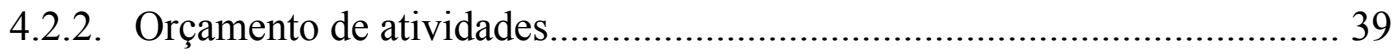

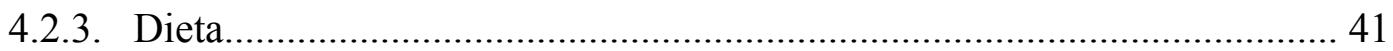

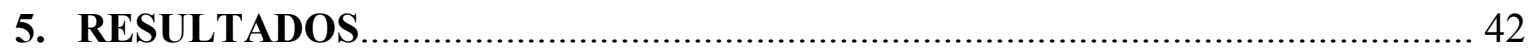

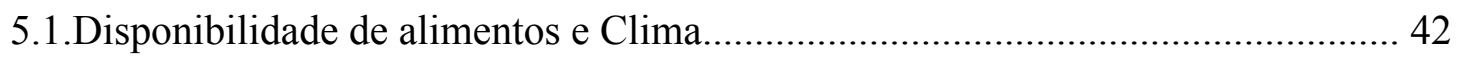

5.1.1. Disponibilidade de caranguejos............................................................ 42

5.1.2. Disponibilidade de flores.................................................................. 42

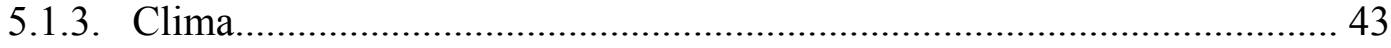

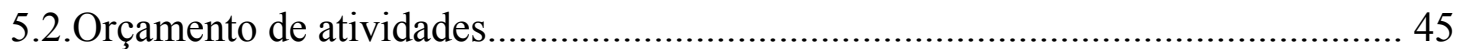

5.2.1. Orçamento de atividades em relação à classe de idade............................. 48

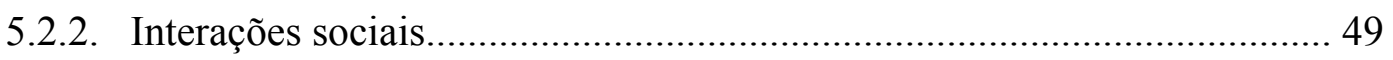

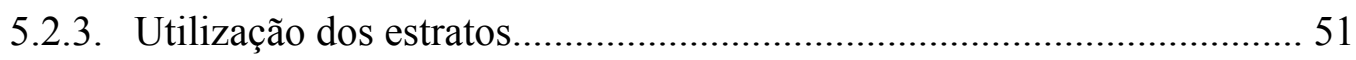

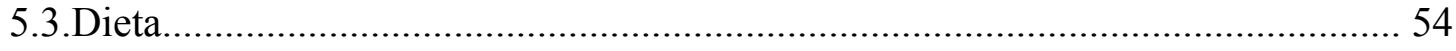

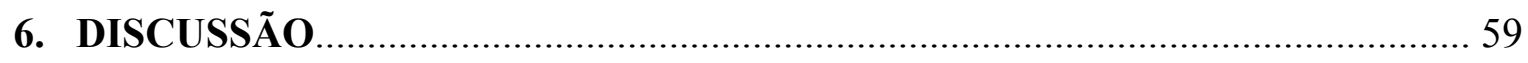

6.1.Disponibilidade de alimento e Clima.................................................................. 59

6.2.Orçamento de atividades e Interações sociais....................................................... 60

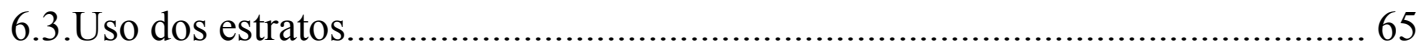

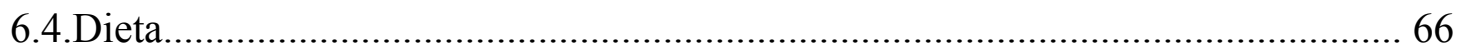

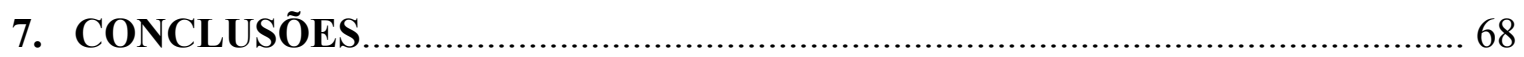

CAPÍTULO III- Uso de ferramentas por macacos-prego (Sapajus libidinosus) em Manguezal no Maranhão: evidências indiretas e caracterização dos sítios de quebra... 70

1. INTRODUÇÃ

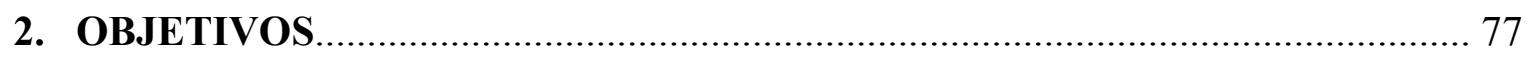

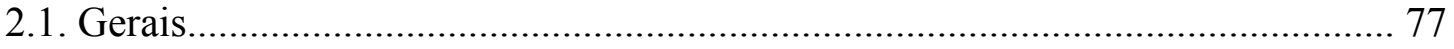

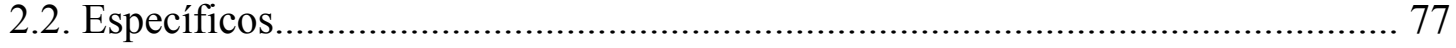

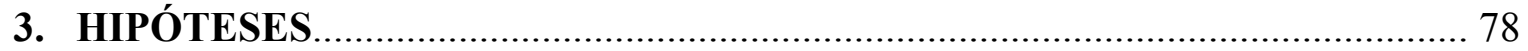

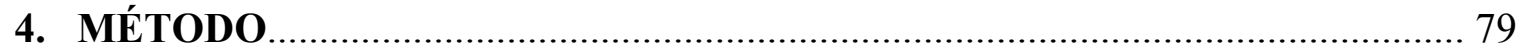

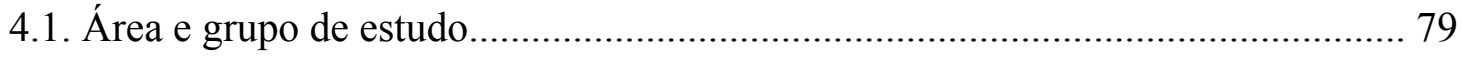

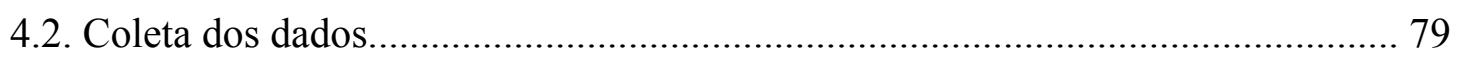

4.2.1. Mapeamento, caracterização e densidade dos sítios de quebra.................. 79

4.2.2. Evidências de quebra e frequência de uso de ferramentas.......................... 80

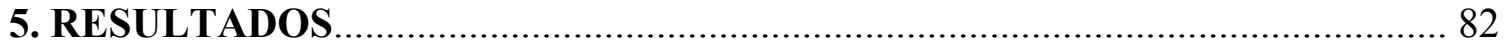


5.1. Caracterização e densidade dos sítios de quebra.................................................. 82

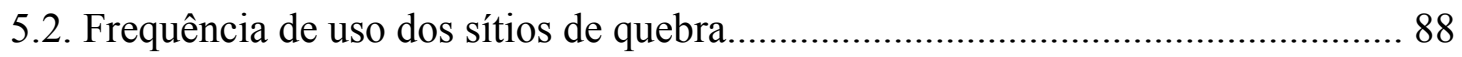

6. DISCUSSÃO

6.1. Caracterização e densidade dos sítios de quebra utilizados pelos macacos-prego

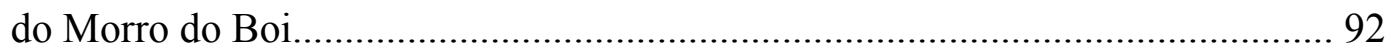

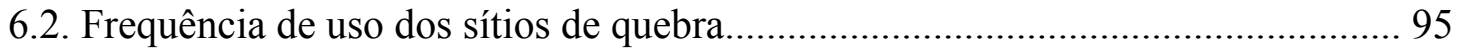

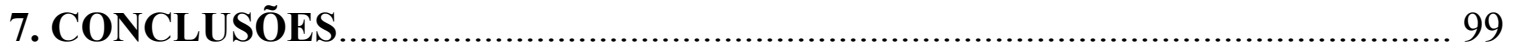

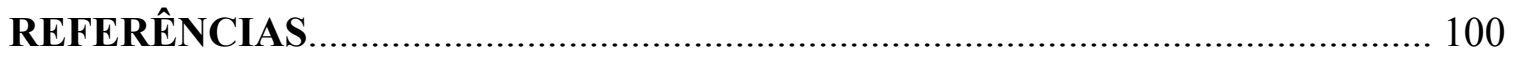




\section{APRESENTAÇÃO}

A ideia de realizar minha pesquisa de doutorado com macacos-prego (Sapajus libidinosus) que habitam Manguezal surgiu em meados de 2008, após um estudo inicial em que foi detectada a presença de grupos que usavam martelos de madeira para quebrar crustáceos e moluscos na região dos Pequenos Lençóis Maranhenses (dos Santos, 2010). O estudo de dos Santos (2010) foi o "pontapé” inicial para o conhecimento da espécie nesse tipo de habitat criando a oportunidade para a execução de mais estudos que ampliassem as informações sobre o uso de ferramentas, inserindo aspectos da ecologia desses primatas em um ambiente tão pouco explorado.

A escassez de estudos com primatas em manguezais pode ser em decorrência da variação das marés, que inundam o ambiente duas vezes ao dia, e da própria vegetação, que apresenta um emaranhado de raízes aéreas, limitando o deslocamento do pesquisador na área. Este é o primeiro estudo que aborda, além do uso de ferramentas, o orçamento de atividades e a dieta de um grupo selvagem de S. libidinosus em Manguezal. Portanto, apresenta relevância juntamente com outros estudos realizados pela minha orientadora, Prof ${ }^{\mathrm{a}}$. Dr ${ }^{\mathrm{a}}$. Patrícia Izar, contribuindo com o objetivo da sua linha de pesquisa dentro do Laboratório de Etologia Cognitiva (LEC), do Departamento de Psicologia Experimental da Universidade de São Paulo, que é investigar a relação entre flexibilidade comportamental e variabilidade das características ecológicas das áreas ocupadas por diferentes espécies e populações de Sapajus ssp.

Minha tese está organizada em três capítulos. O capítulo I é uma introdução geral sobre ecologia e flexibilidade de primatas e aspectos dos gêneros Cebus e Sapajus. Além disso, aborda a descrição da área de estudo e do grupo estudado. O capítulo II se refere ao orçamento de atividades, dieta e uso dos diferentes estratos pelos macacos-prego ( $S$. libidinosus) residentes em Manguezal no Maranhão. Já o capítulo III aborda o uso de ferramentas de quebra por macacos-prego (S. libidinosus) residentes em Manguezal no Maranhão por meio de evidências indiretas, além de caracterizar os sítios de quebra. Tanto o capítulo II quanto o capítulo III se apresentam na forma de manuscrito, com introdução, objetivos, hipóteses, metodologia, resultados, discussão, conclusão. As referências bibliográficas de todos os capítulos se encontram no final da tese. 
CAPÍTULO I: Introdução geral 


\section{INTRODUÇÃO}

\subsection{Ecologia de primatas e flexibilidade comportamental}

A diversidade de adaptações relacionadas aos diferentes comportamentos apresentados pelos primatas faz destes animais alvo de inúmeras pesquisas. Estudos de longo prazo que abordam o comportamento e a ecologia dos primatas têm identificado que muitas espécies têm a capacidade de ajustar o seu comportamento em diferentes condições ecológicas (Umpathy \& Kumar, 2000; Jolly, Dobson, Rasamananina, Walker, O`Conner, Salberg et al., 2002; Ménard, 2002; Izar, Verderane, Peternelli-dos-Santos, Mendonça-Furtado, Presotto, Tokuda et al., 2012). Segundo Jones (2005), os indivíduos são altamente dinâmicos, pois apresentam a capacidade de mudar as estratégias comportamentais, dependendo do contexto ambiental. Essa capacidade de alterar os tipos e a quantidade de comportamentos no tempo e no espaço é chamada de flexibilidade comportamental ou plasticidade comportamental (Jones, 2005).

O orçamento de atividades, ou seja, a distribuição ao longo do tempo das diferentes atividades realizadas pelo animal, necessárias para sua sobrevivência e reprodução (Dunbar, 1988) e a dieta revelam padrões gerais de comportamento e também respostas das espécies às diferentes pressões socioecológicas e sobre seu grau de flexibilidade frente às mudanças no ambiente (Isbell, 1991).

A flexibilidade comportamental em relação ao orçamento de atividades pode ocorrer, por exemplo, em decorrência da sazonalidade na oferta de alimentos. No período de baixa oferta de alimentos, os animais podem se deslocar mais e percorrer distâncias maiores dentro da área de uso para compensar as fontes de alimento (Isbell, 1991; Peternelli-dos-Santos, 2009; Izar et al., 2012), podem aumentar o tempo dedicado à alimentação para compensar uma dieta mais pobre (Teichroeb \& Sicotte, 2009), podem reduzir o tempo de deslocamento e aumentar o de descanso para conservar energia (Milton, 1980, 1998) ou, ainda, podem aproveitar melhor os recursos disponíveis maximizando a obtenção de nutrientes (Silva,Veríssimo \& Oliveira, 2011). Em relação à dieta, a flexibilidade na escolha dos itens alimentares foi discutida, por exemplo, por Ménard (2002) com a espécie Macaca sylvanus. O autor identificou duas "fases" de alimentação que são ajustadas pelos macacos de acordo com a estação do ano: uma "fase granívora" quando a dieta é predominantemente composta por 
sementes de herbáceas e uma "fase insetívora", quando um alimento proteico é mais abundante na dieta. A mudança de uma fonte de alimento para outra pode ocorrer dentro e entre estações e os padrões de seleção de alimentos podem ser diferentes por idade/sexo e individualmente (Altmann, 1998).

Primatas que vivem em manguezais são pouco estudados, porém para Macaca fascicularis foi verificado que a variação da maré e a dieta influenciaram no orçamento de atividades (Son, 2004). Esses primatas aumentaram o tempo de descanso nos períodos do dia em que a maré enche e após a enchente, se deslocaram rapidamente em busca dos macrobentos. Son (2004) sugere que a alimentação de macrobentos influencia o tempo gasto nas demais atividades, pois como são recursos de alta permitem o forrageio de outros tipos de alimentos e aumentam também o tempo para as atividades sociais. Contudo, muitas informações sobre a ecologia de primatas que habitam manguezais são desconhecidas, sendo necessários mais estudos que busquem ampliar esse conhecimento, incluindo espécies do Novo Mundo.

\subsection{Gêneros Cebus e Sapajus}

\subsubsection{Taxonomia, distribuição, dieta e flexibilidade comportamental}

A principal característica morfológica que diferenciava os primatas do gênero Cebus para classificar as espécies era a ausência ou presença de tufos de pelos longos e eréteis na extremidade da cabeça (Ford \& Hobbs, 1996). Porém, devido à incerteza na taxonomia, diante da enorme variabilidade fenotípica dos seus representantes, características anatômicas foram utilizadas para dividi-los em forma robusta (macacos-prego) e forma grácil (caiararas) (Groves, 2001; Silva Jr., 2001).

Ainda assim, é importante para a taxonomia de um grupo a inclusão de dados moleculares que associados às demais características contribuem para o estabelecimento mais fiel possível da filogenia do grupo. Em virtude disso, uma nova classificação para esses primatas foi recentemente proposta através de evidências moleculares e biogeográficas associadas às diferenças morfológicas, ecológicas e comportamentais (Lynch Alfaro, Boubli, Olson, Di Fiore, Wilson, Gutiérrez-Espeleta et al., 2012a). Lynch Alfaro et al. (2012a) 
sugerem a separação do gênero Cebus em dois: Cebus e Sapajus, com o gênero Cebus compreendendo as formas gráceis, com quatro espécies (C. albifrons, $C$. olivaceus, $C$. capucinus e C. kaapori) e o gênero Sapajus compreendendo as formas robustas, com oito espécies (S. apella, S. macrocephalus, S. libidinosus, S. cay, S. nigritus, S. robustus, S. xanthosternos e S. flavius).

Segundo os autores, a formação do rio Amazonas foi responsável por criar uma separação norte-sul que isolou os primatas que ali viviam, gerando a ramificação que deu origem a Cebus e a Sapajus (Lynch Alfaro et al., 2012a). Por isso, os gêneros Cebus e Sapajus apresentam ampla distribuição geográfica, desde a América Central até a América do sul, com Cebus apresentando ocorrência na América Central e na Amazônia e Sapajus exclusivamente na América do Sul. No Brasil, os macacos-prego (gênero Sapajus) ocupam diversos ambientes (Amazônia, Cerrado, Caatinga, Matas Semi-Decíduas e Mata Atlântica) e todos os estratos arbóreos de florestas tropicais inundáveis ou não, florestas primárias, secundárias, palmeirais, campos sulinos/abertos e mangues (Fragaszy, Visalberghi \& Fedigan, 2004a).

Sobre florestas de mangue as informações são limitadas, porém há registros da ocorrência de S. apella, C. olivaceus (Fernandes, 1991; Fernandes \& Aguiar, 1993; Silva Jr., 2001; dos Santos, 2010) e de S. libidinosus (dos Santos, 2010) na Costa Amazônica do Brasil. No estudo de dos Santos (2010), as áreas de manguezais ocupadas por S. apella parecem refletir tendências distintas de ocupação em relação a $S$. libidinosus. Para a primeira espécie, os manguezais funcionam como habitat marginal (Fernandes \& Aguiar, 1993), pois os grupos transitam da terra firme para a floresta alagada possivelmente para complementar a dieta com diferentes recursos, e para S. libidinosus, funcionam como área de uso regular, pois os grupos se encontram isolados das florestas de terra firme, uma vez que estas áreas são fragmentadas pelo avanço de campos de dunas, região conhecida como "Lençóis Maranhenses" (SouzaFilho, 2005). A ocupação de manguezais por macacos-prego pode estar associada, inicialmente, ao seu comportamento exploratório ou condicionada às flutuações dos recursos alimentares em florestas de terra firme das zonas costeiras (dos Santos, 2010).

Os primatas consomem uma variedade de itens alimentares para obter os carboidratos, gorduras e proteínas necessários para sua sobrevivência e reprodução (Fragaszy et al., 2004a). Os macacos-prego são onívoros, ou seja, apresentam uma dieta bastante diversificada, a qual é composta por frutos, sementes, flores, gomas, néctar, bases foliares (principalmente de espécies da família Bromeliaceae), fungos, ovos, invertebrados, pequenos vertebrados e até algumas espécies de ostras e caranguejos em regiões costeiras (Brown \& Zunino, 1990; 
Fragaszy et al., 2004a). Porém, sua dieta pode sofrer variações decorrentes da ação de fatores ecológicos, como, por exemplo, a sazonalidade (Brown \& Zunino, 1990; Peres, 1993; Rímoli, 2001; Izar, 2004), e a maioria das espécies de macacos-prego modifica sua alimentação em períodos de baixa disponibilidade de recursos (Izar et al., 2012).

No estudo de Izar e colaboradores (2012), dados sobre a biomassa dos frutos, orçamento de atividades, alimentação e deslocamento de $S$. nigritus e $S$. libidinosus apresentaram relação com a disponibilidade de frutos em duas áreas distintas (Parque Estadual Carlos Botelho - PECB - e Fazenda Boa Vista - FBV, respectivamente). Na FBV, os macacos-prego (S. libidinosus) passaram mais tempo em repouso e menos tempo em forrageio e deslocamento que os do PECB ( $S$. nigritus), um padrão de orçamento de atividades associado à maior disponibilidade de alimentos (Izar et al., 2012). S. nigritus despendeu mais tempo forrageando folhas, cujas partes consumidas são a base foliar de bromélias e o pecíolo de folhas de palmeiras, ambas energeticamente pobres, mas altamente abundantes e uniformemente distribuídas no habitat (Izar, 2004). Assim, o forrageio de alimentos com tais características energéticas e de distribuição foi uma estratégia para evitar os custos da competição direta, o que se refletiu no predomínio da competição indireta no PECB (Izar et al., 2012).

Em S. libidinosus que habita a Caatinga, uma das estratégias contra a escassez natural de alimentos foi a utilização de tubérculos de Thiloa glaucocarpa (Moura \& Lee, 2004), e em ambiente de Manguezal, o consumo de crustáceos e moluscos (dos Santos, 2010) pode ocorrer em decorrência da reduzida diversidade vegetal (Fernandes, 1999; Fernandes, Virgulino, Nascimento \& Rodrigues, 2005; Menezes, Berger \& Mehlig, 2008) e maior diversidade de presas animais (Macintosh \& Ashton, 2002).

A correlação entre a carnivoria, que pode ser definida como o consumo de carne além de insetos, e habitat sazonal (como por exemplo, ambiente com variação de marés) pode ser observada em alguns primatas (Cebus capucinus: Wainwright, 2002, Morris, 2009; Papio ursinus: Denny \& Gaines, 2007, Lewis \& O'Riain, 2009). Porém, a submersão intertidal durante os ciclos de maré é um fator que limita a intensidade do aproveitamento dos recursos de alta qualidade (por exemplo, ovos de tubarão, mexilhões e caranguejos) e, por isso, o forrageio de alimentos marinhos corresponde a uma proporção mínima do tempo total de forrageio de primatas neste tipo de habitat (Lewis \& O'Riain, 2009). Populações de Cebus capucinus que habitam Manguezais na Costa Rica também aproveitam o período de baixamar para forragear moluscos (Morris, 2009). Esses caiararas não apresentam mandíbulas e dentes fortes e também não usam ferramentas de quebra para obter alimento, como fazem 
algumas espécies de macacos (Macaca fascicularis: Son, 2003; Malaivijitnoud, Lekprayoon, Tandavanittj, Panha, Cheewatham \& Hamada, 2007; Cebus albifrons trinitatis: Phillips, 1998; Sapajus apella: Rocha, Reis \& Sekiama, 1998; Ottoni \& Mannu, 2001; Sapajus libidinosus: Moura \& Lee, 2004; Fragaszy, Izar, Visalberghi, Otonni \& Oliveira, 2004b; Ottoni \& Izar, 2008; dos Santos, 2010; Ferreira, Emidio \& Jerusalinsky, 2010; Sapajus xanthosternos: Canale, Guidorizzi, Kierulff \& Gatto, 2009) e por isso, utilizam a estratégia de bater o molusco no tronco das árvores para facilitar a abertura da concha.

$\mathrm{O}$ desenvolvimento da carnivoria pelos macacos-prego pode ser atribuído às suas características intrínsecas como a flexibilidade dietética e comportamental, o oportunismo e a adaptabilidade diante de novos cenários ecológicos. Em virtude disso, os macacos-prego apresentam a capacidade de explorar recursos alimentares disponíveis no habitat aos quais outras espécies de primatas neotropicais não conseguem ter acesso (Fragaszy et al., 2004a, Sabbatini, Stammati, Tavares \& Visalberghi, 2008). Esses estudos mostram a plasticidade dos gêneros Cebus e Sapajus em relação ao comportamento de forrageio, tanto pela diversidade de recursos e itens incorporados na dieta em diferentes habitats, como pelo fato de utilizarem técnicas de forrageio complexas.

\subsubsection{Uso de ferramentas nos macacos-prego}

Os macacos-prego apresentam em seu repertório comportamental a capacidade de usar ferramentas. Antes do seu conhecimento em populações selvagens, a observação de macacosprego usando ferramentas só era possível em cativeiro (Visalberghi, 1990) e em semiliberdade (Resende, 2004). Hoje, após a realização de vários estudos, sabe-se que diferentes espécies e em ambientes distintos exibem este comportamento (Ottoni \& Izar, 2008; Canale et al., 2009; Ferreira et al., 2010; dos Santos, 2010; Souto, Bione, Bastos, Bezerra, Fragaszy \& Schiel, 2011; Emidio \& Ferreira, 2012).

A população mais estudada até o momento é a de $S$. libidinosus em ecótono de Cerrado/Caatinga na Fazenda Boa Vista (FBV) no Piauí. Os macacos-prego da FBV utilizam habitualmente martelos de pedras para quebra de cocos (Spagnoletti, Visalberghi, Ottoni, Izar \& Fragaszy, 2011). Vários estudos mostram que os macacos escolhem as ferramentas em função do peso e material, os cocos pela resistência de quebra e os locais de quebra de acordo com a eficiência de quebra e seu uso recente por outros indivíduos (Visalberghi, Addessi, 
Truppa, Spagnoletti, Ottoni, Izar \& Fragaszy, 2009a; Fragaszyet al., 2010a; Liu, Fragaszy, Wright, Wright, Izar \& Visalberghi, 2011).

Recentemente, Fragaszy, Wright, Allen, Brown \& Visalberghi (2013) mostraram que os macacos-prego para alcançar a estabilidade do coco na bigorna, batem repetidamente os frutos nas suas depressões antes de colocá-los definitivamente na bigorna e golpeá-los com uma pedra. Isso porque o deslocamento do coco também é considerado um custo, pois o macaco perde tempo procurando-o e com isso aumenta a probabilidade de perder o acesso ao martelo e à bigorna. Segundo os pesquisadores, a seleção de cocos, pedras e bigornas implica atenção a várias propriedades destes objetos e superfícies em relação à sua contribuição para a quebra de cocos. Os macacos podem fazer estas escolhas para otimizar alguma combinação de valores (por exemplo, minimizar o tempo necessário para processar um fruto; maximizar o retorno energético, maximizar a confiabilidade do ganho energético, minimizar o risco de deslocamento ou roubo do recurso por outros membros do grupo).

Outra observação recente na FBV foi o uso de ferramentas para a abertura da castanha de caju (Sirianni \& Visalberghi, 2013). O estudo de Sirianni \& Visalberghi (2013) registrou pela primeira vez que os macacos-prego conseguiram acessar o endosperma nutritivo da castanha de caju evitando os produtos químicos cáusticos que a protegem. Neste caso, eles processam a castanha de caju de forma flexível, associando as características mecânicas e químicas com a maturação do fruto. Assim, foram descritas duas formas de processamento do fruto: 1) quando o fruto está fresco, os macacos-prego esfregam a castanha repetidas vezes em uma superfície áspera até que a casca se abra completamente expondo o endosperma, que é retirado com o dedo indicador e 2) quando o fruto está seco, os macacos-prego utilizam uma ferramenta para quebrar a casca e quase nunca esfregam a castanha. Sirianni \& Visalberghi (2013) sugerem que os macacos-prego utilizam a técnica do "esfregamento" para evitar o contato das substâncias cáusticas com a mucosa da boca, como pode acontecer ao tentarem abrir a castanha com os dentes. No caso dos frutos secos, além da toxicidade, a rigidez da casca também é outro fator que leva os animais a usar ferramentas de quebra.

O uso de ferramenta em $S$. libidinosus da FBV embora seja rotineiro, representa uma pequena porção do tempo gasto por esses macacos nas suas atividades diárias (Verderane, 2010). Além disso, aparentemente contribui para a linearidade da hierarquia de dominância estabelecida entre as fêmeas (Verderane, Izar, Visalberghi \& Fragaszy, 2013), pois foi observado o aumento da competição dentro do grupo e baixos níveis de tolerância entre as fêmeas nos sítios de quebra de alimento. 
No Parque Nacional da Serra da Capivara (PNSC), no Piauí, foi observado que alguns grupos de S. libidinosus usam pedras para cavar, quebrar frutos, para cortar e quebrar troncos, varetas para coletar mel e invertebrados, varetas para acertar presas e animais ameaçadores e pedras para deslocar outra pedra incrustada em um conglomerado e utilização desta última como ferramenta (Mannu \& Ottoni, 2009). As varetas de sonda foram produzidas através de algum procedimento de modificação, como destacar um galho com a mão e/ou boca, retirar as folhas e/ou afinar a ponta do galho (Mannu \& Ottoni, 2009) e a produção e utilização deste tipo de ferramenta foram realizadas principalmente pelos indivíduos adultos e sub-adultos do sexo masculino (Falótico, 2011). Segundo Falótico (2011), as varetas de sonda são bastante usadas durante as capturas de lagartos e os machos apresentam maior taxa de predação de vertebrados do que as fêmeas e provavelmente esse viés na predação também afete o uso das varetas pelas fêmeas. Os achados de Falótico (2011), além de ratificar a diversidade do "kit" de ferramentas usadas pelos macacos-prego do PNSC (Mannu \& Ottoni, 2009), acrescentam uma forma inédita de uso: o arremesso de pedras pelas fêmeas em contexto comunicativo durante o período proceptivo. Adicionalmente a esse "kit" de ferramentas complexo, os macacos-prego do PNSC também exibiram outras maneiras de incluir ferramentas em seus comportamentos, como (1) o uso de folha para envolver uma lagarta e conjuntamente uma pedra para esmagá-la antes de comê-la; (2) o uso de uma vareta para coçar outro indivíduo durante um evento de catação; (3) o uso de um galho com folhas para derrubar abelhas e depois comê-las e (4) o uso de uma vareta para "cutucar" o macho durante display de cio (Falótico, 2011).

Também em áreas de Cerrado, Caatinga, áreas de transição e Mata Atlântica, outras espécies de macacos-prego exibem o comportamento de uso de ferramentas. Em um estudo com S. xanthosternos foi registrado pela primeira vez esse comportamento devido à existência de vestígios, como quebra recente, pó de pedra, marcas de desgaste na bigorna, presença de muitos martelos e de cocos quebrados (Canale et al., 2009). Foram encontrados também indícios de transporte de ferramentas entre sítios de quebra e pedras pequenas com marcas de uso, sugerindo que estas foram usadas por jovens ou indivíduos inexperientes ou que os indivíduos experientes selecionaram pedras inapropriadas para quebrar cocos. Em um estudo com S. flavius, os indivíduos usaram ferramentas de pedra para quebrar sementes duras em área de caatinga (Ferreira, Jerusalinsky, Silva, Sousa Fialho, Araujo Roque \& Fernandes, 2009) e também escolhem pedras apropriadas de acordo com o peso do alimento (Ferreira et al., 2010). Em área de Mata Atlântica, S. flavius usa varetas para "pescar" cupins, porém este comportamento parece ser raro (Souto et al., 2011). 
Em manguezais, existem registros de uso de ferramentas por $S$. libidinosus no litoral do Maranhão (dos Santos, 2010). Nesse tipo de habitat, apesar da exposição a diversas presas animais, como moluscos e crustáceos (Macintosh \& Ashton, 2002), a variação no fluxo das marés inunda o manguezal a cada 6 horas, submergindo esses recursos alimentares. Com a baixa da maré, os macacos intensificam o forrageio dessas presas e podem quebrar as carapaças duras com o auxílio de martelos de madeira (dos Santos, 2010). Porém, pouco se sabe a respeito da emergência desse comportamento neste tipo de habitat.

Esta tese tem como objetivo geral investigar o padrão de comportamento, a dieta e o uso de ferramentas por Sapajus libidinosus que reside em um fragmento de manguezal no litoral leste do Maranhão. S. libidinosus é uma espécie adequada para a coleta de dados em relação à flexibilidade comportamental devido à sua ocupação em habitats com diferentes contextos ecológicos e sua adaptabilidade. 


\section{MÉTODO}

\subsection{Local de estudo}

A presente pesquisa foi realizada em um fragmento de manguezal com 37 ha

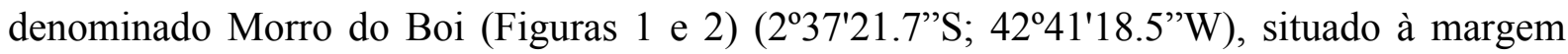
direita do rio Preguiças localizado no município de Barreirinhas, litoral leste do estado do Maranhão. O estuário está inserido em uma região com influência de dunas móveis, lagoas sazonais, vegetação de restinga e campos naturais (IBAMA, 2003; Floriani, Fernandes-Pinto \& Fukuda, 2004), que limitam o manguezal dos estuários mais próximos e criam fragmentos naturais formados por florestas de mangue. A restinga é uma vegetação típica de área costeira e apresenta porte arbóreo baixo e comunidades arbustivas. Nesta região, as dunas de areia avançam sobre essa vegetação e o manguezal, dando origem a um campo de dunas conhecido como "Pequenos Lençóis". Desse modo, esse estuário apresenta florestas de mangue caracterizadas por fragmentos naturais, florestas contínuas bem preservadas e ilhas colonizadas por diversos grupos de $S$. libidinosus.

$\mathrm{Na}$ Costa Amazônica, várias espécies arbóreas associadas ao manguezal são conhecidas e há registro de seis espécies exclusivas no Maranhão, as quais estão distribuídas nos gêneros Rhizophora (mangue vermelho), Avicennia (siriba) e Laguncularia (mangue branco) (Menezes et al., 2008), todos presentes no rio Preguiças (Floriani et al., 2004). As seis espécies deste estuário são: $R$. mangle, $R$. racemosa, $R$. harrissoni, A. germinans (Menezes et al., 2008), A. shaweriana e L .racemosa (dos Santos, 2010).

Nesta região, o clima é caracterizado como tropical sazonal, com duas estações bem definidas: uma estação chuvosa, que ocorre de janeiro a junho, e uma seca, de julho a dezembro. A temperatura é estável ao longo do ano com média anual de $26^{\circ} \mathrm{C}$ e precipitação de 1.600 mm (IBAMA, 2003), abaixo das demais áreas litorâneas da costa Amazônica (Fisch, Marengo \& Nobre, 1998). Anexa à área de estudo existe uma pequena área de restinga com árvores frutíferas (coqueiro - Cocos nucifera, cajueiro - Anacardium occidentale, goiabeira Psidum guajava, murici- Byrsonima crassifolia, guajiru - Chrysobalanus icaco e panã Annona crassiflora). E a fauna da área é composta por diversas espécies, entre anfíbios (Bufo marinus), répteis - serpentes: sucuri (Eunectes murinus) e goipeba (Waglerophis merremii) e jacaré: jacaretingá (Caiman crocodilus) - aves de rapina e mamíferos, como o veado-mateiro 
(Mazma americana), a paca (Agouti paca), o guaxinim (Procyon cancrivorus) e o macacoprego (Sapajus libidinosus). Dentre esses animais, os potenciais predadores de S. libidinosus são Eunectes mutinus, Caiman crocodilus e aves de rapina e o potencial competidor é Procyon cancrivorus que se alimenta de crustáceos durante a noite.

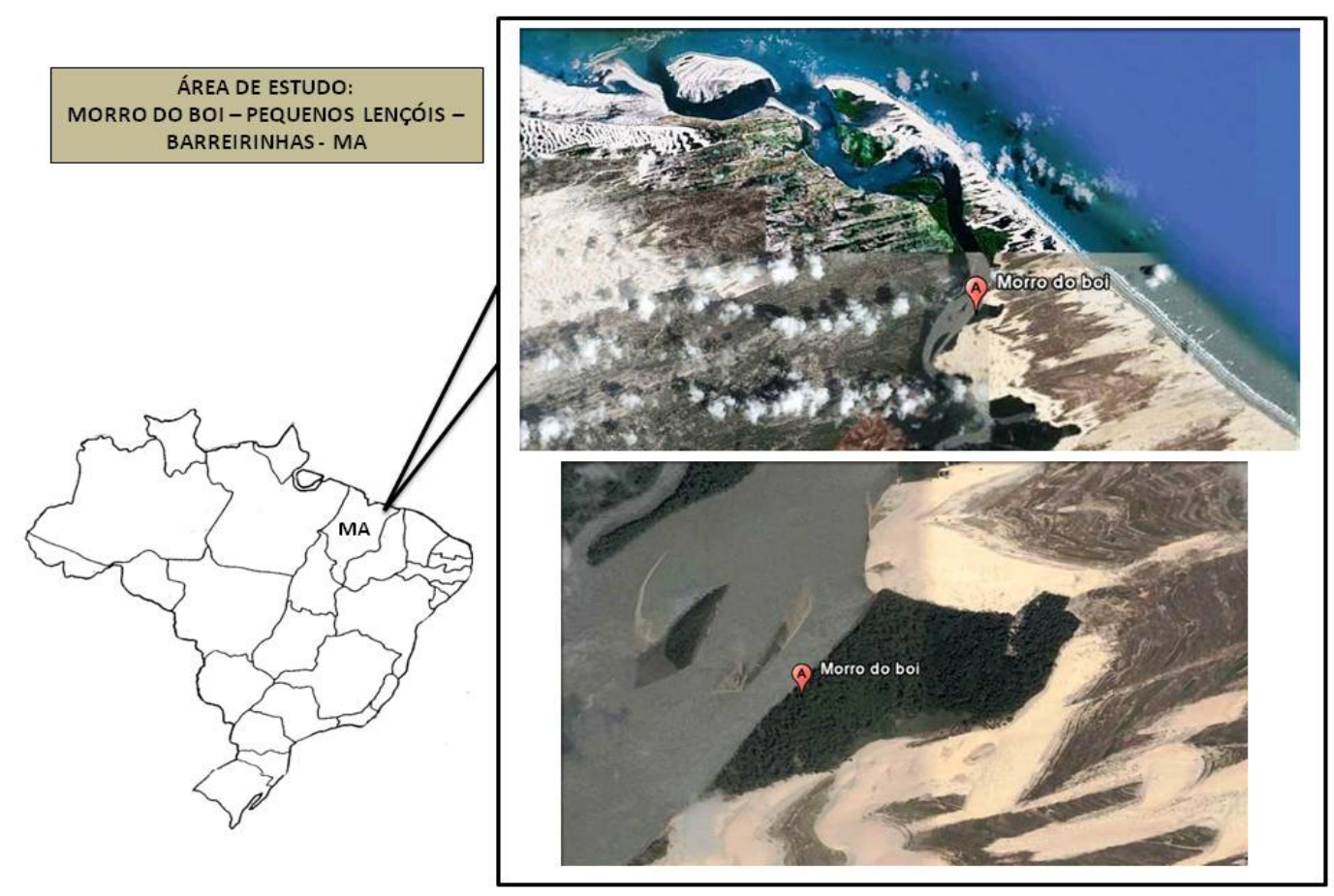

Figura 1. Localização da área de estudo. (A) Fragmento de manguezal (Morro do Boi) onde o grupo de estudo reside nos Pequenos Lençóis Maranhenses, Barreirinhas - MA.
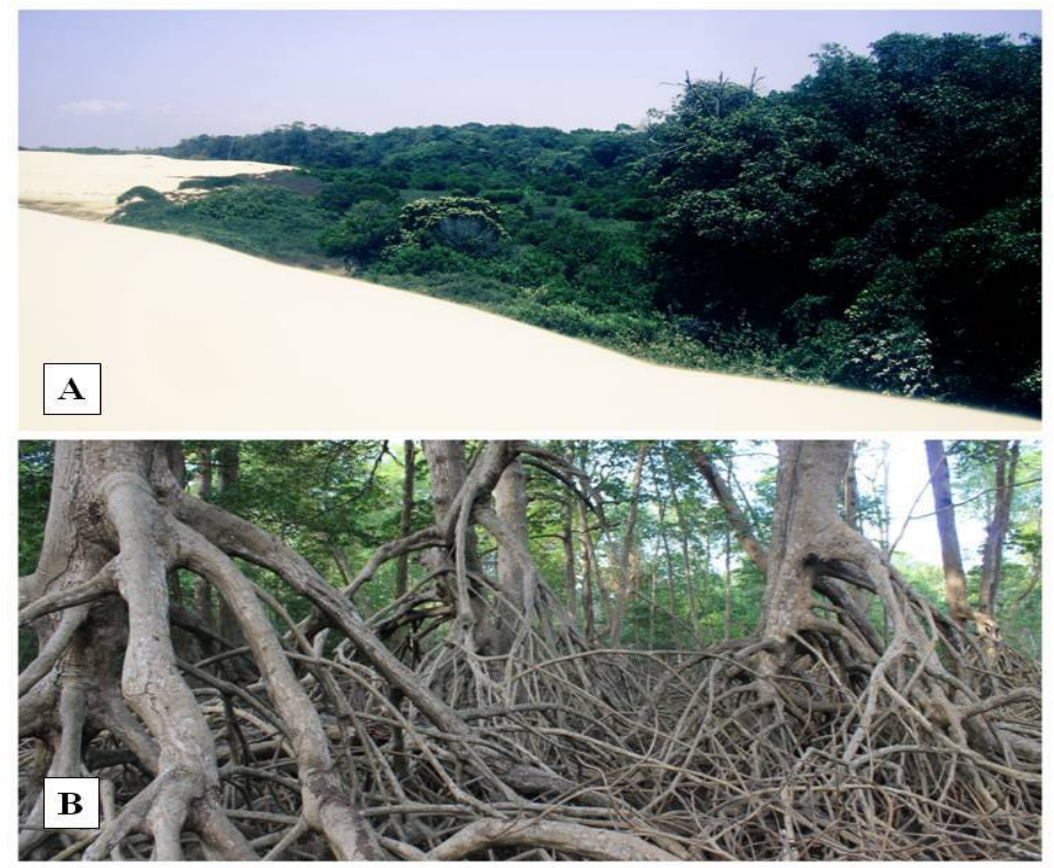

Figura 2. Área de estudo. Vista externa (A) e interna (B) do fragmento de manguezal Morro do Boi, Pequenos Lençóis Maranhenses, Barreirinhas -MA. 


\subsection{Espécie e Grupo de estudo}

A espécie Sapajus libidinosus possui pelagem castanho muito claro, com topete de pêlos curtos e negros. Distribui-se pelo Nordeste (norte do Rio São Francisco) e região Central do Brasil - incluindo o Pantanal do Mato Grosso (Fragaszy et al., 2004a).

O grupo estudado apresentou tamanho de 31 indivíduos, sendo 17 adultos, 6 subadultos, 4 jovens e 4 filhotes e estes dividiam-se em unidades de forrageio, de 2 a 4 indivíduos. Esses indivíduos ficavam dispostos a uma distância média de 2 a 5 metros uns dos outros enquanto forrageavam. Porém, essa distância algumas vezes foi maior, pois nessas ocasiões era visível apenas um indivíduo.

A habituação do grupo como um todo à presença da pesquisadora e de um assistente de campo foi tentada durante todo o estudo, porém apenas parte do grupo tolerava a nossa presença. O possível fator de interferência na habituação do grupo pode ter sido a pressão de caça na área, a qual pode ser considerada intensa, pois tanto no período anterior quanto no período da coleta dos dados foram ouvidos 14 (quatorze) tiros de espingarda e 11 (onze) eventos de sons de motosserra na área.

Acredita-se que essa intervenção humana na área, seja para a caça ou para a extração de madeira, possa ser ainda maior. Para diminuir esses eventos buscamos informar a maior parte dos nativos do Morro do Boi sobre a nossa presença na área e também conscientizar esses moradores a respeito da importância da preservação e conservação dos manguezais e das espécies que ali habitam.

\subsection{Coleta de dados}

Os dados do grupo Morro do Boi foram coletados ao longo de 19 meses, entre setembro de 2011 e março de 2013, porém entre os meses de junho e agosto de 2011 foram realizados esforços de abertura de trilhas e tentativas de habituação do grupo.

O grupo foi acompanhado durante 05 (cinco) dias por mês e as observações foram realizadas em dias de lua crescente e minguante, já que nos demais dias do mês o manguezal passa a maior parte do dia alagado inviabilizando a caminhada. As observações comportamentais foram conduzidas pelo método de varredura instantânea ou "scan-sampling" 
(Altmann, 1974) a cada 10 (dez) minutos, com os indivíduos sendo amostrados por 5 (cinco) minutos. Foi realizado um total de 854 horas de esforço de campo, sendo 415 horas de contato direto com o grupo (coleta sistemática de dados). As 415 horas de observação sistemática resultaram em um aproveitamento de 2490 varreduras e 9090 registros individuais. Esses dados foram utilizados para calcular o orçamento de atividades, quantificar a frequência dos itens alimentares consumidos e o padrão do uso dos diferentes estratos (conforme detalhado no Capítulo. II). O método de "todas as ocorrências" (Altmann, 1974) também foi utilizado para os registros de eventos de interações agonísticas, catação e cópula (Conforme detalhado no Capítulo II). Como não foi possível o registro direto do uso de ferramentas pelos macacosprego devido a não habituação total dos indivíduos somado à dificuldade de locomoção no ambiente, registros indiretos do uso de ferramentas foram coletados baseados na metodologia de Mannu (2002), buscando realizar um mapeamento dos sítios de quebra na área, estimar a frequência de uso dos mesmos, caracterizar as bigornas e martelos e identificar os alimentos encapsulados quebrados com o auxílio dos martelos (Conforme detalhado no Capítulo III). 
CAPÍTULO II: Orçamento de atividades e dieta de um grupo de macacos-prego (Sapajus libidinosus) em área de Manguezal no Maranhão 


\section{INTRODUÇÃO}

$\mathrm{Na}$ primatologia, diversos trabalhos envolvem o entendimento do orçamento de atividades (Digby \& Barreto, 1996; Umapathy \& Kumar, 2000; Di Fiore \& Rodman, 2001; Verderane, 2010; Izar et al., 2012) e, em muitas espécies, o orçamento diário individual varia sazonalmente em resposta a mudanças na abundância, qualidade ou distribuição dos recursos alimentares (Robinson, 1986; Altmann \& Muruthi, 1988; Isbell \& Young, 1993), além de ser influenciado também por outros fatores, como tamanho do grupo, sexo, posição social, condição reprodutiva e grau de perturbação humana na região (Whitten, 1983; Muruthi, Altmann \& Altmann, 1991, Di Fiore \& Rodman, 2001). Flutuações na disponibilidade dos recursos alimentares induzem os primatas que vivem em ambientes sazonais a ajustar suas dietas (Gursky, 2000) e, consequentemente, estes alteram o tempo despendido nas atividades relevantes para sua sobrevivência e reprodução. O aumento ou a redução do forrageio, locomoção, descanso e interações sociais (Izar et al., 2012) e a inclusão de outros alimentos na dieta (Gursky, 2000), inclusive de alimentos alternativos ou de reserva ("fallback food") (Marshall \& Wrangham, 2007; Altmann, 2009; Wright, Wright, Chalk, Verderane, Fragaszy, Visalberghi et al., 2009) são exemplos dessa constante adequação no orçamento de atividades.

O gênero Sapajus tem uma ampla distribuição geográfica e ocupa diferentes habitats como florestas tropicais, manguezais, Cerrado e Caatinga no centro e nordeste do Brasil (Fragaszy, Visalberghi, Fedigan \& Rylands, 2004c). Estes habitats variam grandemente quanto às características ecológicas, assim, a presença e adaptação dos macacos-prego nesses locais pode ser explicada pela flexibilidade comportamental, principalmente em relação ao comportamento alimentar (Fragaszy et al., 2004a). Estudos apontam que para os macacosprego fatores como a pluviosidade e a oferta de alimentos podem alterar o orçamento de atividades (S. apella: Terborgh, 1983; S. nigritus: Rímoli, 2001; Izar et al., 2012; S. libidinosus: Moura, 2004; Izar et al., 2012; Sapajus spp: Ferreira et al., 2008).

Segundo os estudos de Terborgh (1983) e Di Bitetti (2001), S. apella pode apresentar estratégias distintas frente à escassez de recursos alimentares de grande valor energético, como os frutos. Nessa situação, os macacos-prego podem: 1) manter a mesma área de vida, sem aumentar o tempo gasto na locomoção, mas alteram o forrageio e a alimentação para recursos alternativos e menos energéticos como as bromélias (Terborgh, 1983), ou 2) aumentar o deslocamento diário em busca dos alimentos preferidos e com grande valor 
nutricional em locais distantes da sua área de vida (Di Bitetti, 2001), embora estes alimentos possam estar pouco disponíveis e em manchas amplamente dispersas (Fragaszy et al., 2004a).

Na Mata Atlântica, S. nigritus que vive no Parque Estadual Carlos Botelho (PECB) apresenta fissão-fusão e ajusta o tamanho do grupo em decorrência da disponibilidade de alimento (Nakai, 2007). O PECB é uma área que possui evidências de baixa disponibilidade de recursos (Izar, 2004; Nakai, 2007; Taira, 2007; Izar et al., 2012) e os macacos-prego adaptam a dieta conforme a estação do ano. No verão, época com muitas chuvas na região, a disponibilidade de frutos e de invertebrados é maior do que no inverno (Izar et al., 2012) e os indivíduos aumentam o descanso e a locomoção em busca das fruteiras, já que os frutos são um recurso distribuído de forma agregada (Peternelli-dos-Santos, 2009). No período do ano com escassez de frutos e de invertebrados, os macacos-prego aumentam o consumo de recursos alternativos (folhas de bromélias e palmito) e consequentemente aumentam o tempo despendido no forrageio (Nakai, 2007; Taira, 2007; Peternelli-dos-Santos, 2009). Segundo Taira (2007), os macacos-prego do PECB selecionam o tamanho da palmeira de Euterpe edulis de forma a aumentar o benefício em relação ao custo de extração do palmito, e o utilizam como recurso proteico alternativo aos invertebrados durante o período seco. Apesar disso, o consumo de palmito é inferior ao das bromélias (Taira, 2007; Peternelli-dos-Santos, 2009), que é um recurso altamente disponível, com distribuição regular no ambiente e de baixo valor energético (Brown \& Zunino, 1990) e por isso, impõe maior gasto de tempo no forrageio (Peternelli-dos-Santos, 2009).

O forrageamento extrativo apresentado pelos macacos-prego, associado à destreza manual, fornece a condição-chave para o uso de ferramentas de alimentação (Seed \& Byrne, 2010). No PECB não há registros de uso de ferramentas por $S$. nigritus, porém em populações de S. libidinosus que habitam áreas de Cerrado/Caatinga, como a Fazenda Boa Vista (FBV) e o Parque Nacional da Serra da Capivara (PNSC), o uso de ferramentas para a quebra de alimentos encapsulados de origem vegetal é um comportamento rotineiro (Visalberghi, Fragaszy, Ottoni, Izar, de Oliveira \& Andrade, 2007; Mannu \& Ottoni, 2009; Verderane, 2010; Falótico, 2011; Spagnoletti, Visalberghi, Verderane, Ottoni, Izar \& Fragaszy, 2012; Fragaszy, Liu, Wright, Allen, Brown \& Visalberghi, 2013). No estudo de Verderane (2010), o orçamento de atividades não sofreu grandes ajustes entre as estações seca e chuvosa corroborando seus resultados de ausência de escassez de alimentos. Embora a alimentação tenha sido a principal atividade dos macacos-prego da FBV, o uso de ferramentas nessa população apresentou pouca contribuição para o forrageamento dos animais (Verderane, 
2010). O mesmo foi encontrado em outra população de S. libidinosus do PNSC por Falótico (2011).

Em florestas de mangue pouco se sabe sobre o orçamento de atividades de primatas não-humanos devido à escassez de trabalhos que abordam esse tipo de habitat. No estudo de Son (2004), com Macaca fascicularis que habita manguezais no Vietnã, dois fatores são apontados como determinantes na distribuição do tempo nas diversas atividades: 1) a dieta, principalmente a ingestão de macrobentos e 2) a variação da maré.

A dieta dessa espécie consiste, na sua maior parte, de alimentos ricos em proteínas como caranguejos, lagartas, moluscos, camarões, polvos, insetos, sapos, mas também inclui espécies vegetais (Son, 2003a). Quando os macacos forrageiam os macrobentos (caranguejos, camarões, entre outros), que são alimentos ricos em qualidade, eles precisam de menos tempo para forragear outros tipos de recursos e consequentemente possuem mais tempo para dedicar ao repouso e às interações sociais (Son, 2004).

O manguezal é um ecossistema sazonal com variação de maré e apresenta marés mais altas no período da lua nova e lua cheia (Son, 2004). Na maré alta desses períodos, a floresta do mangue ficava inundada em média por 3 horas e os macacos se deslocavam para a parte mais seca da floresta para escapar da subida das águas (Son, 2003b). Com essa situação, a proporção de tempo de repouso é significativamente maior e de deslocamento significativamente menor (Son, 2004). O forrageio, nesses períodos de maré alta, só aumentava após a baixa da maré, quando os macacos se moviam mais rapidamente do que o usual em busca dos macrobentos. Segundo Son (2004), o forrageio de macrobentos após a enchente foi uma característica do comportamento alimentar dos macacos de mangue, a qual é bastante diferente das populações de floresta de interior. Tal mecanismo adaptativo no comportamento alimentar pode estar relacionado com as condições ecológicas e os macacos podem estrategicamente forragear intensivamente alimentos de origem animal em períodos de alta abundância de macrobentos na área. Dessa forma, Son (2004) levanta a possibilidade de que o comportamento oportunista tenha um impacto na distribuição do orçamento de atividades diárias dessa espécie.

Uma vez que os primatas parecem equilibrar o seu orçamento de atividades para se adaptar às condições ambientais (Izar, 2004; Nakai, 2007; Peternelli-dos-Santos, 2009), ele pode ser usado para comparar diferentes populações da mesma espécie que habitam diferentes habitats. Apesar de vários estudos abordarem populações selvagens de macacos-prego (Terborgh, 1983; Spironello, 2001; Izar, 2004; Lynch Alfaro, 2007; Verderane, 2010; Falótico, 2011), poucos trabalhos apresentam informações sobre a ecologia de populações de 
Sapajus que habitam manguezal, como o de dos Santos (2010), que estudou o mesmo grupo de macacos-prego do presente estudo. Nossa pesquisa abordou o padrão de atividades e a dieta de um grupo de S. libidinosus residentes em um fragmento de manguezal, que apresentou como limites geográficos dunas móveis e um rio. Associados às essas limitações se somaram o pequeno tamanho da área, o que restringe o movimento dos animais, a variação das marés, a disponibilidade sazonal dos recursos e o uso de ferramentas de quebra para acessar alimentos encapsulados de origem animal. Dentro desse contexto, nossa pesquisa foi relevante para o conhecimento das estratégias comportamentais desses primatas em condições ecológicas e ambientais até então pouco exploradas. 


\section{OBJETIVOS}

\subsection{Gerais}

Investigar o orçamento de atividades e a dieta de um grupo de macacos-prego $(S$. libidinosus) que habitava um fragmento de Manguezal no Maranhão. Avaliar se os fatores ambientais e a disponibilidade de recursos influenciam no orçamento de atividades e na dieta, visando contribuir para a compreensão da flexibilidade e da adaptabilidade apresentada pelas espécies do gênero Sapajus.

\subsection{Específicos}

- Avaliar a oferta temporal de caranguejos e flores no Manguezal do Morro do Boi;

- Averiguar a atividade diária do grupo nos períodos seco e chuvoso;

- Analisar a atividade diária nas diferentes classes etárias nos períodos seco e chuvoso;

- Descrever a dieta, identificando os itens alimentares que são consumidos e quantificar os alimentos disponíveis nos períodos seco e chuvoso;

- Descrever o padrão de uso dos diferentes estratos (solo e copas das árvores) pelos macacosprego e verificar se existem variações sazonais. 


\section{HIPÓTESES}

Hipótese 1: Existe uma correlação entre o tempo gasto em cada atividade do repertório comportamental e o período seco/chuvoso do ano.

Previsão (1): Devido à baixa disponibilidade dos alimentos no período seco, os indivíduos aumentam a procura por recurso alimentar para suprir suas necessidades energéticas diárias. Logo, o forrageio é a atividade predominante nesse período do ano.

Previsão (2): No período seco, os recursos vegetais (flores e frutos) ficam menos disponíveis, logo a procura por alimentos de origem animal é maior do que no período chuvoso.

Hipótese 2: Existe uma correlação entre item alimentar ingerido e a classe etária dos animais. Previsão: Itens alimentares de origem animal são mais frequentes na dieta de animais maduros, pois necessitam de habilidades motoras e cognitivas para o seu reconhecimento, captura e manipulação.

Hipótese 3: Existe uma correlação entre padrão de atividade, uso dos diferentes estratos e o período seco/chuvoso do ano.

Previsão (1): No período chuvoso a disponibilidade dos recursos vegetais (flores) aumenta com isso os animais utilizam com mais frequência o estrato superior da floresta de mangue.

Previsão (2): No período seco os recursos vegetais apresentam menor disponibilidade, aumentando a procura por itens alimentares de origem animal no estrato inferior do manguezal. 


\section{MÉTODOS}

\section{1. Área e grupo de estudo}

A pesquisa foi realizada em um fragmento de manguezal com área de 37 ha denominado Morro do Boi (2³7'21.7'S; 4241'18.5'W), situado à margem direita do rio Preguiças, localizado no município de Barreirinhas, nordeste do estado do Maranhão. Os indivíduos observados neste estudo pertencem a um grupo selvagem de macacos-prego ( $S$. libidinosus). A descrição mais detalhada sobre a área e o grupo de estudo encontra-se no Capítulo I.

\subsection{Coleta dos dados}

\subsubsection{Disponibilidade de alimento e Clima}

\subsubsection{Disponibilidade de caranguejos}

As estimativas de densidade dos caranguejos semiterrestres têm sido abordadas com certa frequência na literatura (Lourenço, Paula \& Henrique, 2000; Flores, Abrantes \& Paula, 2005; Wunderlich, Pinheiro \& Rodrigues, 2008). Em função do modo de vida e do habitat ocupado por seus representantes, diversos métodos de amostragem têm sido avaliados para determinar com maior fidedignidade a densidade populacional (Skov \& Hartnoll 2001; Skov, Vaninni, Shunula, Hartnoll \& Cannicci, 2002). Skov \& Hartnoll (2001) fizeram uma análise comparativa entre três métodos para a estimativa da densidade de caranguejos (contagem das galerias ou tocas, contagem binocular e escavação), verificando que a contagem direta das galerias superestimava a densidade, embora representasse melhor o tamanho populacional. Assim, o método de estimativa indireta da densidade do caranguejo-uçá (Ucides cordatus) no presente estudo, pela quantificação do número de galerias/área, minimizou o viés amostral, 
em função da facilidade no reconhecimento das galerias (cada galeria abriga um indivíduo) desta espécie por sua morfologia externa e inclinação de $45^{\circ}$ em relação ao sedimento (Wunderlich et al., 2008). Portanto, para avaliar a disponibilidade mensal dos caranguejos no Morro do Boi, utilizamos esta metodologia que também foi aplicada por dos Santos (2010) em sua pesquisa com o mesmo grupo de estudo.

Desta forma, a densidade de caranguejos da espécie Ucides cordatus foi verificada mediante a contagem do número total de galerias efetivamente ocupada em uma área de $4 \mathrm{~m}^{2}$ durante a baixa-mar, no período de setembro de 2011 a março de 2013. O tamanho da área estimada foi escolhido também em função da dificuldade de se coletar a totalidade dos caranguejos presentes em cada área amostral. Embora o pequeno tamanho de parcela de contagem de caranguejos pareça não refletir bem a área, o padrão de distribuição dos caranguejos no solo do manguezal é uniforme conforme vários estudos que analisaram o padrão de distribuição e de densidade do caranguejo Ucides cordatus nos manguezais da região Norte e Nordeste do Brasil (Alcântara-Filho, 1978; Castro, 1986; Almeida \& Melo, 1996; Alvez \& Nishida, 2004).

\subsubsection{Disponibilidade de flores}

A estimativa mensal da disponibilidade do recurso vegetal (flores de Rhizophora mangle) teve início a partir de março de 2012 devido às diferentes metodologias testadas para verificar a disponibilidade vegetal. Uma vez que o manguezal é um ambiente sazonal e a variação da maré pode impedir métodos como, por exemplo, o pitfall (Izar, 2004), pois altera qualquer vestígio de recursos que estejam localizados no solo. Por isso, o método utilizado para a contagem mensal das flores de Rhizophora mangle foi semelhante ao da contagem dos caranguejos.

\subsubsection{Clima}

Os dados climáticos, como pluviosidade, temperaturas média, máxima e mínima e umidade relativa do ar foram obtidos do Instituto Nacional de Meteorologia (INMET), para a 
estação de Farol Preguiças situada à margem oposta da área de estudo.

\subsubsection{Análise estatística}

Para verificar as hipóteses nulas de que não existe variação sazonal (período seco $\mathrm{x}$ chuvoso) na disponibilidade de recursos foi utilizado um teste para comparação de médias. Os dados climáticos permitiram verificar, através de testes de correlação, as hipóteses nulas de que não há variação na disponibilidade de recursos em função da variação de temperatura, pluviosidade e umidade. O nível de significância foi de $\mathrm{p} \leq 0,05$.

\subsubsection{Orçamento de atividades}

O grupo de S. libidinosus foi acompanhado durante 05 (cinco) dias por mês e as observações foram realizadas em dias de lua crescente e minguante quando foi possível a entrada e a caminhada dentro do manguezal. As observações iniciavam a partir das 06h00min ou assim que a maré baixava e se estendiam até às $17 \mathrm{~h} 30 \mathrm{~min}$, um pouco antes de escurecer totalmente, devido à difícil locomoção na área de estudo.

Para a amostragem das atividades diárias foi utilizado o método de varredura instantânea ou "scan-sampling" (Altmann, 1974) a cada 10 (dez) minutos, com os indivíduos sendo amostrados por 5 (cinco) minutos. Em cada scan foram registrados:

1) a faixa etária dos indivíduos observados, quando possível - para analisarmos o tempo despendido pelas diferentes classes de idade em cada atividade;

2) a atividade dos animais (Tabela 1) para analisarmos o tempo despendido pelos animais para cada uma de suas atividades e quais variáveis ambientais (pluviosidade; temperatura; umidade; disponibilidade de recursos) podem afetar o padrão de atividades do grupo;

3) O estrato em que os animais desenvolvem suas atividades - solo, estrato arbóreo com altura entre 0,1 e $5 \mathrm{~m}(\leq 5 \mathrm{~m})$ e maior que $5 \mathrm{~m}(>5 \mathrm{~m})$ - para analisarmos o tempo utilizado pelos macacos nos diferentes estratos do manguezal e verificar a relação entre o estrato e o orçamento de atividades do grupo. 
Foram registrados pelo método de "todas as ocorrências" (Altmann, 1974) os seguintes eventos:

4) Interações agonísticas intra-grupo: esses eventos foram registrados para investigarmos a influência dos fatores ecológicos, como a disponibilidade de alimentos, nas relações sociais entre os indivíduos;

5) Interações afiliativas: catação e cópula.

Tabela 1. Categorias comportamentais registradas pelo método de varredura no grupo de macacosprego (S. libidinosus) do Morro do Boi no período de setembro de 2011 a março de 2013.

\begin{tabular}{|c|c|}
\hline $\begin{array}{c}\text { Categoria } \\
\text { comportamental }\end{array}$ & Descrição \\
\hline Forrageio (FOR) & $\begin{array}{l}\text { Investigação do ambiente em busca de alimento, } \\
\text { observando a área ao redor. }\end{array}$ \\
\hline Ingestão (ING) & $\begin{array}{l}\text { Quando o animal engole o alimento e possível } \\
\text { identificação do item alimentar que está sendo } \\
\text { consumido. Alimento de origem vegetal (ING VEG) ou } \\
\text { alimento de origem animal (ING ANI). }\end{array}$ \\
\hline Repouso (REP) & Quando o animal estiver deitado. \\
\hline Deslocamento (DESL) & Deslocar-se de um ponto a outro. \\
\hline $\begin{array}{l}\text { Interação social (INT } \\
\text { SOC) }\end{array}$ & $\begin{array}{l}\text { Atividade social que pode ser do tipo catação, quando } \\
\text { dois ou mais inspecionam ou limpam o pelo com as mãos } \\
\text { ou a boca; brincadeira social, quando a interação social } \\
\text { não é agonística, podendo envolver corridas, perseguição, } \\
\text { mordidas, tapinhas ou apenas toques; e agonismo. }\end{array}$ \\
\hline Outros (OUT) & $\begin{array}{l}\text { Qualquer atividade que não se enquadra nas categorias } \\
\text { descritas acima, como auto-catação, beber água, } \\
\text { vigilância, cópula etc. }\end{array}$ \\
\hline
\end{tabular}

Como o número de indivíduos observados a cada amostra de varredura variou pela diminuição da coesão do grupo durante o forrageio e devido também à dificuldade de habituação do grupo, as amostras foram normalizadas pelo número de animais visualizados a cada varredura, conforme Izar e Resende (2007). Nesse caso, se em uma varredura foram observados 3 indivíduos forrageando e 2 repousando, a proporção de cada atividade nessa 
varredura foi 0,6 para forrageio e 0,4 para repouso. A proporção normalizada das amostras foi calculada mensalmente e para todo o período de estudo. Para verificar se as atividades comportamentais do grupo apresentam variação sazonal foi utilizado um teste para comparação de médias.

\subsubsection{Dieta}

Para investigarmos a proporção do consumo de cada item na dieta do grupo e se existe variação no consumo dos itens alimentares no decorrer do estudo, os itens foram categorizados e anotados, como: fruto, flor, parte vegetativa (propágulo) e presa. Para verificar se as proporções dos itens alimentares consumidos apresentaram variação sazonal foi utilizado um teste para comparação de médias. Análises de correlação foram conduzidas para avaliar as hipóteses nulas de que não existe influência das variáveis ecológicas no padrão de atividades, na dieta e na frequência de interações sociais do grupo. 


\section{RESULTADOS}

\subsection{Disponibilidade de alimento e Clima}

\subsubsection{Disponibilidade de caranguejos}

O número de tocas $/ \mathrm{m}^{2}$ não variou significativamente ao longo dos meses e, por isso, não encontramos nenhuma diferença significativa entre as estações seca e chuvosa em relação à disponibilidade de caranguejos $(\mathrm{U}=44,50000 ; \mathrm{p}=0,967436)$ (Figura 1). A densidade média de caranguejos no Morro do Boi ao longo dos 19 meses foi de 5,7 tocas $/ \mathrm{m}^{2}$.

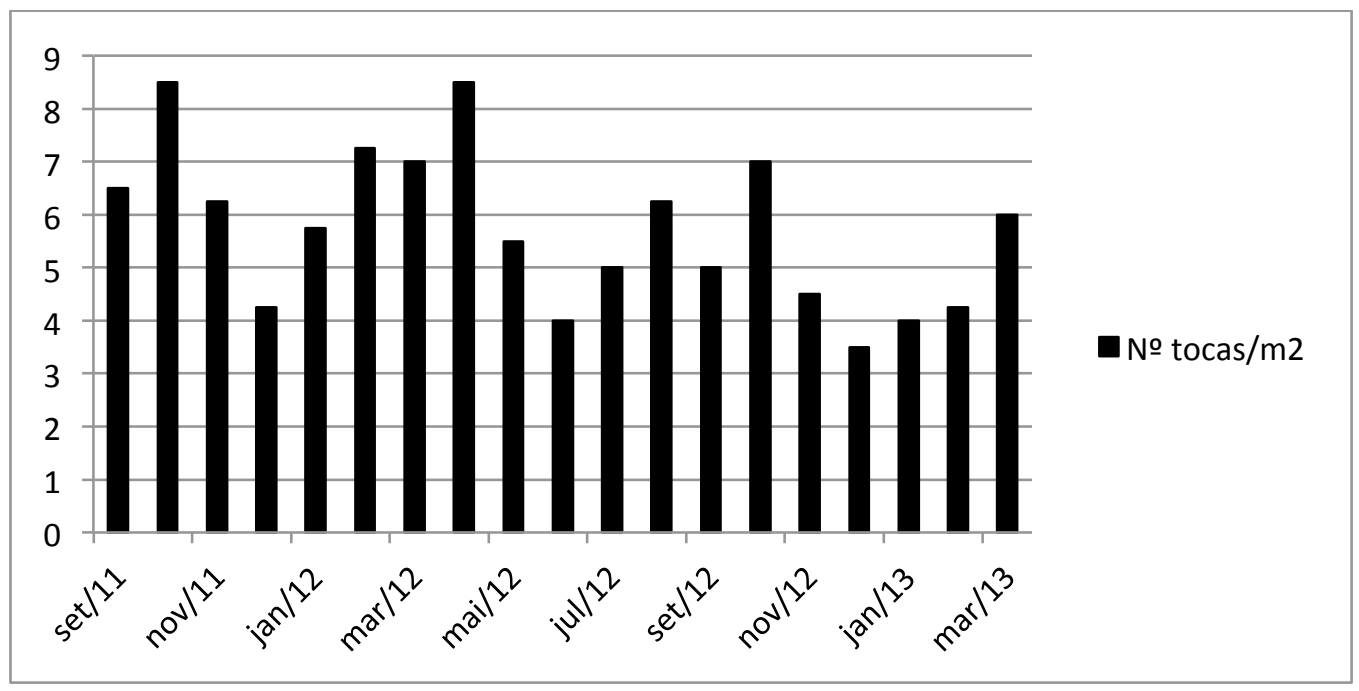

Figura 1. Disponibilidade mensal de caranguejo (Ucides cordatus) por metro quadrado na área de uso do grupo de macacos-prego (S. libidinosus) do Morro do Boi, no período de setembro de 2011 a março de 2013.

\subsubsection{Disponibilidade de flores}

A disponibilidade da flor de Rhizophora mangle variou entre os meses (Figura 2). Segundo o teste de Mann-Whitney existiu diferença significativa entre as estações seca e chuvosa $(U=1,00000 ; p=0,004275)$, sendo que na estação chuvosa a disponibilidade de flor 
foi maior que na estação seca (estação chuvosa: média $=15,82$; mediana $=14$; intervalo entre quartis $=11 ; \mathrm{dp}=6,83$; estação seca: média $=4,79$; mediana $=4$; intervalo entre quartis $=$ $3,25 ; \mathrm{dp}=3,27)$.

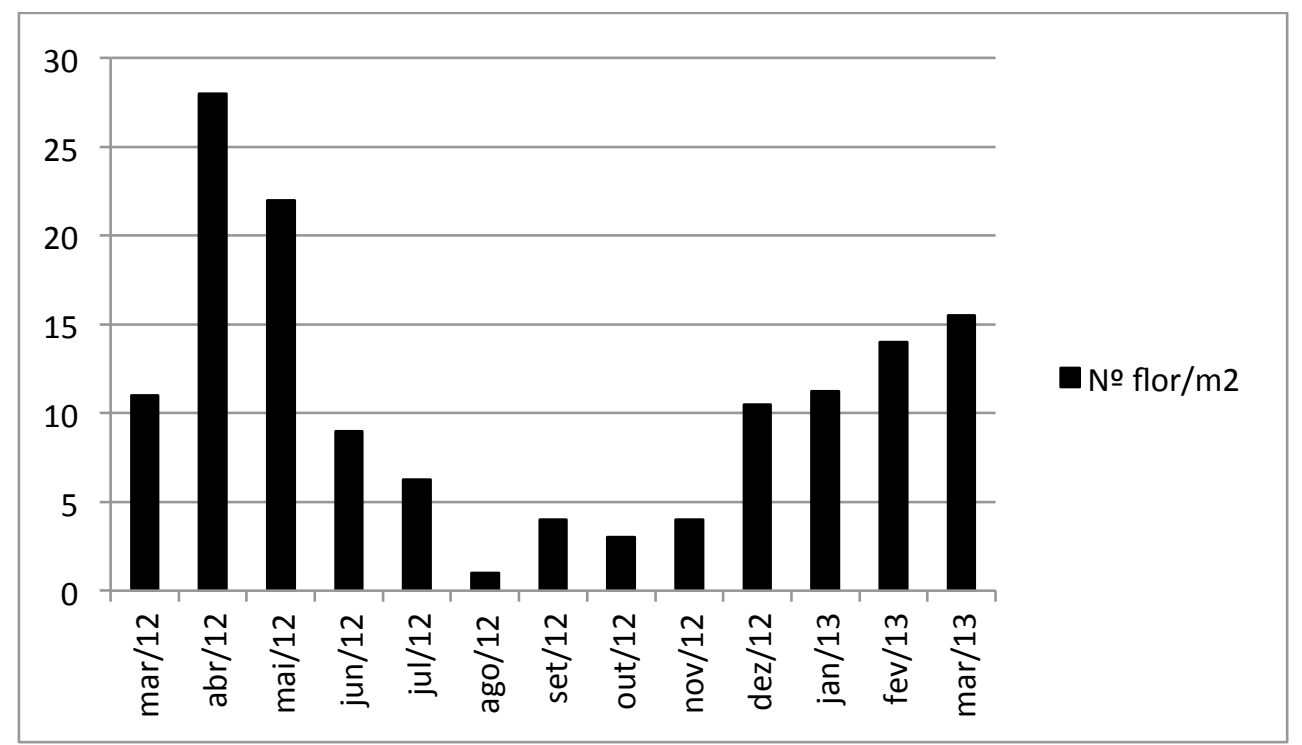

Figura 2. Disponibilidade mensal de flor de Rhizophora mangle por metro quadrado na área de uso do grupo de macacos-prego (S. libidinosus) do Morro do Boi, no período de março de 2012 a março de 2013.

\subsubsection{Clima}

No período de coleta de dados, a temperatura média do ar foi de $27,7^{\circ} \mathrm{C}$, a máxima atingiu $35,7^{\circ} \mathrm{C}$ (novembro de 2011 ) e a mínima registrada foi de $21,3^{\circ} \mathrm{C}$ (março de 2012 ). A precipitação mínima foi registrada nos meses de agosto e setembro de $2012(0 \mathrm{~mm})$, seguido de setembro do ano anterior $(0,4 \mathrm{~mm})$ e a máxima no mês de fevereiro $(239,8 \mathrm{~mm})$. A umidade relativa do ar aumentou com o aumento da pluviosidade, porém a máxima registrada foi no mês de março de 2012 (77,2\%) (Figura 3).

Não houve variação na temperatura entre as estações seca e chuvosa, mas a umidade e a precipitação foram maiores na estação chuvosa (umidade: $U=0,00 ; p=0,000239$; precipitação: $U=2,00 ; p=0,000447)$. A correlação de Spearman mostra uma associação positiva entre umidade e precipitação (Spearman $R=0,851998$; $p<0,05$ ). 


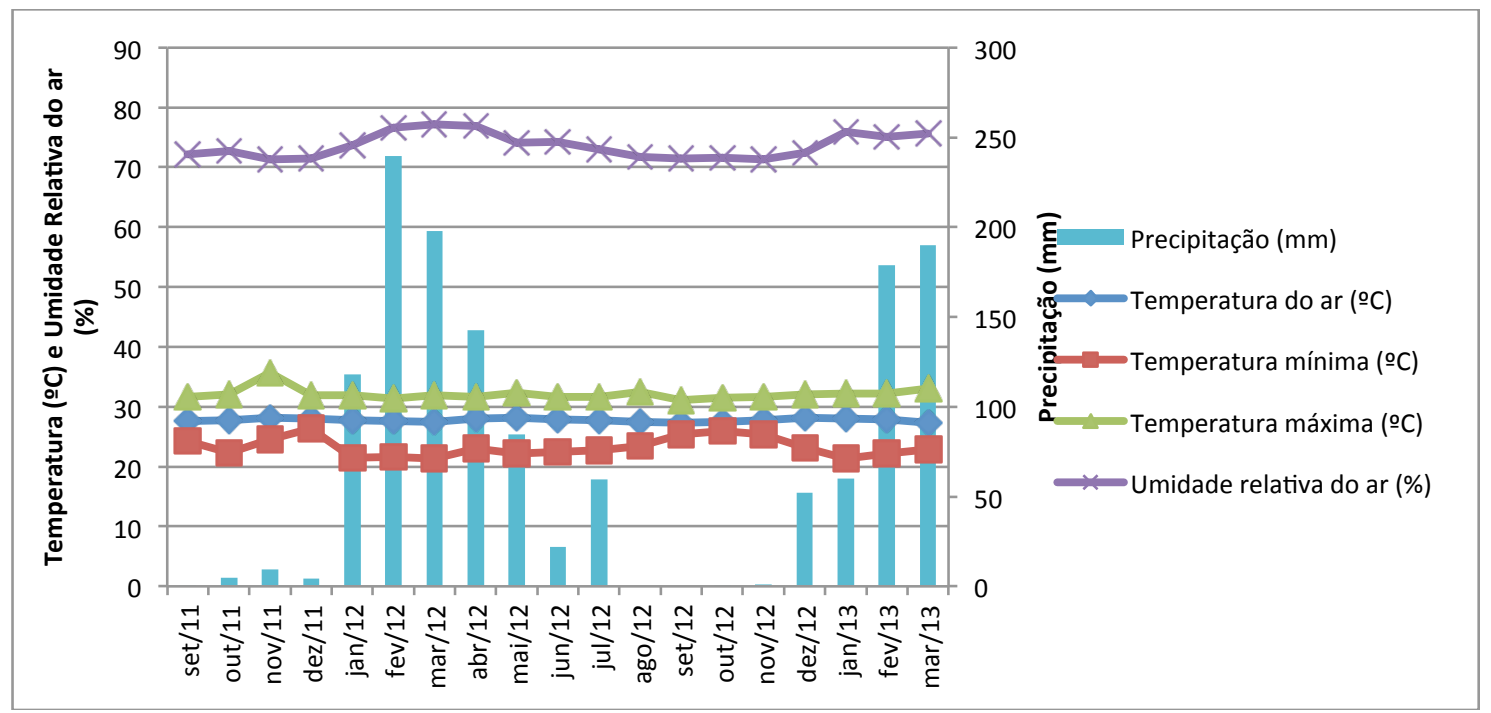

Figura 3. Dados climáticos da Estação Farol Preguiças correspondentes ao período de setembro de 2011 a março de 2013.

Para verificar se houve influência das variáveis climáticas (temperatura, umidade e precipitação) na disponibilidade de recursos (caranguejos e flores), foi realizada a correlação de Spearman. Segundo o teste, a precipitação (Figura 4) e a umidade (Figura 5) estiveram associadas à disponibilidade de flor (precipitação: Spearman $\mathrm{R}=0,841598, \mathrm{p}<0,05$; umidade: Spearman $\mathrm{R}=0,767539, \mathrm{p}<0,05)$. Nenhuma das variáveis climáticas avaliadas influenciou a disponibilidade de caranguejos.
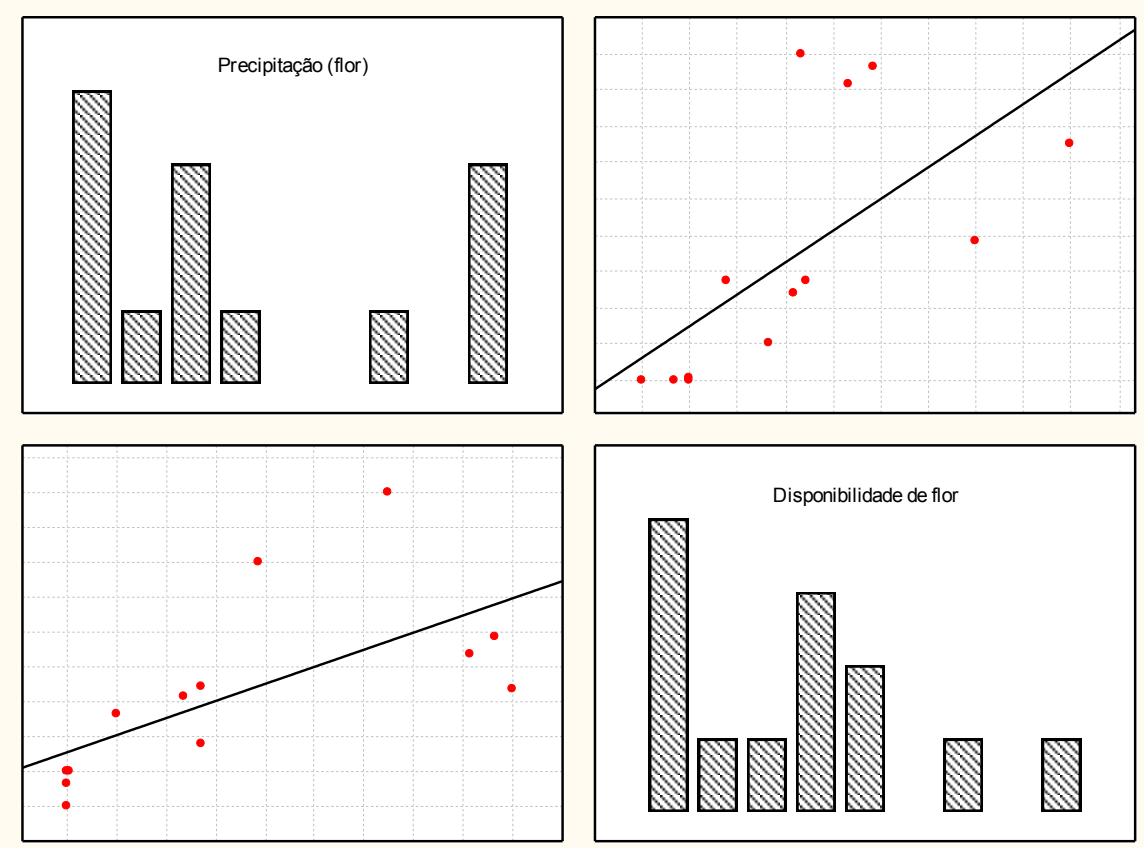

Figura 4. Correlação de Spearman significativa e positiva entre precipitação e disponibilidade de flor (Rhizophora mangle) no Manguezal do Morro do Boi. 

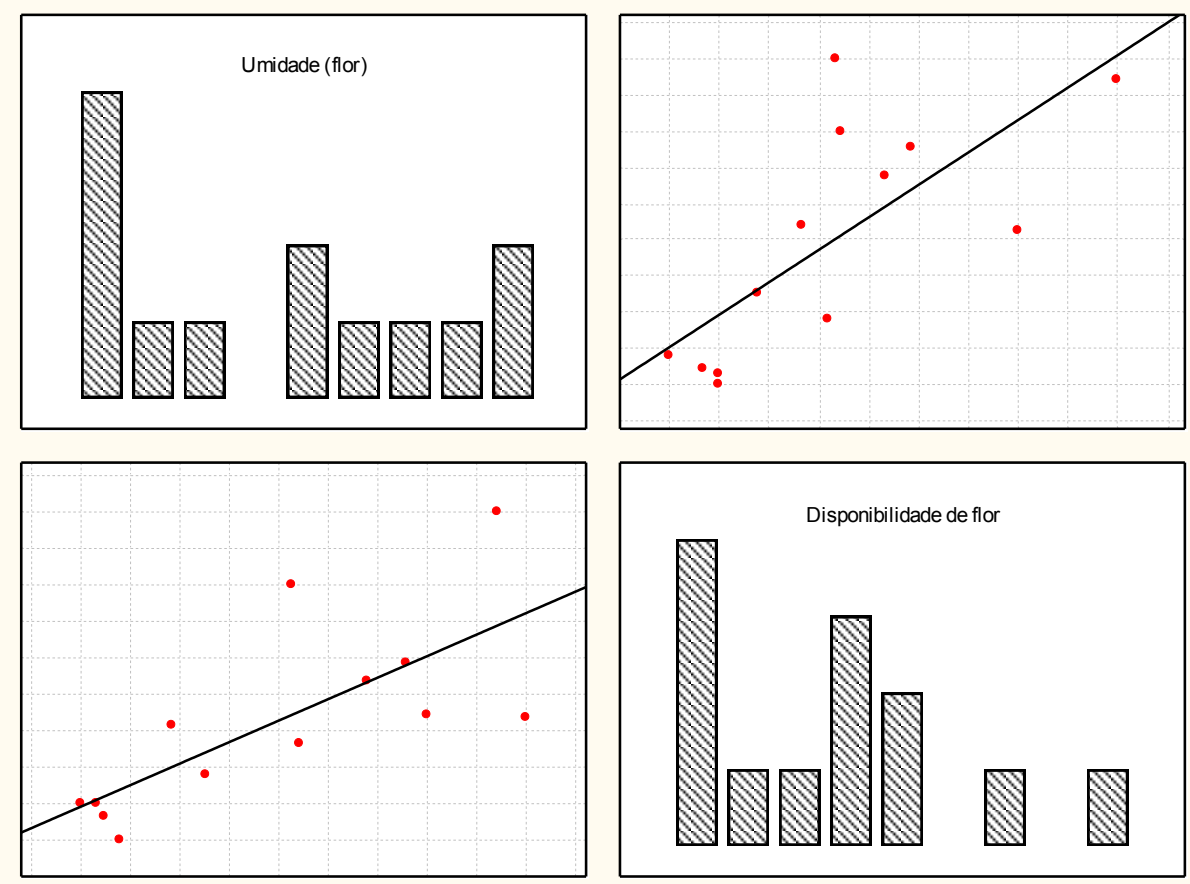

Figura 5. Correlação de Spearman significativa e positiva entre umidade e disponibilidade de flor (Rhizophora mangle) no Manguezal do Morro do Boi.

\subsection{Orçamento de atividades}

Ao longo dos 19 meses de observação do grupo Morro do Boi foram totalizadas 854 horas de esforço de campo e destas, 415 horas foram de contato direto com o grupo (coleta sistemática de dados). As 415 horas de observação sistemática resultaram em um aproveitamento de 2490 varreduras e 9090 registros individuais.

Os dados comportamentais quando submetidos ao teste de Kruskall-Wallis revelaram diferenças significativas entre as atividades $(H=89,19 ; \mathrm{p}=0,000)$, sendo o forrageio a atividade com maior proporção de tempo gasto. Do total de observações, o grupo passou $63,44 \%$ do tempo forrageando e $16,92 \%$ do tempo em deslocamento. O tempo despendido para a alimentação foi de $10,63 \%$, sendo $9,7 \%$ de ingestão de recursos vegetais e $0,93 \%$ de ingestão animal. A interação social e repouso representaram 5,24 \% e 3,75\% dos registros, respectivamente (Figura 6). Outros comportamentos, entre eles a cópula, somaram 0,02\% dos registros. 


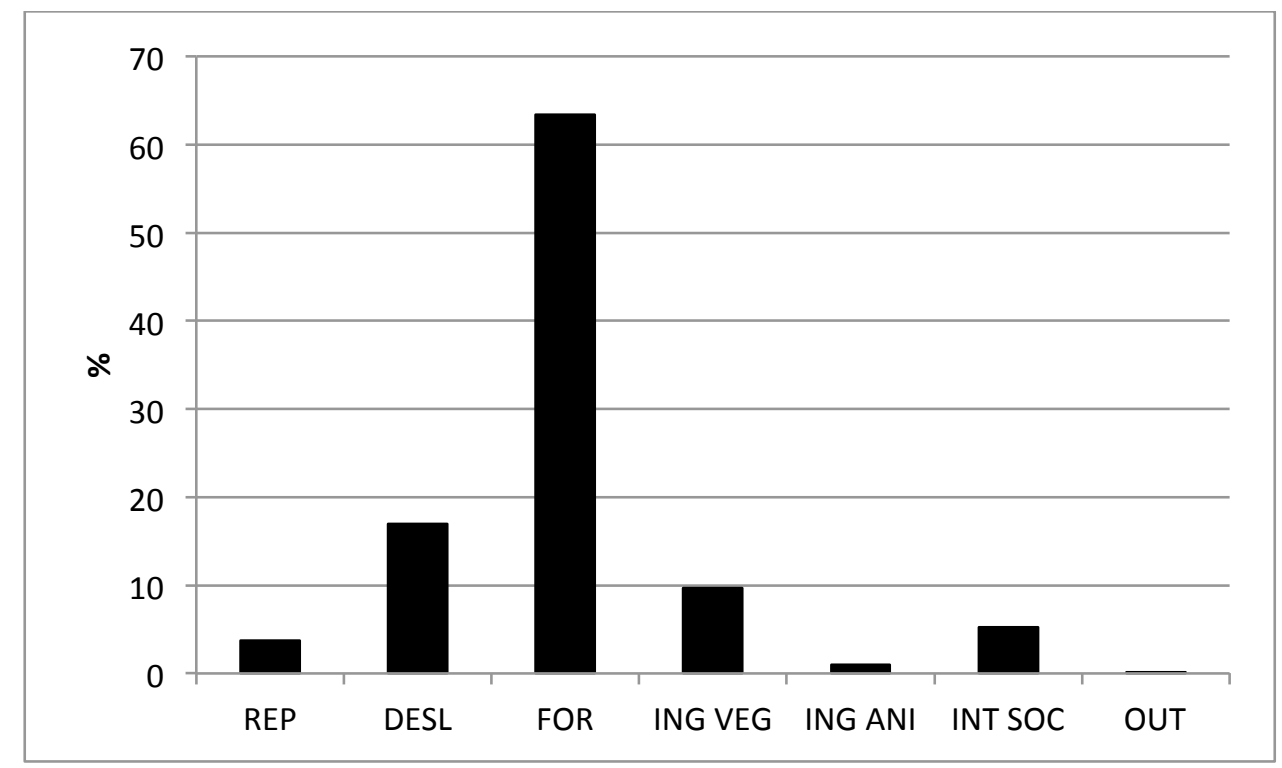

Figura 6. Orçamento de atividades - REP: repouso; DESL: deslocamento; FOR: forrageio; ING VEG: ingestão vegetal; ING ANI: ingestão animal; INT SOC: interação social; OUT: outros - do grupo Morro do Boi, no período de setembro de 2011 a março de 2013.

Dos comportamentos testados dois a dois (Mann-Whitney a posteriori) todos apresentaram diferença significativa $(\mathrm{p} \leq 0,05)$ (Tabela 2$)$.

Tabela 2. Valores de Mann-Whitney para o orçamento de atividades do grupo Morro do Boi, no período de setembro de 2011 a março de 2013. REP: repouso; DESL: deslocamento; FOR: forrageio; ING VEG: ingestão vegetal; ING ANI: ingestão animal; INT SOC: interação social.

\begin{tabular}{|c|c|c|}
\hline Atividade & $\mathbf{U}$ & $\mathbf{p}$ \\
\hline Rep - Desl & 6.00000 & 0.000000 \\
\hline Rep - For & 0.000 & 0.000000 \\
\hline Rep - Ingveg & 48.00000 & 0.000110 \\
\hline Rep - Ingani & 57.50000 & 0.00330 \\
\hline Rep - Intsoc & 100.0000 & 0.018765 \\
\hline Loc - For & 0.00 & 0.000000 \\
\hline Loc - Ingveg & 66.0000 & 0.000829 \\
\hline Loc - Ingani & 0.00 & 0.000000 \\
\hline Loc - Intsoc & 46.0000 & 0.000086 \\
\hline For - Ingveg & 0.00 & 0.000000 \\
\hline For - Ingani & 0.00 & 0.000000 \\
\hline For - Intsoc & 0.00 & 0.000000 \\
\hline Ingveg - Ingani & 0.00 & 0.000004 \\
\hline Ingveg - Intsoc & 113.500 & 0.050460 \\
\hline Ingani - Intsoc & 27.0000 & 0.000007 \\
\hline
\end{tabular}

A porcentagem dos comportamentos registrados variou no decorrer dos meses, conforme a Figura 7. É relevante ressaltar que o forrageio foi a atividade em que o grupo despendeu mais tempo durante todo o estudo, apresentando maior porcentagem do tempo total 
de observação nos meses de dezembro de 2011 e novembro de 2012. O mês em que esta atividade ocorreu em menor frequência foi setembro de 2012, quando o tempo gasto em interação social, principalmente agonística, foi maior.

Para verificar se houve variação sazonal no orçamento de atividades, a proporção de cada atividade foi comparada entre as estações seca e chuvosa. Os dados submetidos ao teste de Mann-Whitney não revelaram nenhuma diferença das atividades entre as estações (Tabela $3)$.

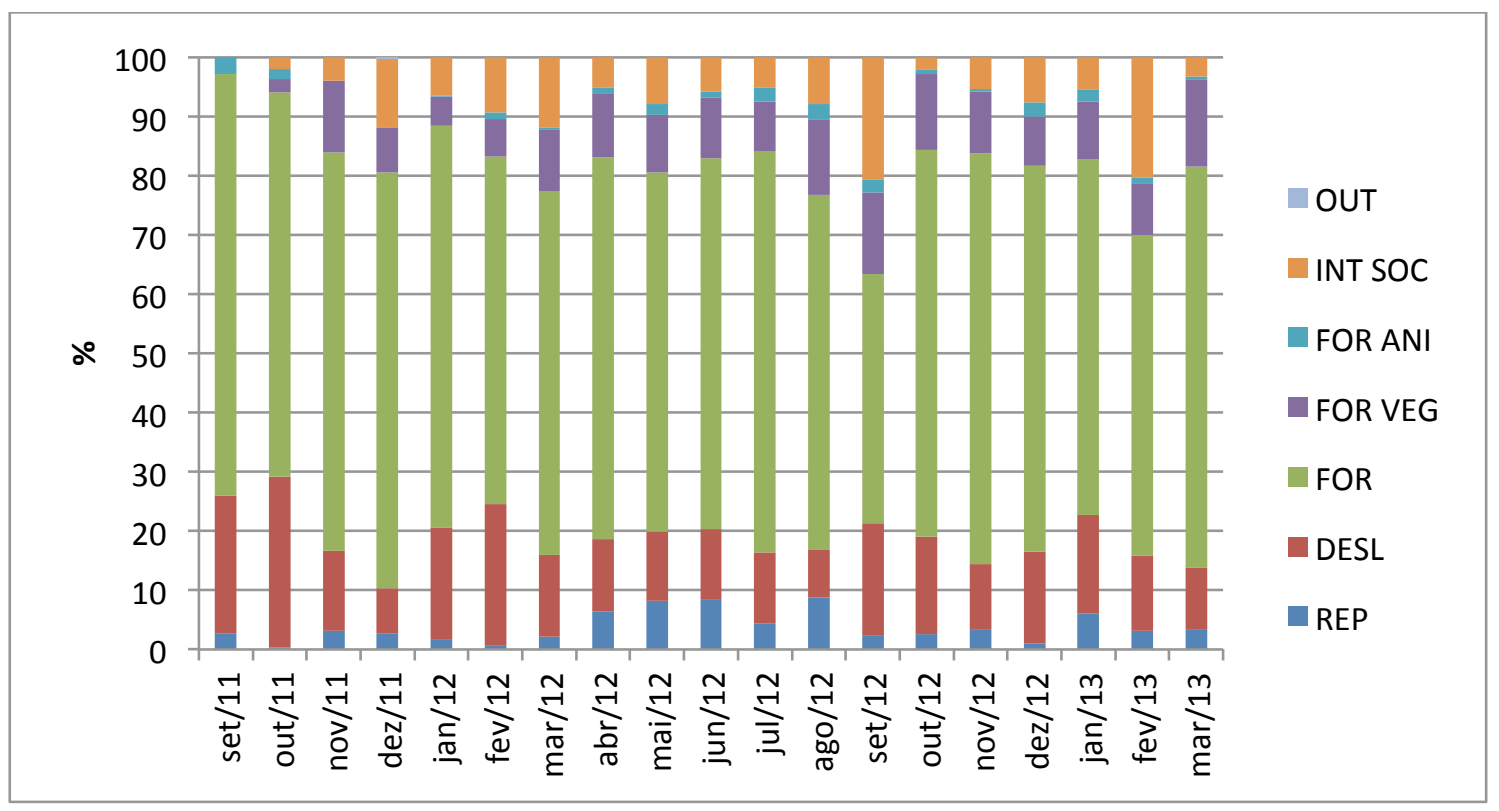

Figura 7. Orçamento de atividades - REP: repouso; DESL: deslocamento; FOR: forrageio; ING VEG: ingestão vegetal; ING ANI: ingestão animal; INT SOC: interação social; OUT: outros - do grupo Morro do Boi, no período de setembro de 2011 a março de 2013.

Tabela 3. Valores de Mann-Whitney para o orçamento de atividades nas estações seca e chuvosa do grupo Morro do Boi, no período de setembro de 2011 a março de 2013.

\begin{tabular}{|c|c|c|}
\hline $\begin{array}{c}\text { Atividade (estação seca } \mathbf{x} \\
\text { chuvosa) }\end{array}$ & $\mathbf{U}$ & $\mathbf{p}$ \\
\hline Repouso & 35.00000 & 0.414217 \\
\hline Deslocamento & 44.00000 & 0.081650 \\
\hline Forrageio & 26.00000 & 0.120820 \\
\hline Ingestão vegetal & 45.00000 & 1.000 \\
\hline Ingestão animal & 33.00000 & 0.327188 \\
\hline Interação social & 31.00000 & 0.253000 \\
\hline
\end{tabular}


Foram realizados também testes de correlação para verificar a associação entre as atividades diárias, entre estas e a disponibilidade de caranguejos e flores e se houve influência das variáveis climáticas (temperatura, umidade e precipitação) no orçamento de atividades. Houve associação significativa e negativa entre repouso e deslocamento (Spearman $\mathrm{R}=$ $0,687719 ; \mathrm{p}<0,05)$ e entre forrageio e interações sociais (Spearman $\mathrm{R}=-0,601754 ; \mathrm{p}<$ 0,05). Porém, nenhuma associação do orçamento de atividades foi encontrada com a disponibilidade de recursos alimentares (caranguejos e flores) e com as variáveis climáticas.

\subsubsection{Orçamento de atividades em relação à classe de idade}

Em relação à faixa etária, observou-se que nas três classes de idade (jovem, subadulto e adulto), a atividade mais frequente foi o forrageio seguido do deslocamento, da ingestão vegetal, do repouso e da ingestão animal.

Para testar se houve diferença entre o tempo gasto em cada atividade pelas classes de idade foi realizado o teste de Kruskall-Wallis. Este teste revelou diferença significativa apenas em relação à ingestão animal $(H=17,21789 ; \mathrm{p}=0,0002)$ (Figura 8). Os dados analisados pelo teste de Mann-Whitney apresentaram diferenças significativas entre jovem e sub-adulto $(\mathrm{U}=$ $83,50000 ; \mathrm{p}=0,004628)$ e entre jovem e adulto $(\mathrm{U}=45,00000 ; \mathrm{p}=0,000076)$. Entre as classes sub-adulto e adulto não houve diferença significativa $(\mathrm{p}=0,918613)$.

A proporção de cada atividade nas diferentes classes de idade foi comparada entre as estações seca e chuvosa. Os dados submetidos ao teste de Mann-Whitney não revelaram nenhuma diferença nas classes sub-adulto e adulto, apenas nos jovens. Segundo o teste, a estação seca influenciou o aumento do forrageio entre os jovens $(U=17,00000 ; p=$ 0,022244) e uma tendência para o aumento da ingestão vegetal $(U=21,50000 ; p=0,05)$ e do deslocamento $(U=21,00000 ; p=0,05)$ no período chuvoso. 


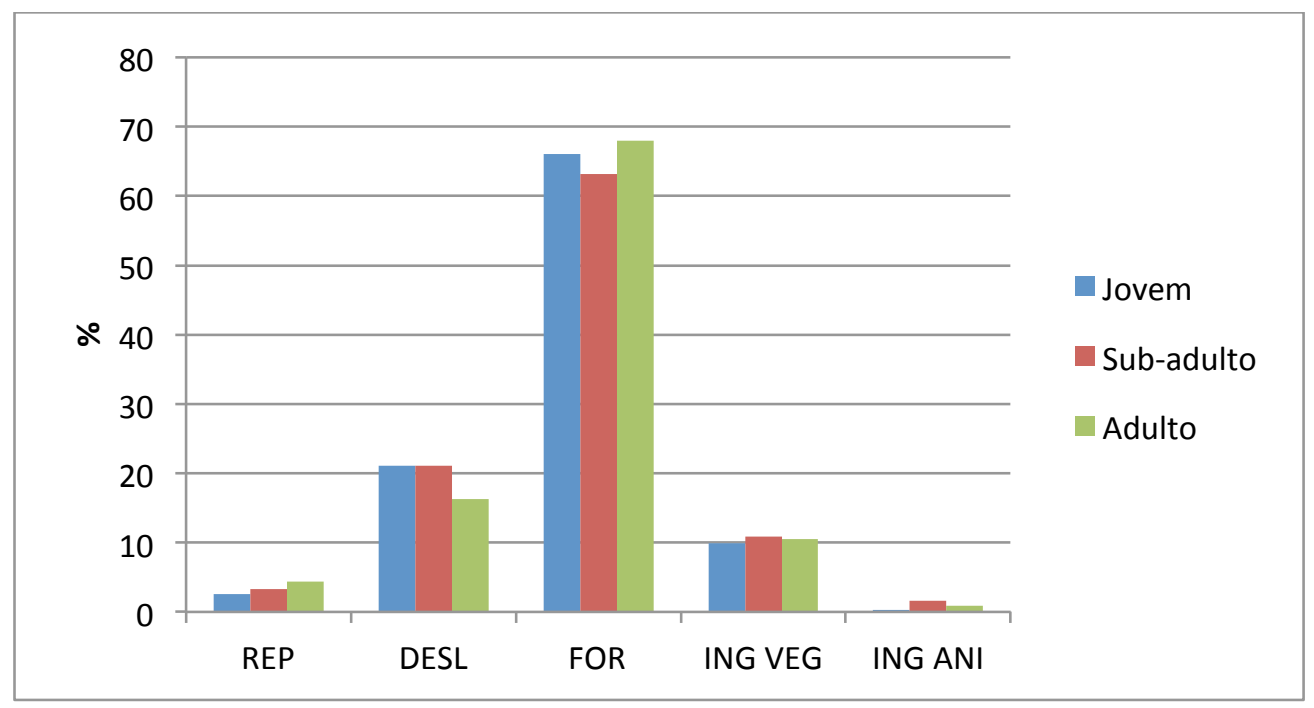

Figura 8. Orçamento de atividades em relação à classe de idade dos macacos-prego (S. libidinosus) do Morro do Boi, no período de setembro de 2011 a março de 2013 (REP: repouso; DESL: deslocamento; FOR: forrageio; ING VEG: ingestão vegetal; ING ANI: ingestão animal).

\subsubsection{Interações sociais}

Em relação às interações sociais, a maior proporção foi de agonismo $(96,96 \%)$, resultando em aproximadamente 2,15 eventos de agonismo por hora de observação. As demais interações sociais registradas no período foram catação social $(2,93 \%)$ e cópula $(0,1 \%)$ e ocorreram em menor proporção (Figura 9). Essa diferença percentual entre os três tipos de interação social é significativa $(H=45,40235 ; \mathrm{p}=0,0000)$. Houve diferença entre agonismo e catação $(U=0,00000 ; p=0,000000)$, entre agonismo e cópula $(U=0,00 ; p=$ 0,000) e entre catação e cópula $(U=91,00000 ; p=0,008977)$. Entre as estações não houve diferença significativa entre cada tipo de interação social (Tabela 4).

Ao longo dos meses a frequência de agonismo e catação pouco sofreu alteração (Figura 10). Mesmo não havendo diferença significativa entre as estações, na maioria dos meses da estação seca, o agonismo foi a atividade que predominou, sendo a única registrada. Porém, no mês de agosto de 2012, que também faz parte da estação seca, o percentual de catação foi o maior de todos os meses de estudo $(12,82 \%)$ e o de agonismo o menor $(87,18 \%)$. 


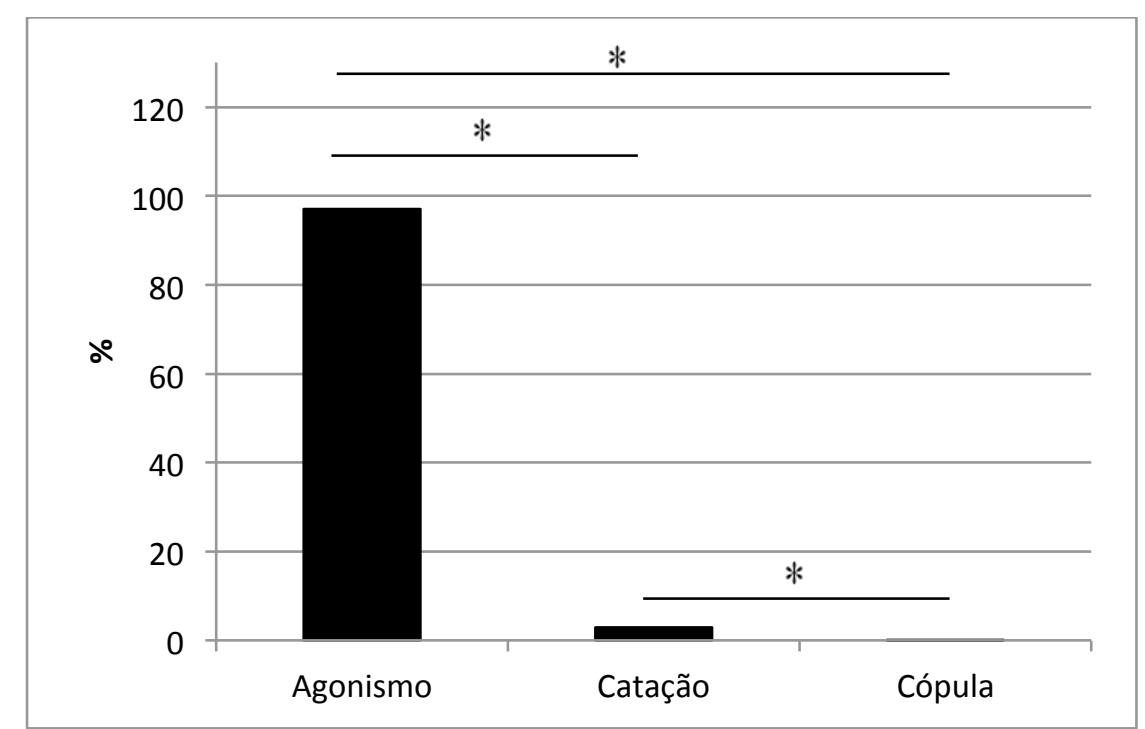

Figura 9. Interações sociais do grupo Morro do Boi no período de setembro de 2011 a março de 2013.

Tabela 4. Valores de Mann-Whitney para os tipos de interações sociais nas estações seca e chuvosa do grupo Morro do Boi, no período de setembro de 2011 a março de 2013.

\begin{tabular}{|c|c|c|}
\hline $\begin{array}{c}\text { Atividade social (estação } \\
\text { seca x chuvosa) }\end{array}$ & $\mathbf{U}$ & $\mathbf{p}$ \\
\hline Agonismo & 42.00000 & 0.806496 \\
\hline Catação & 41.00000 & 0.743972 \\
\hline Cópula & 40.50000 & 0.713303 \\
\hline
\end{tabular}

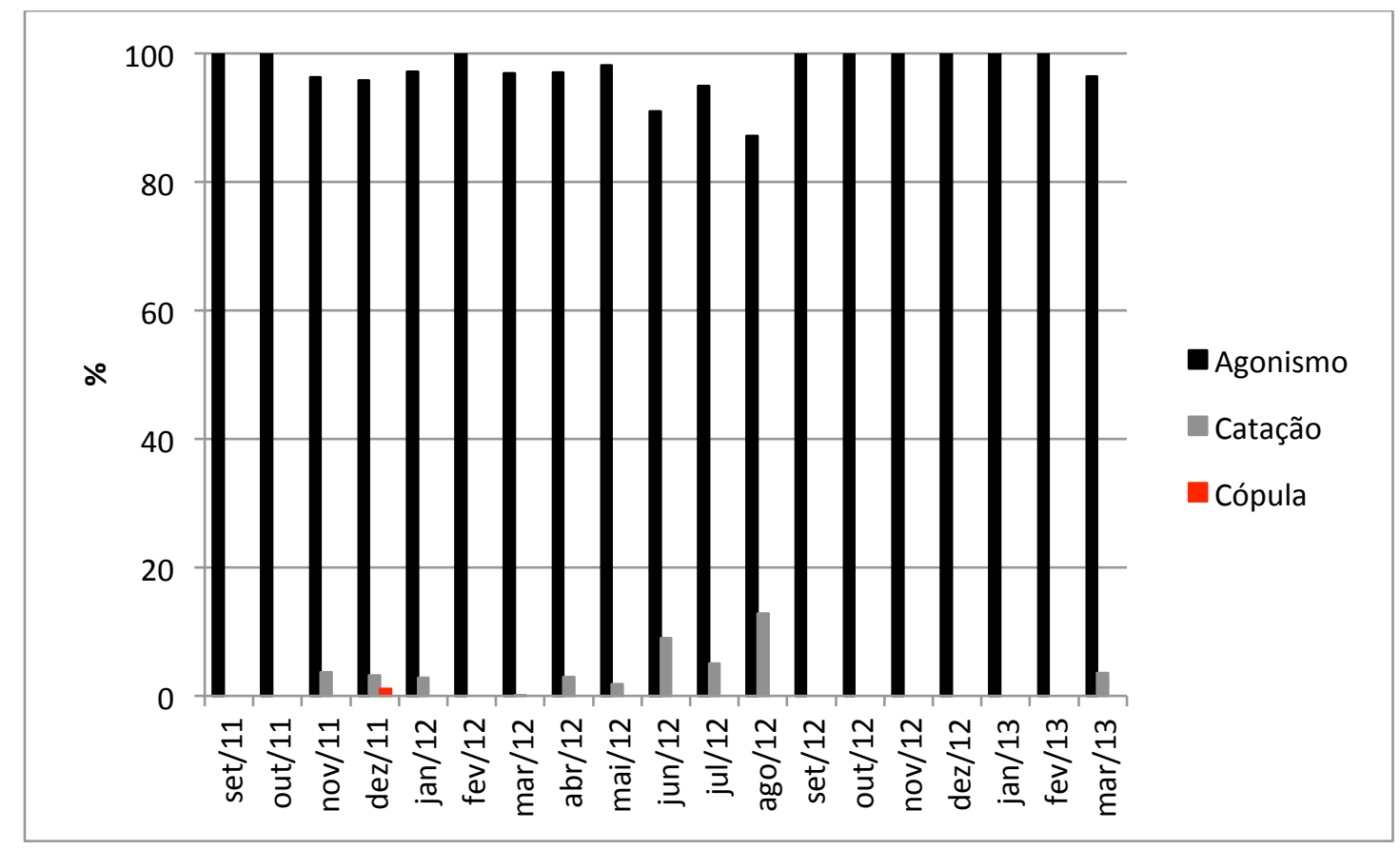

Figura 10. Percentual de interações sociais no grupo Morro do Boi no período de setembro de 2011 a março de 2013. 
Não foi possível identificar todos os contextos em que os agonismos aconteceram, mas do total de agonismos registrados, a maioria foi em contexto de alimentação (71,63\%), tanto de recursos vegetais quanto de recursos animais. A ocorrência de perseguição com agressão e mordidas entre os indivíduos envolvidos foi possível ser identificada em 1,4\% dos eventos. Também ocorreram agonismos após a detecção de batidas de martelos nas bigornas para a quebra dos alimentos encapsulados $(0,72 \%, \mathrm{~N}=46)$. É relevante ressaltar dois episódios de agonismo em contexto de alimentação: 1) os indivíduos costumavam forragear caranguejos na área cortada por um rio ou igarapé (ver no Cap. III área B4 do mapa dos sítios de quebra) e neste local foi registrada a maior duração de um evento agonístico que surgiu após os barulhos de quebra (o evento durou 5 minutos); 2) houve disputa por caranguejo entre dois indivíduos que forrageavam juntamente com o grupo próximos ao chão; o portador do caranguejo fugiu correndo pelas raízes aéreas e subiu pela vegetação do mangue com a presa na boca, terminando de comer na copa da árvore.

Em relação à catação, poucos eventos foram registrados ao longo da pesquisa $(n=27)$. A maioria dos eventos de catação foi entre o macho dominante e uma fêmea (59,25\%). Tanto o macho quanto a fêmea realizaram e receberam catação. Os demais eventos foram entre indivíduos subordinados, porém não foi possível a identificação dos mesmos. O único evento de cópula registrado no mês de dezembro de 2011 envolveu indivíduos subordinados.

A associação entre as atividades diárias e as interações sociais foi significativa e positiva entre agonismo e locomoção (Spearman $\mathrm{R}=0,673262 ; \mathrm{p}<0,05$ ) e entre catação e repouso (Spearman $\mathrm{R}=0,600928 ; \mathrm{p}<0,05)$ e significativa e negativa entre agonismo e repouso (Spearman $\mathrm{R}=-0,545287 ; \mathrm{p}<0,05)$, entre catação e locomoção (Spearman $\mathrm{R}=$ 0,662134; $\mathrm{p}<0,05$ ) e entre catação e agonismo (Spearman $\mathrm{R}=-0,2253 ; \mathrm{p}<0,05$ ).

\subsubsection{Utilização dos estratos}

A utilização dos diversos estratos da floresta de mangue também foi registrada e os macacos-prego desenvolveram suas atividades a maior parte do tempo no estrato arbóreo com altura superior a 5 metros ao longo de todos os meses de observação (Figura 11). Os dados analisados pelo teste de Kruskal-Wallis mostraram diferenças significativas na frequência do uso desses três estratos $(\mathrm{H}=46,73313 ; \mathrm{p}=0,000)$. Comparando-se os pares de estratos (solo e $<5$ metros; solo e $>5$ metros e $<5$ e $>5$ metros) o teste de Mann-Whitney também revelou 
diferença significativa entre esses pares $(U=24,00000, p=0,000 ; U=0,00000, p=0,000 ; U$ $=0,0000, \mathrm{p}=0,000$, respectivamente).

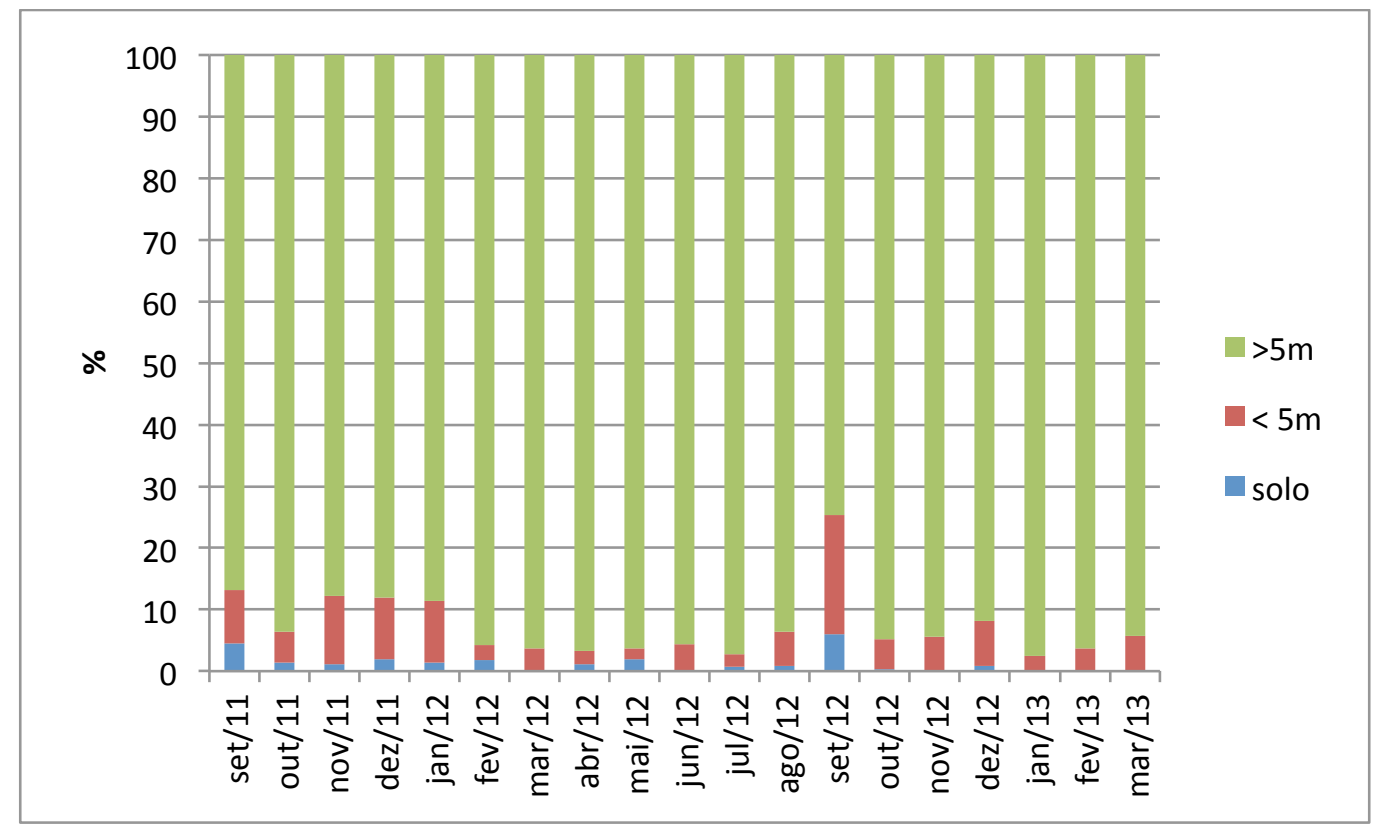

Figura 11. Uso dos diferentes estratos da floresta de mangue pelos macacos-prego (S. libidinosus) do Morro do Boi no período de setembro de 2011 a março de 2013.

A frequência total dos registros de uso do espaço com altura superior a 5 metros foi de 93,84\%, seguido do uso de estratos arbóreos com altura inferior a 5 metros com 5,27\% e do uso do solo com $0,9 \%$ (Figura 12). O uso do solo pelos macacos-prego ocorreu apenas em contexto de forrageio e alimentação de item animal (caranguejos, turus e gastrópodes) (Figura $13)$.

O mês de setembro de 2012 se destaca por ser o que teve menor proporção de uso do estrato com altura superior a 5 metros e maior proporção do estrato abaixo de 5 metros e do solo. Nesse mês os macacos-prego foram vistos com mais frequência descendo ao chão para forragear. 

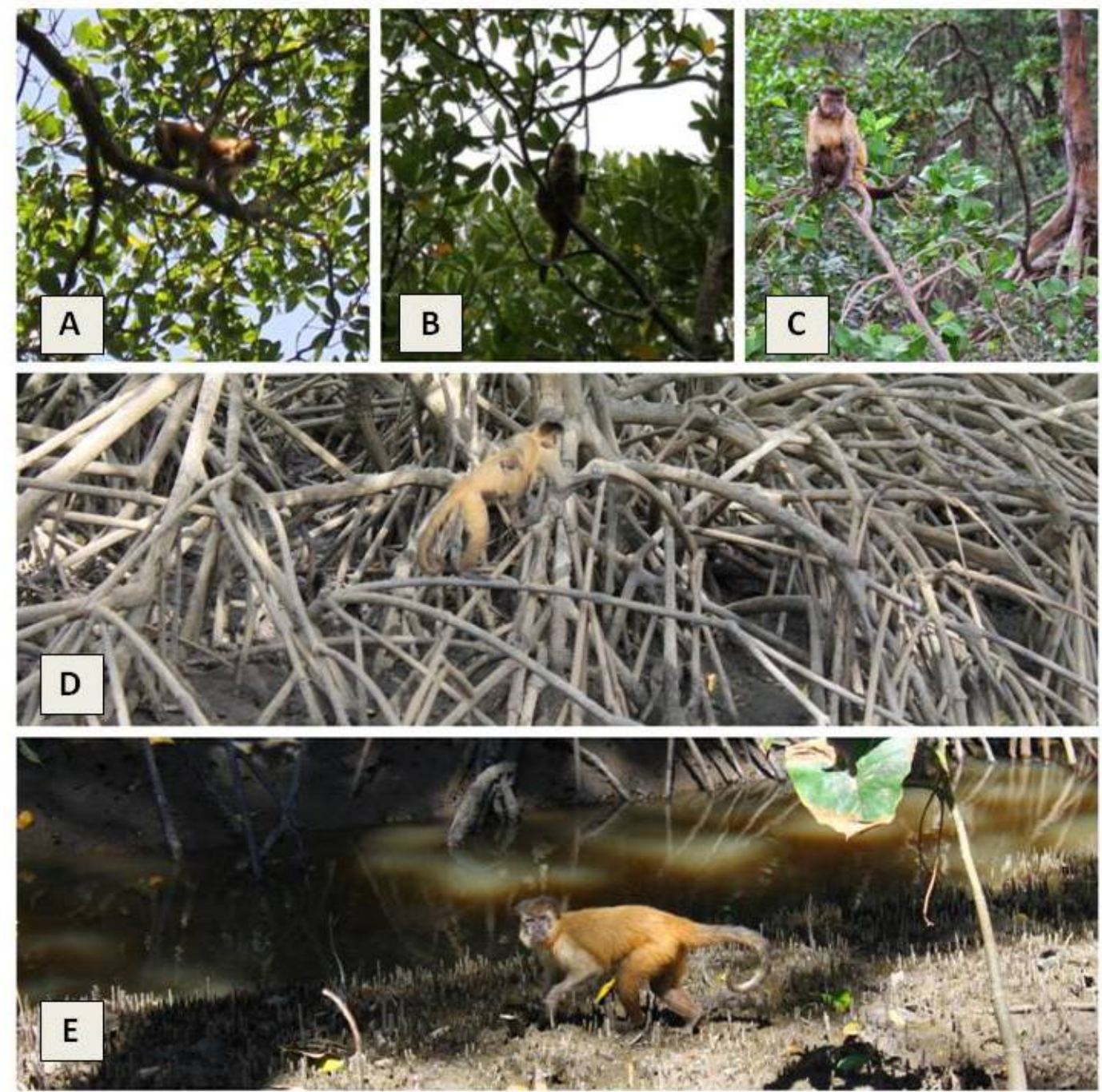

Figura 12. Diferentes estratos utilizados pelos macacos-prego (S. libidinosus) do Morro do Boi durante o período de setembro de 2011 a março de 2013. (A) e (B) Uso de estratos com altura superior a 5 metros. (C) e (D) Uso de estratos com altura abaixo de 5 metros, exceto solo. (E) Uso do solo como estrato.
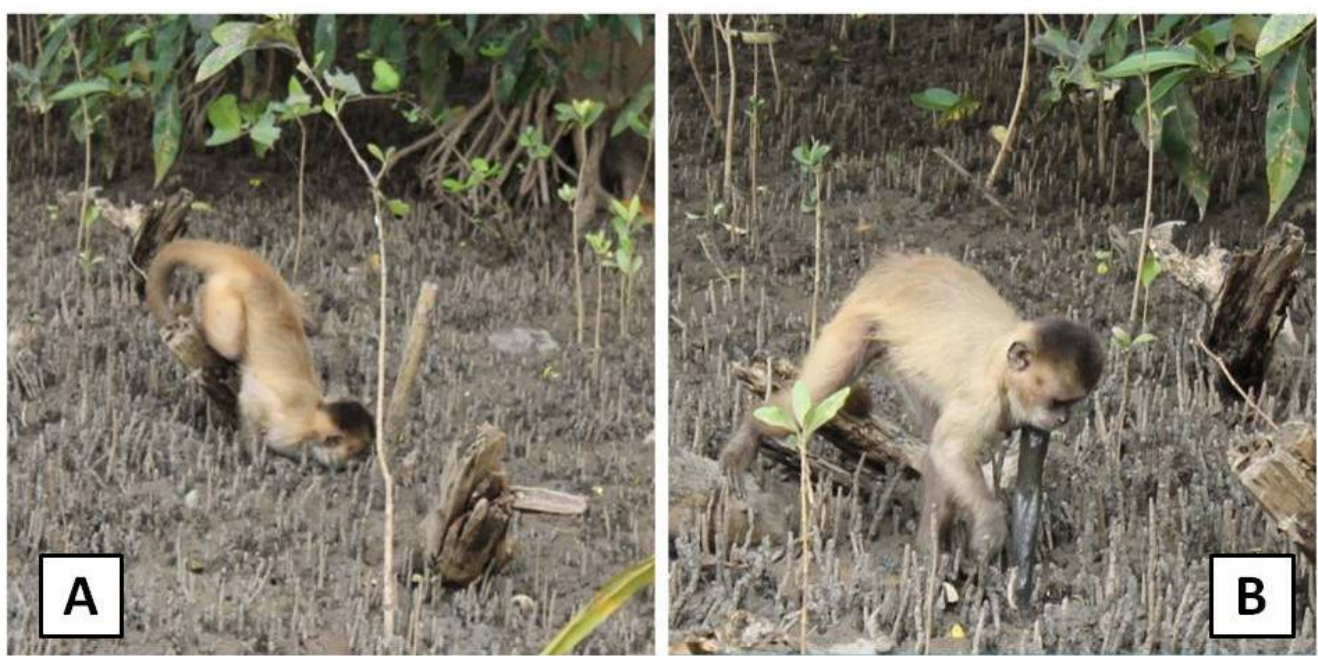

Figura 13. (A) e (B). Fêmea de macaco-prego (S. libidinosus) do grupo Morro do Boi forrageando no solo do manguezal em busca de caranguejo. 
Comparando-se o uso de cada estrato da floresta de mangue entre as estações seca e chuvosa, não foi encontrada nenhuma diferença significativa na frequência do uso do solo pelos macacos-prego $(U=26,0000 ; p=0,165125)$. Porém, o uso dos estratos inferiores a 5 metros e maiores que 5 metros diferiu entre as estações. Segundo nossos dados submetidos ao teste de Mann-Whitney, os macacos-prego do grupo Morro do Boi utilizaram o estrato inferior a 5 metros com mais frequência na estação seca $(U=18,00000 ; p=0,027487)$ e utilizaram o estrato superior a 5 metros com mais frequência na estação chuvosa $(\mathrm{U}=$ 15,0000; $\mathrm{p}=0,014306)$.

Foi verificada também a ocorrência de associação entre as atividades diárias e o uso dos estratos, porém nenhum resultado foi significativo.

\subsection{Dieta}

A dieta do grupo de macacos-prego do Morro do Boi consistiu de propágulos e frutos de Avicennia germinans (Figura 14), de propágulos, flores e ponta de raiz de Rhizophora mangle (Figura 15), dos frutos de murici (Byrsonima crassifolia) e de guajiru (Chrysobalanus icaco) (Figura 16), além de caranguejos (Ucides sp.), gastrópodes, bivalves, turus (Figura 17) e pequenos invertebrados localizados nas copas das árvores (Figura 18).

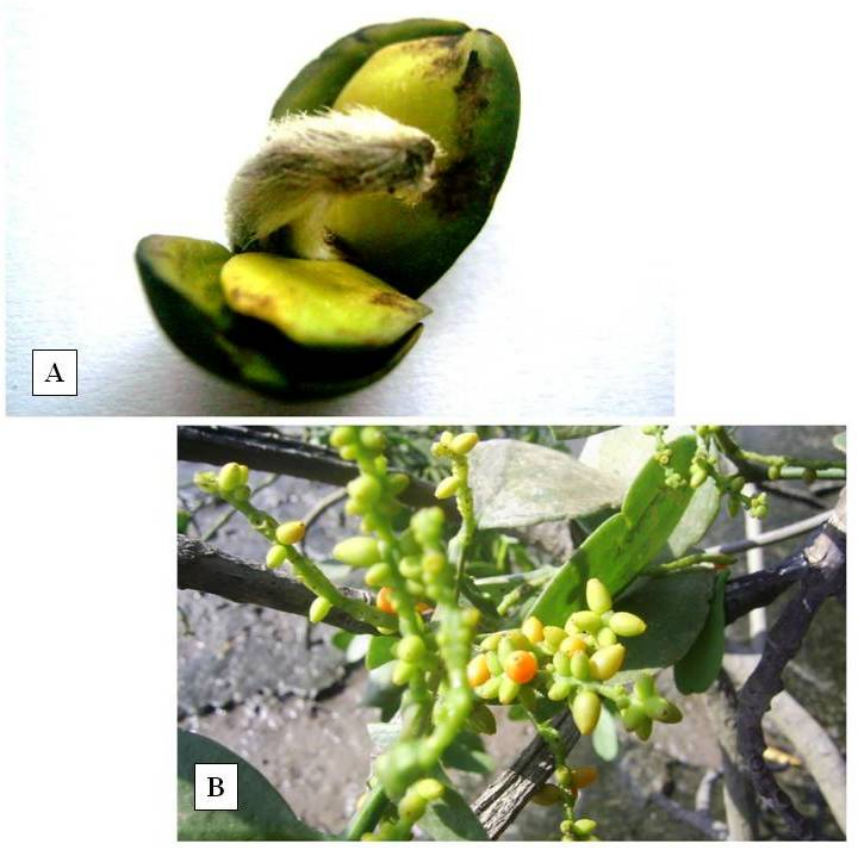

Figura 14. Itens da dieta dos macacos-prego (S. libidinosus) do Morro do Boi no período de setembro de 2011 a março de 2013. (A) Propágulo de Avicennia germinans.(B) Fruto de Avicennia germinans. 

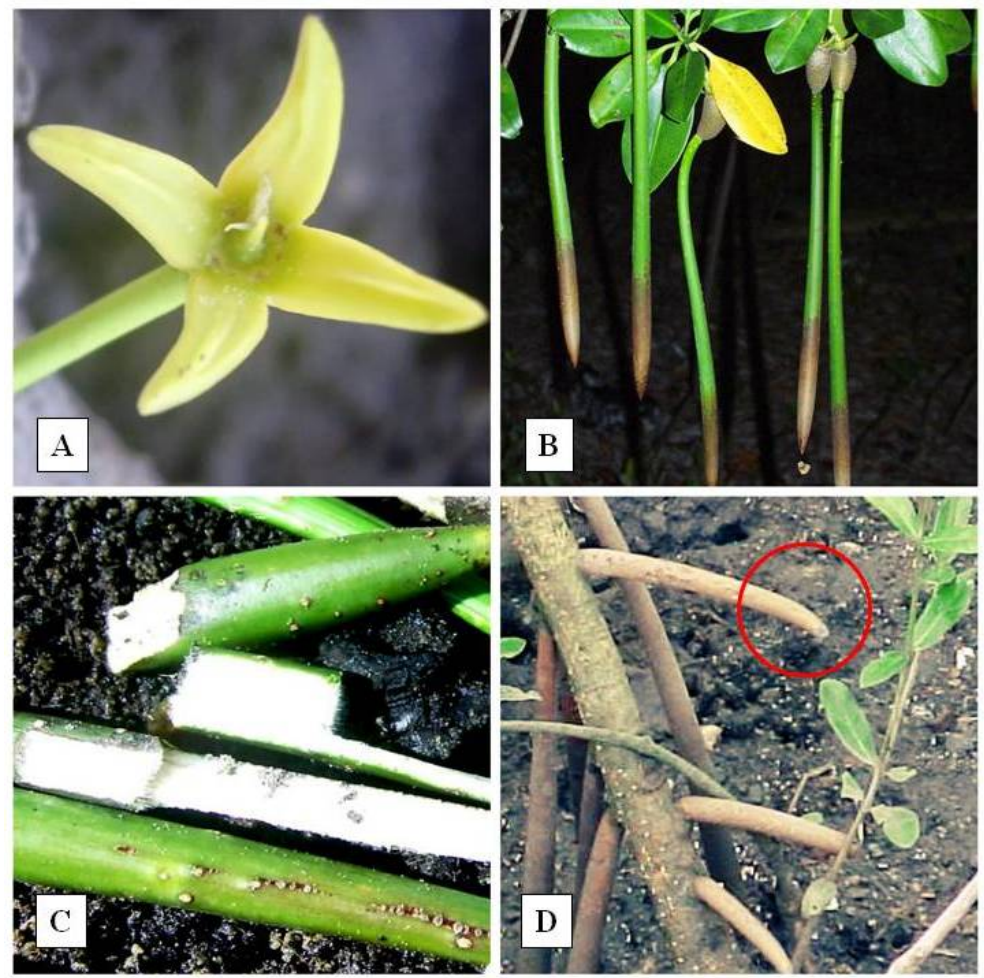

Figura 15. Itens da dieta dos macacos-prego (S. libidinosus) do Morro do Boi no período de setembro de 2011 a março de 2013. (A) Flor de Rhizophora mangle. (B) e (C) Propágulos de Rhizophora mangle. (D) Detalhe da ponta da raiz de Rhizophora mangle.
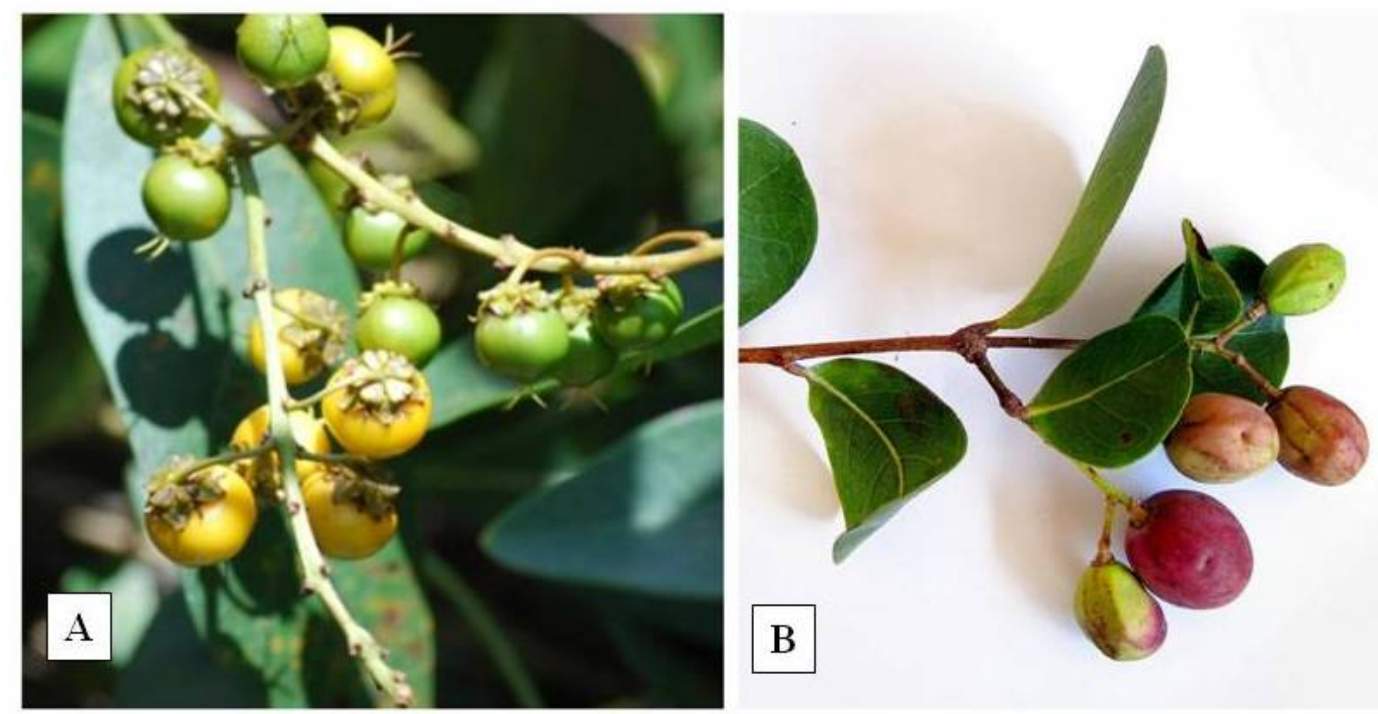

Figura 16. Itens da dieta dos macacos-prego (S. libidinosus) do Morro do Boi no período de setembro de 2011 a março de 2013. (A) Murici (Byrsonima crassifolia). (B) Guajiru (Chrysobalanus icaco). 


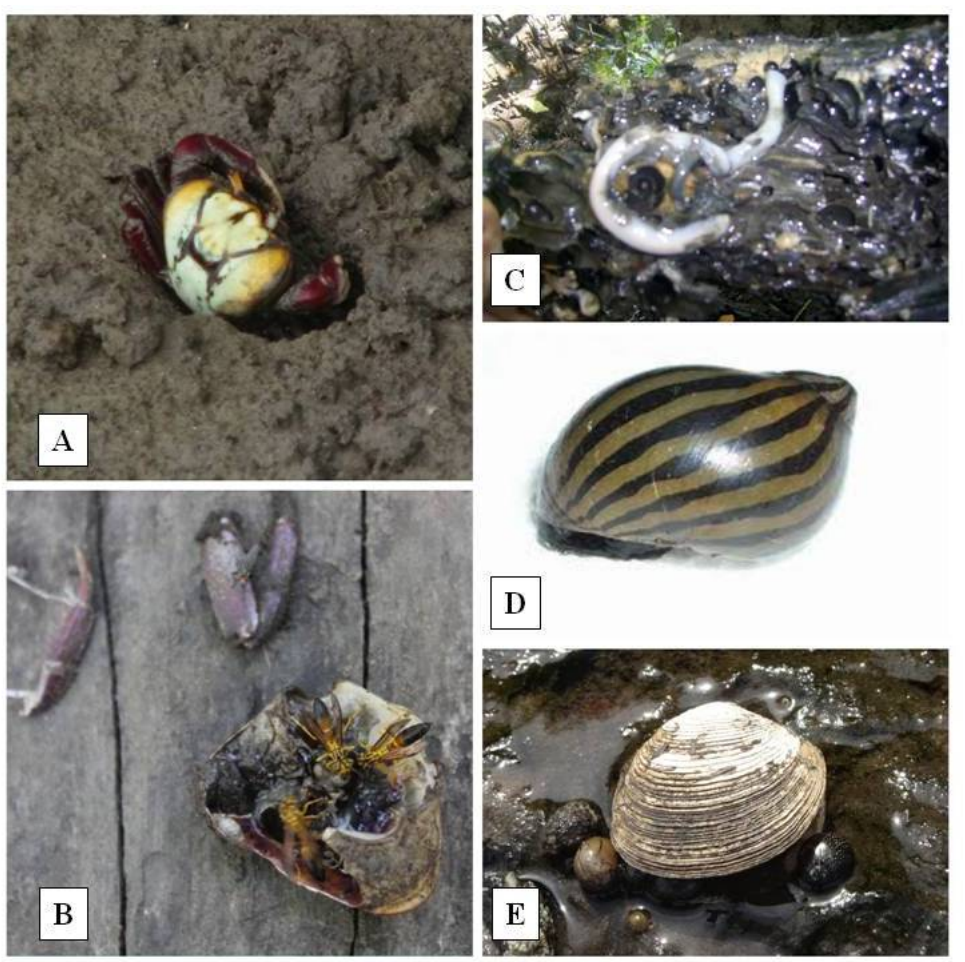

Figura 17. Itens da dieta dos macacos-prego (S. libidinosus) do Morro do Boi no período de setembro de 2011 a março de 2013. (A) e (B) Caranguejo (Ucides cordatus). (C) Turu (Teredo sp.). (D) Gastrópode (Neritina sp.). (E) Bivalves e gastrópodes.

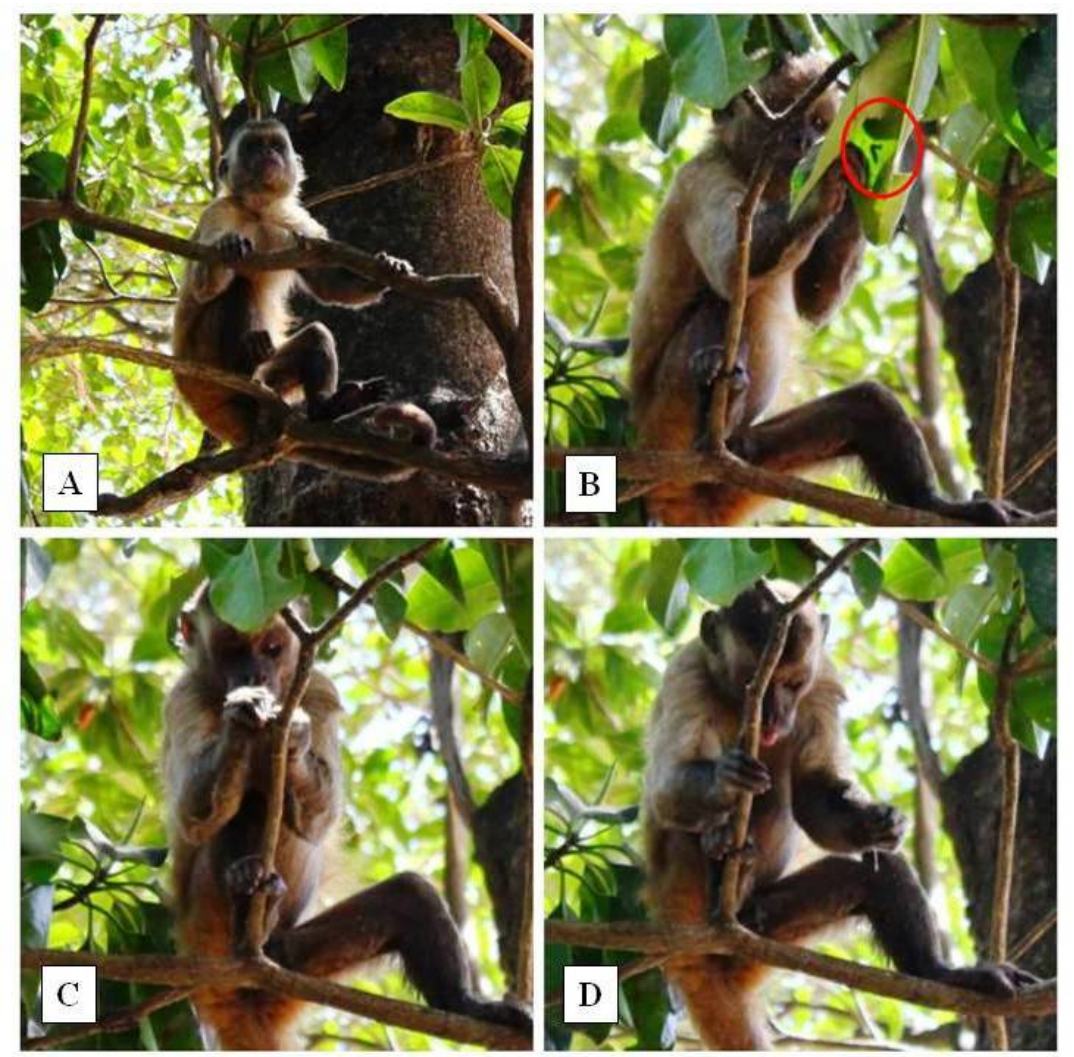

Figura 18. Forrageio e alimentação de invertebrado (lagarta) por um indivíduo de S. libidinosus do Morro do Boi. (A) Forrageio. (B) Captura da lagarta (em detalhe no centro do círculo vermelho). (C) Manuseio da lagarta. (D) Ingestão da lagarta. 
Ao longo dos meses de observação também foram encontradas fezes com fragmentos das carapaças e brânquias dos caranguejos ingeridos $(\mathrm{n}=20$, Figura 19A). A inclusão do fruto de Avicennia germinans na dieta dos macacos-prego só foi registrada através de evidências encontradas nas fezes dos indivíduos (Figura 19B e 19C), pois esse fruto se torna muito críptico na copa das árvores. Evidências também permitiram a inserção dos gastrópodes (Neritina sp.), bivalves e turus (Teredo sp.) na dieta, pois foram encontrados fragmentos das carapaças e conchas desses animais nos sítios de quebra (detalhes no Cap. III).

A frequência da ingestão de cada item alimentar variou ao longo das observações, sendo que os recursos vegetais foram mais frequentes na dieta do grupo $(88,16 \%)$ em comparação com os recursos animais $(8,93 \%)$ e os itens não identificados $(2,91 \%)$ registrados no período. A maior proporção dos itens alimentares foi de propágulos $(83,6 \%)$, significativamente superior aos demais itens alimentares $\left(\chi^{2}=394,24 ; p=0,000\right)$. Os demais itens alimentares apresentaram proporção de ingestão inferior: invertebrados $(6,44 \%)$, flores $(3,43 \%)$, itens não identificados $(2,9 \%)$, caranguejos $(2,5 \%)$, frutos $(0,93 \%)$ e ponta da raiz do mangue vermelho (0,2\%) (Figura 20). Houve uma associação significativa e negativa entre ingestão de propágulos e ingestão de caranguejos (Spearman $\mathrm{R}=-0,593612 ; \mathrm{p}<0,05$ ).

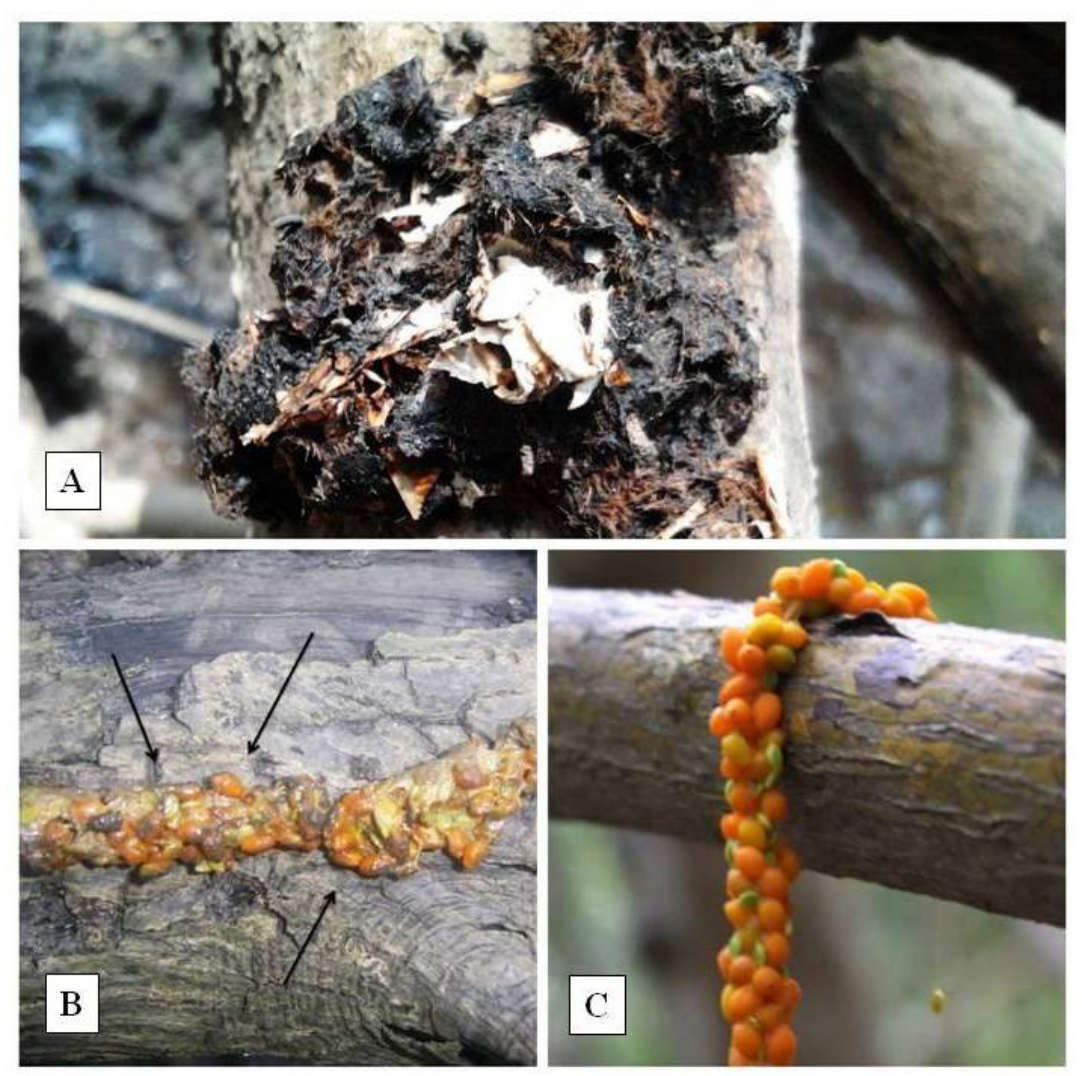

Figura 19. Fezes com vestígios dos alimentos consumidos pelos macacos-prego (S. libidinosus) do Morro do Boi. (A) Caranguejo. (B) e (C) Frutos de Avicennia germinans. 


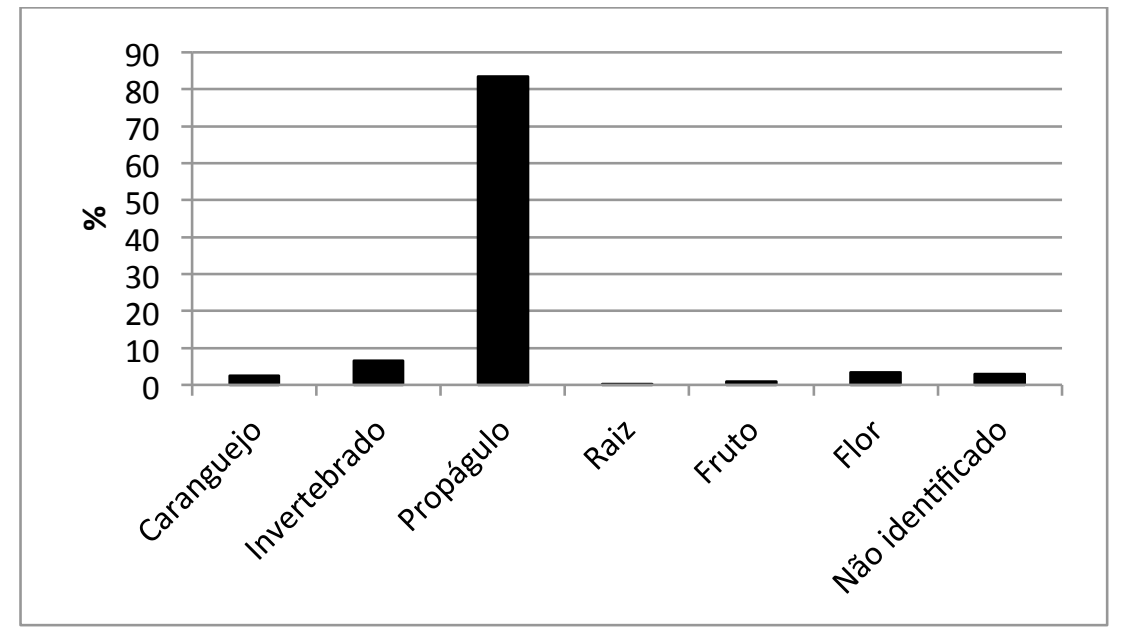

Figura 20. Tipos de alimentos ingeridos pelos macacos-prego (S. libidinosus) do grupo Morro do Boi no período de setembro de 2011 a março de 2013.

As frequências de ingestão dos itens alimentares foram comparadas entre as estações para verificar se a estação do ano tem influência no tipo de alimento que é consumido pelos macacos-prego do grupo Morro do Boi. O teste de Mann-Whitney apontou diferença apenas na ingestão de flores entre as estações seca e chuvosa $(U=18,00000 ; p=0,027487)$, sendo a maior frequência de ingestão nos meses chuvosos (Figura 21).

A correlação de Spearman foi realizada para verificar a associação entre as variáveis climáticas (temperatura, umidade e precipitação) e a dieta. Segundo o teste, as variáveis precipitação e umidade estiveram associadas à ingestão de flor (precipitação: Spearman $\mathrm{R}=$ 0,568798, $\mathrm{p}<0,05$; umidade: Spearman $\mathrm{R}=0,603716, \mathrm{p}<0,05)$.

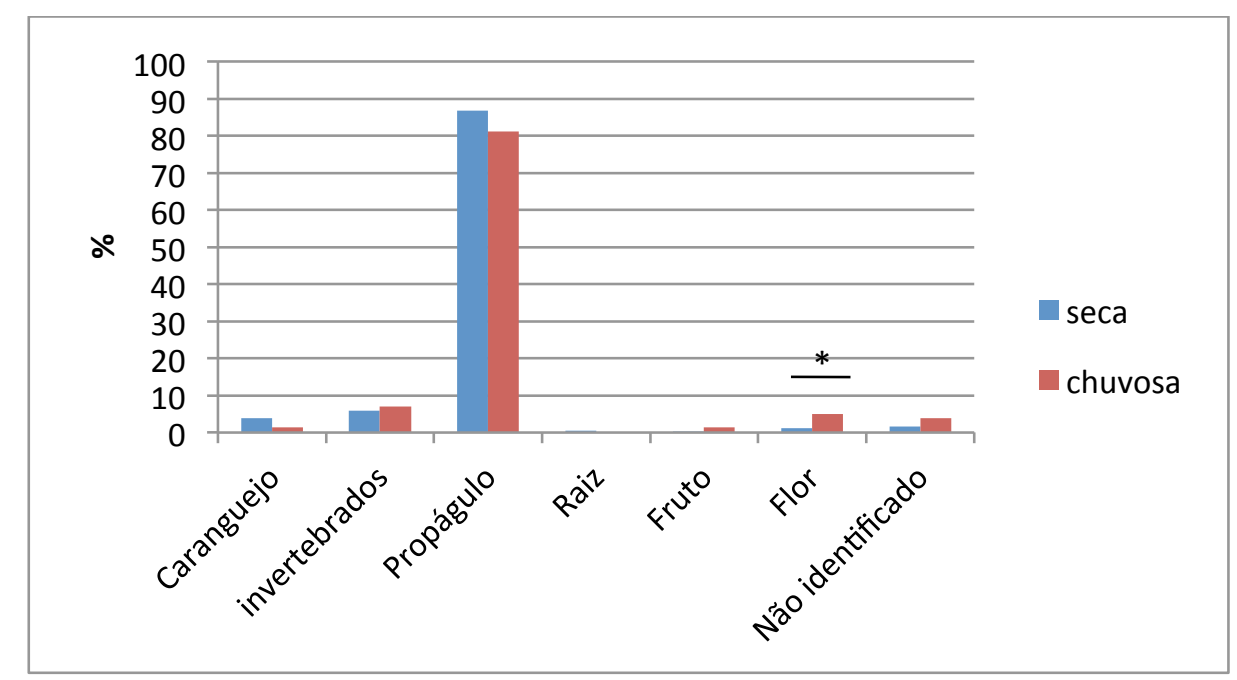

Figura 21. Tipos de alimentos ingeridos pelos macacos-prego (S. libidinosus) do grupo Morro do Boi nas estações seca e chuvosa no período de setembro de 2011 a março de 2013. 


\section{DISCUSSÃO}

\subsection{Disponibilidade de alimento e clima}

A frequência de recursos alimentares na área variou ao longo dos meses, porém a influência dos fatores climáticos (precipitação e umidade) na disponibilidade de alimentos foi significativa apenas em relação às flores de Rhizophora mangle. A disponibilidade de recursos vegetais nas florestas de mangue em áreas tropicais sofre influência dos fatores climáticos, principalmente da precipitação que limita a fenologia das espécies (Fernandes, 1999; Mehlig, 2006; Nadia, Morellatto \& Machado, 2012). Nadia et al. (2012) realizaram um estudo sobre a fenologia reprodutiva de manguezais no Nordeste do Brasil e este estudo revelou alguns padrões de floração e frutificação de espécies de mangue. Segundo o estudo, os mangues da espécie Rhizophora mangle apresentam floração o ano todo, porém exibem um padrão sazonal significante no pico de floração que se dá na estação chuvosa, corroborando nossos resultados, assim como a associação significativa e positiva encontrada entre precipitação e disponibilidade de flor. Além desse estudo, outros realizados em florestas de mangue em diversas localidades do Brasil reforçam que o padrão de floração de Rhizophora mangle é contínuo e que o pico de floração está relacionado com a estação chuvosa (Fernandes, 1999; Mehlig, 2006).

A produção de propágulos de $R$. mangle, assim como a floração, ocorreu continuamente, mas com um pico sazonal entre a estação seca e chuvosa e esteve fortemente associada com a duração do dia (Nadia et al., 2012). No nosso estudo não mensuramos a disponibilidade de propágulos, porém foi observado que o mesmo esteve disponível ao longo das estações, pois de acordo com nossos resultados sobre a composição alimentar dos macacos-prego do grupo Morro do Boi, este item foi o mais frequente na dieta do grupo.

Os recursos animais encapsulados (caranguejos) estiveram disponíveis tanto na estação seca quanto na chuvosa, sem sofrer influência da sazonalidade. Além disso, a densidade média de caranguejos na área seguiu o padrão encontrado nos manguezais brasileiros situados na zona equatorial (Alcântara-Filho, 1978; Castro, 1986; Almeida \& Melo, 1996; Alvez \& Nishida, 2004). Segundo Sastry (1983), os crustáceos podem se reproduzir durante todos os meses do ano (padrão contínuo) ou apenas durante os meses de condições ambientais mais favoráveis (padrão descontínuo ou sazonal). Os resultados 
mostram que durante o período da pesquisa os macacos-prego não sofreram nenhuma redução significativa nos recursos alimentares, pois os caranguejos estiveram disponíveis ao longo do ano assim como os propágulos de mangue.

\subsection{Orçamento de atividades e interações sociais}

O orçamento de atividades exibido pelos macacos-prego (Sapajus libidinosus) do Morro do Boi apresentou o mesmo padrão encontrado em outras populações e espécies de macacos-prego (S. nigritus: Rímoli, Strier \& Ferrari, 2008; Cebus albifrons: Matthews, 2009; S. libidinosus: Falótico, 2011, Verderane, 2010; S. nigritus e S. libidinosus: Izar et al., 2012).

No Morro do Boi, assim como no Parque Nacional da Serra da Capivara (PNSC) (Falótico, 2011), o forrageio foi a principal atividade exibida pelos animais. O forrageio associado à alimentação também se destaca das demais atividades na Fazenda da Boa Vista (FBV) (Verderane, 2010), na Estação Biológica de Caratinga (EBC) (Rímoli et al., 2008) e no Parque Estadual Carlos Botelho (PECB) (Taira, 2007, Peternelli-dos-Santos, 2009, Izar et al., 2012).

A proporção de tempo despendida na locomoção encontrada no Morro do Boi também foi muito semelhante à encontrada no PNSC, porém foi inferior à da FBV, do PEBC e do Parque Nacional de Brasília (PNB: Sabbatini, Tammati, Tavares, Giuliani \& Visalberghi, 2008). Alguns trabalhos mostram que o tempo despendido na locomoção é afetado pelo tamanho do grupo social (Isbell, 1991; Steenbek \& van Schaik, 2001), sendo que grupos com alta densidade de indivíduos apresentarão uma tendência maior em competir por alimento dentro do mesmo grupo e para evitar os custos envolvidos na competição, aumentarão o tempo gasto na locomoção (van Schaik et al.,1983; Isbell, 1991, Snaith \& Chapman, 2007). Nossos resultados mostraram o inverso, visto que o grupo Morro do Boi apresentou tamanho semelhante ao do PNSC e superior ao das demais áreas e menor área de vida em relação à todas essas populações. Além disso, apresentou a particularidade de habitar uma área fragmentada e isolada, o que diminuiu a possibilidade de deslocamento dos animais fora das limitações da floresta de mangue. A restrição locomotora em decorrência do pequeno tamanho da área foi observada no padrão de locomoção do grupo, que ocorreu de maneira circular várias vezes durante o dia, incluindo a visitação das mesmas fontes alimentares. Esse 
padrão encontrado no Morro do Boi se assemelhou ao encontrado em Chiropotes satanas chiropotes em área fragmentada e pequena (Boyle, Lourenço, da Silva \& Smith, 2009).

Os cuxiús do estudo de Boyle et al. (2009) habitavam um fragmento florestal de 10 hectares e apresentaram menor distância percorrida, maior visitação das mesmas árvores de alimentação, seguiram caminhos mais circulares e se movimentaram de forma mais uniforme no habitat do que populações da mesma espécie em áreas fragmentadas maiores (100 ha) e em floresta contínua. Eles sugerem que a repetida visitação das fontes alimentares ao longo do dia pelos macacos indica que eles não esgotam seus recursos de imediato e que o tamanho do fragmento florestal influencia o uso do espaço assim como a composição vegetal e a disponibilidade de recursos permeiam a potencialidade da área em oferecer recursos adequados para as espécies. O efeito da fragmentação de florestas na distribuição e permanência de seis espécies de primatas, incluindo os macacos-prego ( $S$. apella), foi estudado anteriormente por Boyle (2008). Especificamente em relação aos macacos-prego, Boyle (2008) encontrou uma intolerância à fragmentação florestal que foi explicada pela significativa redução na área de vida (1 ha e 10 ha) e a recolonização de fragmentos maiores (100 ha), com possibilidade de deslocamento entre fragmentos de mesmo tamanho. Áreas fragmentadas com tamanho entre 1 ha e 10 ha aumentam a densidade populacional e consequentemente a competição pelos recursos alimentares, levando os indivíduos a buscar áreas que suportem o seu estabelecimento. A presença e manutenção dos macacos-prego no manguezal do Morro do Boi foram indicativos de que área permitia a sobrevivência e reprodução dos indivíduos, porém de acordo com Boyle et al. (2009), nossos resultados apontaram que a pequena área de vida em um ambiente fragmentado e alta densidade de indivíduos aumentaram o despendido com o forrageio e não com a locomoção, possivelmente pelas limitações de recursos alimentares e de espaço.

Grupos que vivem em habitats com recursos disponíveis e de boa qualidade energética, ou seja, alimentos que são capazes de sustentar os membros por mais tempo, apresentam menor tempo gasto em locomoção e forrageio e maior tempo em descanso e consequentemente em interações sociais afiliativas, como a catação (Iwamoto \& Dunbar, 1983; Dunbar, 1992; Bronikowski \& Altmann, 1996). Em relação aos comportamentos sociais e ao repouso, nossos resultados seguiram o mesmo padrão encontrado em S. nigritus (Rímoli et al., 2008; Peternelli-dos-Santos, 2009; Izar et al., 2012), ou seja, os macacos-prego do Morro do Boi dedicaram mais tempo e esforço na busca de alimentos e consequentemente, apresentaram menos tempo para descansar e interagir socialmente. Isso explica os poucos 
eventos de catação registrados ao longo do estudo e a baixa frequência de descanso, bem como a associação positiva entre esses dois comportamentos.

A frequência de interação social entre os indivíduos é relevante para a coesão do grupo e uma vez que esse tempo é prejudicado pelo aumento demasiado do mesmo, a união e a harmonia entre os membros desequilibram, podendo levar à maior ocorrência de interações agonísticas, à formação de unidades de forrageio (Dunbar, 1992, Nakai, 2007) e até a sua fissão (Lehmann, Korstjens \& Dunbar, 2007). Esse padrão é observado em grupos de $S$. nigritus estudados na Estação Biológica de Caratinga (Rímoli et al., 2008) e no Parque Estadual Carlos Botelho (Nakai, 2007) e se mostra compatível com o que foi observado nesse grupo. No grupo Morro do Boi foi observada a formação de unidades de forrageio, com tamanho entre 2 e 4 indivíduos e em algumas vezes indivíduos solitários. Quando as unidades de forrageio se encontravam e ocorria uma maior aproximação entre todos os membros do grupo nas fontes alimentares, aumentavam os eventos de agonismo, inclusive quando envolvia o consumo de caranguejos nos sítios de quebra. Nossos dados não apontaram correlação entre agonismo e frequência de uso de martelos, porém em S. libidinosus da FBV foi observada essa relação (Verderane, Izar, Visalberghi \& Fragaszy, 2013). Segundo Verderane et al. (2013), geralmente os sítios de quebra comportam poucos indivíduos e estes passam menos tempo nos locais de quebra do que em fontes alimentares com distribuição agregada. Nos sítios de quebra da FBV foi registrado um elevado índice de agonismo em contexto de disputa por alimentos, e embora os cocos catulé e piaçava sejam considerados recursos alternativos (Wright et al., 2009; Spagnoletti et al., 2012) parecem ser nutricionalmente valiosos, pois fornecem, principalmente às fêmeas, maior retorno energético em comparação com outros alimentos (Fragaszy, Liu, English, \& Simpson, 2010b). Nesses locais de quebra as fêmeas foram significativamente menos tolerantes à presença de coespecíficos do que em outras fontes de alimento e esses achados na FBV indicam que o uso de ferramentas na alimentação gera competição intra-grupo entre as fêmeas assim como acontece na disputa de recurso usurpáveis (Verderane et al., 2013). Portanto, o elevado agonismo no Morro do Boi, quando comparado com os dados da FBV, pode ser um indício de competição intra-grupo por recursos alternativos que complementam a dieta, mas precisa ser melhor investigado.

A comparação do orçamento de atividades com outras espécies de primatas em ambiente com condições ecológicas e topográficas semelhantes também é relevante. Em Macaca fascicularis que habita manguezais no Vietnã, a principal atividade é o repouso (Son, 2004), diferindo dos nossos resultados. Son (2004) sugere que esse comportamento se dá pelo 
aprovisionamento dos indivíduos com alimento e também pela alta ingestão de macrobentos (crustáceos e moluscos), que são alimentos de alta qualidade. Segundo o autor, os macacos sob essas condições gastam menos tempo para forragear e obter comida suficiente, o que leva ao aumento do tempo livre para descanso e catação. Nessas mesmas condições de aprovisionamento com alimento antrópico, porém se tratando de Sapajus libidinosus, Sabbatini et al. (2008) mostraram que os macacos-prego gastaram mais tempo repousando do que realizando outra atividade, concordando com o argumento de Son (2004).

Nossa hipótese de que o tempo despendido nas diversas atividades diárias estaria correlacionado com a estação do ano não foi confirmada pelos nossos resultados. Embora no período seco, com a diminuição da precipitação na área e da oferta de flores de Rhizophora mangle, o forrageio tenha apresentado as maiores frequências, nenhuma diferença foi encontrada entre as estações no orçamento de atividades. Nossa previsão de que no período seco os recursos vegetais estariam menos disponíveis se confirmou, porém a procura por alimentos de origem animal permaneceu inalterada visto que os macacos-prego tinham à disposição outros recursos alimentares, como os propágulos que foram consumidos em maior frequência durante toda a pesquisa. Durante a estação seca também ocorreu o aumento da disputa pelo recurso disponível e isso consequentemente refletiu na exclusividade de registros agonísticos como tipo de interação social na maioria dos meses da estação seca, embora o agonismo tenha sido igualmente frequente nas duas estações. O agonismo entre os membros do grupo sucedeu tanto em disputas por recursos vegetais (propágulos) nas copas das árvores quanto por recursos encapsulados no solo.

Nossos resultados estão de acordo com a hipótese de que o item alimentar ingerido varia com a classe etária dos indivíduos. No nosso estudo, os animais jovens apresentaram uma significativa redução na ingestão de alimentos de origem animal quando comparados com os indivíduos mais velhos. No estudo de Peternelli-dos-Santos (2009) com S. nigritus no $\mathrm{PECB}$, a dieta e os estratos de forrageio variaram conforme a idade e o sexo dos indivíduos. Em relação à preferência dos estratos de forrageio, os animais adultos forragearam mais invertebrados de tamanho grande nas bromélias enquanto que os imaturos (infantes e jovens) utilizaram mais os galhos e folhas na procura por pequenos invertebrados (Peternelli-dosSantos, 2009). Essa diferença foi explicada de acordo com o argumento de Janson e van Shaik (1993), que se baseia na necessidade dos jovens buscarem itens de fácil obtenção, pois estes são menos experientes e menos habilidosos do que os adultos para localizar o alimento e porque seu tamanho corporal menor reduz o acesso a determinados itens alimentares. Assim, o período juvenil é relevante para que o indivíduo desenvolva as habilidades de forrageio do 
adulto e se for prolongado permite mais tempo para o desenvolvimento e aprendizagem dos comportamentos de forrageio (Pereira \& Fairbanks, 1993).

No Morro do Boi, foi observado que o forrageio dos animais jovens também se caracterizou pela maior exploração de invertebrados em galhos dos mangues. Porém, outros tipos de alimentos de origem animal, principalmente os caranguejos, estiveram significativamente em maior frequência na dieta dos adultos e sub-adultos, confirmando nossa previsão de que estes itens estariam em maior proporção nos indivíduos mais velhos, pois estes recursos demandam habilidades motoras e cognitivas para o seu reconhecimento, captura e manipulação. Presas difíceis de capturar, como os caranguejos, e outros alimentos que além dessas habilidades precisam de força para a sua extração, como o pecíolo da folha de Euterpe edulis (Taira, 2007; Peternelli-dos-Santos, 2009) são mais frequentes na dieta dos adultos, porém os achados de Peternelli-dos-Santos (2009) indicam que a falta de habilidade e força seria determinante para o padrão alimentar dos jovens se não fosse a alta frequência de exploração do palmito pelos infantes. .

Segundo Fragaszy et al. (2004a), primatas que vivem em ambientes onde a disponibilidade dos recursos varia tendem a ajustar suas atividades diárias de acordo com a influência dos fatores sazonais. Os macacos-prego do PECB apresentaram diferenças entre as estações seca (inverno) e chuvosa (verão) no padrão de forrageio e deslocamento em virtude da sazonalidade alimentar, aumentando o forrageio de recursos alternativos na estação seca e o deslocamento em busca de fontes ricas, como os frutos, na estação chuvosa (Peternelli-dosSantos, 2009; Izar et al., 2012). O manguezal do Morro do Boi se encontra em uma área com variações climáticas bem marcadas durante o ano, ou seja, metade do ano é marcada por um período bastante chuvoso e a outra metade por um período bem seco que conforme discutido no item 6.1, afetou a disponibilidade de um recurso vegetal. Essa sazonalidade apresentou uma influência direta no ajuste de dois comportamentos dos macacos-prego jovens do Morro do Boi. Estes indivíduos aumentaram o forrageio na estação seca e a ingestão vegetal na estação chuvosa, o que pode ser resultado do próprio desenvolvimento dos comportamentos juvenis. Desta forma, durante a estação chuvosa esses animais aproveitaram as oportunidades e otimizaram suas taxas de ingestão vegetal e na estação seca com a redução desses itens, aumentaram a procura por outros recursos alimentares. 


\subsection{Uso dos estratos}

Os macacos-prego normalmente se deslocam de forma quadrúpede, andando sobre os quatro membros e viajam principalmente sobre galhos com cinco centímetros de diâmetro ou mais, usando a cauda como auxílio no transporte (Biondi, 2010). Eles exibem muitos padrões de locomoção enquanto se movimentam em um ambiente, usando o chão e todos os estratos da vegetação (Feagle \& Mittermeier, 1980; Fresse \& Oppenheimer, 1981; Garber \& Rehg, 1999). Segundo Terborgh (1983), os macacos-prego são considerados primatas arborícolas, que utilizam de preferência os estratos médios e inferiores das florestas e dependendo das condições ecológicas do habitat em que vivem, podem também exibir terrestrialidade.

Nossos resultados mostram que os macacos-prego do Morro do Boi realizam suas atividades a maior parte do tempo em estratos com altura superior a 5 metros. Nossa hipótese de que existiria uma correlação entre o padrão de atividade e o uso dos diferentes estratos não foi confirmada pelos resultados. Porém, a associação entre o uso dos estratos e o período do ano foi confirmada. A sazonalidade influenciou o uso dos estratos com altura superior e inferior a 5 metros, porém não teve relação com o uso do solo.

Segundo Enstam e Isbell (2004), o uso dos estratos é afetado por características do ambiente, como a estrutura da vegetação, a distribuição dos recursos alimentares no tempo e espaço e o risco de predação. Os manguezais possuem vegetação que podem atingir até 50 metros de altura (Lacerda \& Schaeffer-Novelli, 1999) e conforme os resultados discutidos no item 6.1, o manguezal do Morro do Boi apresentou variação na distribuição dos recursos alimentares. Além disso, o risco potencial de predação que os macacos-prego sofreriam na área decorreria de predadores aéreos (aves de rapina) e terrestres (cobras e jacarés) que foram avistados na área. Essas características ambientais podem explicar o maior uso dos estratos com altura superior a 5 metros durante a estação chuvosa e dos estratos inferiores a 5 metros na estação seca. Na estação chuvosa a disponibilidade de flores foi acentuada e sendo este um recurso uniformemente distribuído na copa das árvores, influenciou o predomínio do uso dos estratos com alturas superiores a 5 metros nessa estação. Na estação seca, com a diminuição da disponibilidade das flores e frutos houve uma maior procura por recursos alternativos e com reserva de energia, como os recursos encapsulados de origem animal presentes nos estratos inferiores a 5 metros. Este resultado foi reforçado pela maior observação dos indivíduos descendo ao chão para forragear no período seco, principalmente em setembro de 2012, que foi o mês em que os macacos-prego foram vistos com mais frequência no solo. 
Primatas que habitam manguezais no Vietnã utilizam estratos da floresta que se encontram fora do alcance da subida das águas e só utilizam o solo após a baixa da maré e em contexto de forrageio de macrobentos (Son, 2004), padrão semelhante ao encontrado no nosso estudo. No estudo de Verderane (2010) e de Falótico (2011) com S. libidinosus na FBV e no Parque Nacional da Serra da Capivara, respectivamente, expostos a outras condições ecológicas foi encontrada uma maior utilização do solo pelos macacos-prego quando comparados aos do Morro do Boi (MB: 0,9\%; FBV: dois grupos, sendo um 32,5\% e o outro $35 \%$; PNSC: dois grupos, sendo um com 43,6\% e o outro com 32,3\%). Mesmo apresentando baixo percentual em relação às duas outras áreas, talvez devido à não habituação de todos os indivíduos do grupo ou em decorrência da variação da maré, S. libidinosus do Morro do Boi despendeu mais tempo no uso dos estratos inferiores do que populações de macacos-prego habitantes de floresta que utilizam quase que exclusivamente os estratos superiores (Izar et al., 2012). Conforme argumento de Enstam e Isbell (2004), essa diferença de utilização dos estratos em populações da mesma espécie ocorre em decorrência da ação de fatores ambientais locais e nesse caso, a terrestrialidade e o uso do solo na FBV e no PNSC pode ser um reflexo do tipo de vegetação, da disponibilidade de alimentos no solo e do uso frequente de ferramentas por esses macacos.

\subsection{Dieta}

Estudos sobre a dieta e comportamento alimentar de primatas selvagens são necessários para entender a adaptação ecológica das espécies ao seu ambiente e em florestas de mangue os dados são escassos. Os macacos-prego do Morro do Boi apresentaram uma dieta ampla dentro das possibilidades encontradas no manguezal, que é um ecossistema que apesar da baixa diversidade de espécies vegetais abriga diversas espécies de animais. A dieta do grupo consistiu em sua maioria de propágulos de Rhizophora mangle, mas incluiu também invertebrados encontrados na vegetação e dentro dos galhos, flores, frutos, caranguejos, gastrópodes e ponta de raiz.

Son (2003a) investigou a dieta de Macaca fascicularis em manguezal para buscar mais informações sobre a ecologia de primatas que habitam um ambiente extremamente sazonal. Segundo o estudo, os primatas passaram mais tempo se alimentando de partes das árvores do mangue, como fruto, folha, raiz, flor, botões de flor e casca, principalmente do mangue 
vermelho (Rhizophora mangle). Nossos resultados apresentaram o mesmo padrão em relação à alimentação de recursos vegetais, porém em relação aos recursos animais nossos resultados diferiram na proporção dedicada à alimentação entre invertebrados nos galhos de mangue e alimentos encapsulados (caranguejos e turus). Em Macaca fascicularis, o tempo gasto capturando e consumindo caranguejo é maior que os demais recursos animais e em $S$. libidinosus do Morro do Boi a proporção de ingestão de invertebrados encontrados na vegetação e dentro dos galhos dos mangues foi maior do que de animais encapsulados. Tal padrão pode representar um "artefato" do baixo grau de habituação do grupo, o que pode ter reduzido as descidas ao solo para forragear.

Segundo Son (2003a), os macacos buscam proteínas e gorduras no mangue, uma vez que o teor desses itens nutricionais é maior nos caranguejos do que nos invertebrados dos galhos, das folhas e frutos de mangue. Além disso, os caranguejos possuem maior quantidade de minerais como o cálcio e fósforo do que os demais tipos de alimento. Populações de macacos-prego sujeitos à baixa disponibilidade de recursos limitantes, como os frutos, engajam-se em atividade como o aumento do forrageio e o consumo de partes vegetativas de plantas, que são recursos abundantes e de fácil obtenção, apesar de serem de baixo valor nutricional (Peternelli-dos-Santos, 2009; Verderane, 2010).

Nossos resultados mostraram que o período do ano influenciou na proporção de ingestão de flores, sendo o consumo deste recurso mais abundante na estação chuvosa. No período seco, com a redução na disponibilidade de flores e com o propágulo do mangue vermelho sempre disponível, os macacos-prego investiram no seu consumo e também no de caranguejos e outros recursos encapsulados de origem animal (ver discussão no Cap. III). Tal estratégia de forrageio apresentada pelos indivíduos do Morro do Boi confirma a flexibilidade e adaptabilidade dos macacos-prego frente às diversas condições ecológicas dos habitats em que vivem. 


\section{CONCLUSÕES}

1- A oferta de alimento encapsulado de origem animal (caranguejos - Ucides cordatus) no manguezal do Morro do Boi não sofreu variação acentuada ao longo do período da pesquisa e seguiu o padrão encontrado para os manguezais brasileiros situados na zona equatorial.

2- A oferta de recurso vegetal (flores de Rhizophora mangle) no manguezal do Morro do Boi sofreu influência da sazonalidade (regime de chuvas e umidade), apresentando-se maior no período chuvoso.

3- O orçamento de atividades do grupo Morro do Boi foi semelhante ao encontrado em algumas populações selvagens de Sapajus libidinosus e de S. nigritus. Porém, a proporção de tempo despendido nas diferentes atividades quando comparadas a essas populações apresentou variações.

4- A alta densidade de indivíduos presente no grupo Morro do Boi promoveu diferenças no orçamento de atividades, sendo o forrageio e a locomoção as principais atividades. Desta forma, o tempo despendido no repouso e interações sociais foi afetado e o reflexo disso foi o elevado número de eventos agonísticos no grupo.

5- A idade apresentou correlação com a frequência de ingestão de itens animais, sendo maior nos indivíduos adultos e sub-adultos. A redução na ingestão de recursos de origem animal na classe dos jovens foi peculiar ao período juvenil quando estão em fase de desenvolvimento e aprendizagem das habilidades de forrageio.

6- A sazonalidade influenciou o aumento do forrageio na estação seca e da ingestão vegetal na estação chuvosa nos macacos-prego jovens do Morro do Boi. O período juvenil levou estes indivíduos a otimizar as taxas de ingestão vegetal no período de maior disponibilidade e na ausência destes promoveu o aumento da procura por outros recursos alimentares.

7- O padrão de utilização dos estratos do ambiente manguezal pelos macacos-prego do Morro do Boi se assemelhou ao encontrado em populações de Cebus e Sapajus de floresta úmida, com predomínio de estratos arbóreos altos, embora tenham utilizado os estratos inferiores, inclusive o solo, em maior proporção do que essas populações. Em comparação com S. libidinosus de Cerrado/Caatinga (PNSC e FBV), os macacosprego do Morro do Boi apresentaram menor uso do solo, podendo ser este um reflexo da variação das marés e do baixo nível de habituação do grupo, o que pode ter 
reduzido ou limitado o tempo de uso desse estrato para o forrageio de itens encapsulados que podem ser extraídos com martelos de quebra (ver cap. III).

8- A dieta dos macacos-prego do Morro do Boi se assemelhou a de primatas que vivem em manguezal, com o predomínio de recursos vegetais do mangue. A inclusão de itens animais encapsulados (caranguejos, gastrópodes etc) na dieta se deu de forma oportunista, durante a baixa da maré e quando os recursos vegetais amplamente distribuídos na área foram reduzidos. 
CAPÍTULO III: Uso de ferramentas por macacos-prego (Sapajus libidinosus) em Manguezal no Maranhão: evidências indiretas e caracterização dos sítios de quebra 


\section{INTRODUÇÃO}

A onivoria é uma das características marcantes dos primatas do gênero Sapajus (Lynch Alfaro, Silva Jr. \& Rylands, 2012b). Associadas a essa característica estão sua adaptabilidade, flexibilidade comportamental e o uso de ferramentas, comportamento que comumente é observado nos grandes símios (van Schaik, Deaner \& Merrill, 1999). O estudo do uso de ferramentas, além do eixo da evolução e cultura humanas, apresenta-se também como um campo de pesquisa relevante para aprimorar o conhecimento sobre a flexibilidade comportamental de primatas não-humanos.

A definição do termo "ferramenta" pode ser ambígua, pois está aberta a diversas interpretações, incluindo visões subjetivas e até antropocêntricas, sendo, portanto, objeto de intensa discussão na literatura (para revisão, ver Resende, 2004 e Falótico, 2011), que sintetizam todas essas visões do termo "ferramenta". No nosso estudo, seguiremos Falótico (2011), que adotou, em seu estudo com macacos-prego (Sapajus libidinosus), a definição mais recente de "uso de ferramentas", de St. Amant \& Horton (2008): “o uso de ferramentas é a influência de controle sobre um objeto externo livremente manipulável (a ferramenta), com o objetivo de: 1) alterar as propriedades físicas de outro objeto, substância, superfície ou meio (o alvo, que pode ser o usuário da ferramenta ou outro organismo) por meio de uma interação mecânica dinâmica ou 2) medir o fluxo de informação entre o usuário da ferramenta e o ambiente ou outros organismos no ambiente" (pag. 1203).

Os macacos-prego e caiararas apresentam em seu repertório comportamental similaridades com os chimpanzés, entre as quais se destacam a manipulação complexa de objetos, a tolerância social, a partilha de alimento e o uso de ferramentas, indicando uma convergência comportamental (Visalberghi \& McGrew, 1997). Eles são os únicos primatas neotropicais que usam ferramenta (Fragaszy, Izar, Visalberghi, Otonni \& Oliveira, 2004c). Na natureza já foi observado o uso de ferramentas, de modo espontâneo, para acessar alimentos ou outros recursos subterrâneos, encapsulados ou introduzidos em outros tipos de substratos, além de água de cavidades nas árvores por algumas espécies de Sapajus e por Cebus albifrons trinitatis (Phillips, 1998; Rocha, Reis \& Sekiama, 1998; Fragaszy et al., 2004c; Canale et al., 2009; dos Santos, 2010; Verderane, 2010). Porém, este comportamento não é encontrado em todas as populações e espécies de caiararas e de macacos-prego.

Mesmo em populações para as quais não há registros de uso de ferramentas, é comum observar a expressão de comportamentos extrativos para aquisição de alimento encapsulado, 
como em Sapajus apella, S. nigritus e Cebus albifrons. S. apella apresenta um rosto largo acompanhado de fortes músculos mastigatórios que produzem elevadas forças para mastigar e processar os alimentos (Wright, 2005), além de grandes áreas oclusais pós-caninas, grandes pré-molares e molares quadrados com esmalte espesso e cúspides baixas, o que permite a quebra de recursos vegetais duros e resistentes como, por exemplo, os cocos (Kay, 1981; Anapol \& Lee, 1994). Rotineiramente, estes macacos acessam alimentos encapsulados (cocos, moluscos, entre outros) usando seus dentes caninos e pré-molares e/ou batendo o alimento em superfícies duras (Izawa, 1979; Terborgh, 1983; Boinski, Quatrone \& Swartz, 2001). Em S. nigritus, já foi observada a extração de palmito da espécie Euterpe edulis (Taira, Verderane, Ottoni \& Izar, 2002) como recurso proteico alternativo aos invertebrados (Taira, 2007). Em Cebus albifrons, a quebra e abertura de cocos da palmeira Astrocaryum é realizada por meio do seu sistema mastigatório e eles também são capazes de selecionar e quebrar cocos que tenham sido infestados por besouros e que ainda contêm endosperma não danificado (Terborgh,1983).

Em contraste, existem muitos registros de uso de ferramentas em populações selvagens de $S$. libidinosus que vivem em habitats abertos como a caatinga e o cerrado brasileiros, os quais apresentam características similares aos ambientes de savana (Fragaszy et al., 2004c; Visalberghi et al., 2007; Mannu \& Ottoni, 2009; Verderane, 2010; Fragaszy et al., 2013). Na Fazenda Boa Vista (FBV), Gilbués, no Piauí, a utilização de pedras pelos macacosprego para quebrar cocos é uma atividade rotineira, o que foi incialmente constatado devido a evidências encontradas (restos de cocos e marcas de uso nas bigornas) em numerosos sítios de quebra (Visalberghi et al., 2007).

Recentemente, foi observado que esses macacos, além de abrirem cocos de diversas palmeiras com ferramentas, também o fazem com a castanha de caju (Sirianni \& Visalberghi, 2013). De acordo com as autoras, a inovação deste comportamento apresentado por $S$. libidinosus reflete o elevado nível de flexibilidade dessa espécie, visto que outros primatas não-humanos que vivem em áreas com cajueiros não consomem a castanha, apenas a polpa do caju, como por exemplo, Papio sp., Colobus guereza e chimpanzés.

Os macacos-prego (S. libidinosus) da FBV, que usam martelos de pedra para quebrar cocos e castanhas, enfrentam como desafio ao sucesso deste comportamento a escassez de pedras no ambiente. Tal desafio é superado com o transporte dos martelos de pedra para as bigornas (Visalberghi et al., 2007) ou até mesmo do martelo e do coco (Visalberghi, Spagnoletti, da Silva, Andrade, Ottoni, Izar \& Fragaszy, 2009b). Segundo Visalberghi et al. (2009b), a necessidade de transportar alimentos e martelos até as bigornas envolve tanto 
desafios físicos (por exemplo, carregar os elementos) quanto cognitivos (por exemplo, antecipar as necessidades futuras, o que representa mentalmente as informações que estão fora de vista e planejar o curso de ação).

O transporte dos alimentos e dos martelos até os sítios de quebra adiciona um gasto energético à exibição do comportamento de uso de ferramentas. Por isso, alguns estudos têm sido realizados tanto para investigar as características dos martelos utilizados pelos macacosprego selvagens (Fragaszy, Pickering, Liu, Izar, Ottoni \& Visalberghi, 2010a), quanto das bigornas (Liu, Fragaszy, Wright, Wright, Izar \& Visalberghi, 2011; Massaro, Liu, Visalberghi \& Fragaszy, 2012). O estudo de Massaro et al. (2012) mostra que os macacos-prego selecionam a ferramenta com base no peso do martelo e na distância percorrida para transportá-lo até a bigorna. Os resultados dos experimentos em campo indicam que: (1) os indivíduos variam na sua sensibilidade à distância de transporte, (2) poucos metros são percebidos como um custo substancial por parte de alguns macacos e (3) o peso corporal dos macacos afeta suas decisões. Logo, podemos perceber que a maioria dos macacos-prego escolhe os martelos mais próximos à bigorna como forma de reduzir os custos com o transporte.

Além da seleção de ferramentas, os macacos-prego podem também escolher bigornas com base nas depressões resultantes da dinâmica da quebra (Fragaszy et al., 2013). Segundo Goren-Inbar, Sharon, Melamed e Kislev (2002), a quebra de cocos com ferramentas de quebra pode deixar características de uso nas bigornas e martelos, tais como depressões que podem variar em sua dimensão horizontal e profundidade. O estudo de Liu et al. (2011) aponta que os macacos-prego da FBV, quando expostos a diferentes bigornas, preferem aquela mais eficiente com base no número de golpes necessários para quebrar o alimento e no total de alimentos quebrados. Os pesquisadores também apontam a influência do contexto social na escolha das bigornas, pois os macacos selecionam com maior frequência aquelas utilizadas anteriormente por outros indivíduos.

Além de S. libidinosus e $S$. flavius, o uso de ferramentas foi registrado também para a espécie S. xanthosternos, por meio de vestígios, como quebra recente, pó de pedra, marcas de desgaste na bigorna, presença de muitos martelos e de cocos quebrados (Canale et al., 2009). Foram encontrados também indícios de transporte de martelos entre sítios de quebra e pedras pequenas com marcas de uso, sugerindo que estes martelos foram usados por jovens ou indivíduos inexperientes ou que os indivíduos experientes selecionaram pedras inapropriadas para quebrar cocos.

A seleção de ferramentas para obter alimento não é um comportamento exclusivo dos 
macacos-prego, sendo encontrada também em outros primatas não humanos. Em Pan troglodytes, os martelos são selecionados de acordo com a resistência do coco a ser quebrado (Boesch \& Boesch, 1983) e eles manufaturam e usam ferramentas com propriedades específicas para pegar mel e pescar cupins (Sanz \& Morgan, 2009; Sanz, Call \& Morgan, 2009; Sanz, Schoening \& Morgan, 2010). Em Macaca fascicularis aurea, pedras de diferentes formas são selecionadas para funções distintas, como raspar e martelar (Gumert, Kluck \& Malaivijitnond, 2009), principalmente para quebrar ostras e obter a carne (Malaivijitnoud et al., 2007; Gumert \& Mallaivijitnond, 2012) Malaivijitnoud et al. (2007) observaram em M. fascicularis o uso de pedras para quebrar conchas de crustáceos e moluscos em diferentes tropas e também o transporte das pedras quando se movimentavam do local de caça. Ao longo do estudo, pedaços de gastrópodes, bivalves e caranguejos foram encontrados na superfície das rochas onde as pedras eram deixadas, com sinais de esmagamento. Portanto, a seleção de ferramentas de acordo com as propriedades do alimento e o transporte destas até os sítios de quebra revelam que existe um planejamento para o uso de ferramentas (Visalberghi et al., 2007).

A incorporação de mariscos na dieta por primatas não humanos, apesar de pouco comum, pode ser observada também em macacos-prego nos Manguezais Amazônicos (Fernandes \& Aguiar, 1993; Port-Carvalho, Ferrari, Magalhães, 2004) e o uso de ferramentas durante a alimentação desses primatas já foi observado na natureza (Fernandes, 1991; dos Santos, 2010). Contudo, existem poucas observações sobre uso de ferramentas por primatas em ambiente de manguezal, possivelmente pela dificuldade de deslocamento do observador nesse ambiente, o que compromete estudos em grandes áreas.

Macacos-prego que habitam manguezais vivem em um ambiente com diversidade reduzida de recursos vegetais (Schaeffer-Novelli, Cintrón-Molero, Adaime, \& Camargo, 1990), mas disponíveis ao longo de quase todo o ano (Fernandes, 1999; Fernandes, Virgulino, Nascimento \& Rodrigues, 2005; Menezes, Berger \& Mehlig, 2008; Nadia, Morellatto \& Machado, 2012), e com riqueza de presas animais, como moluscos e crustáceos (Macintosh \& Ashton, 2002). Porém, estão sujeitos às diversas condições ambientais que afetam a disponibilidade dos alimentos, como a variação no fluxo de marés que inunda periodicamente o manguezal, submergindo moluscos e abrigos de crustáceos ao longo do dia (dos Santos, 2010). Diante deste cenário ecológico, os macacos-prego ajustam sua dieta para explorar os recursos disponíveis que se apresentam, em sua maioria, protegidos por uma concha.

De fato, o uso facultativo de ferramenta de quebra foi observado no estudo de dos Santos (2010) por grupos de S. libidinosus residentes em manguezal. Os indivíduos utilizaram 
pedaços de madeira como martelos para a quebra de moluscos gastrópodes (Neretina sp) e de caranguejos (Ucides cordatus), porém, no consumo deste último recurso, o uso de ferramenta de quebra não foi obrigatório. Nesse caso, a presa foi manipulada por uma ou ambas as mãos e batida repetidas vezes contra uma bigorna. Outro item alimentar animal consumido por macacos-prego em manguezal sem a utilização de martelos, em um comportamento tipicamente destrutivo, foram os moluscos bivalves perfuradores de madeira (turus). Nesse forrageio extrativo, os macacos-prego inspecionavam e transportavam pedaços de troncos podres até as bigornas de rizóforos ou bigornas de troncos e batia-os contra o substrato até quebrar e acessar os turus.

Alguns estudos vêm testando hipóteses para explicar a ocorrência do uso de ferramentas na exploração de alimentos encapsulados por macacos-prego em determinadas condições ambientais e ecológicas (Moura \& Lee, 2004; Ottoni \& Izar, 2008; Emidio \& Ferreira, 2012; Spagnoletti, Visalberghi, Verderane, Ottoni, Izar \& Fragaszy, 2012). As principais hipóteses acerca do uso de ferramentas por primatas não-humanos são: 1) Hipótese da necessidade ou do gargalo energético, que prediz que o uso de ferramentas surge da necessidade de quebrar alimentos encapsulados como resposta à escassez dos principais recursos alimentares e 2) Hipótese da oportunidade, que argumenta que o uso de ferramentas emerge do acesso simultâneo a martelos e recursos encapsulados e que é mais provável ocorrer em populações que vivem em ambientes com elevada oferta de alimento, pois estas apresentam um alto grau de tolerância social e coesão grupal (Coussi-Korbel \& Fragaszy, 1995; van Schaik et al., 1999; van Schaik \& Knott, 2001; van Schaik, Fox \& Fechtman, 2003; Fox, van Schaik, Sitompul \& Wright, 2004).

Além dessas duas principais hipóteses para explicar a emergência do comportamento de uso de ferramentas, Visalberghi, Fragaszy, Izar \& Ottoni (2005) propõem a terrestrialidade. A hipótese da terrestrialidade prevê que o uso de ferramentas pelos macacosprego está fortemente associado ao tempo gasto com o forrageio no chão, particularmente para os alimentos encapsulados. Nesse caso, os macacos-prego despendem mais tempo na procura e coleta de alimentos no chão ao invés das árvores, aumentando desta forma as chances de processar alimentos no local onde as ferramentas estão presentes.

Sendo o manguezal um ecossistema costeiro sujeito ao regime das marés (SchafferNovelli, 1995), a inundação duas vezes ao dia pode ser um fator que impeça a terrestrialidade dos macacos-prego neste tipo de floresta. Além disso, o solo é pouco consistente devido às inundações, permanecendo sempre úmido e pouco compactado (Schaffer-Novelli, 1995). Em Macaca fascicularis que habita florestas de mangue, os indivíduos forrageiam nos locais mais 
secos da floresta assim que a área de uso é afetada pela variação da maré (Son, 2004). Após a enchente, os macacos se movem mais rapidamente do que o usual em busca de macrobentos, apresentando a terrestrialidade apenas nessas condições. Segundo Son (2004), o forrageio de macrobentos após a baixa da maré é uma característica do comportamento alimentar dos macacos de mangue, sendo bastante diferente de populações de floresta de interior.

Devido à existência de poucos trabalhos na literatura sobre a ecologia e uso de ferramentas por macacos-prego que habitam manguezais e aos diversos fatores ambientais e ecológicos presentes nesse habitat realizamos novas investigações nesse ambiente para verificar a importância do uso de ferramentas na alimentação desses primatas. 


\section{OBJETIVOS}

\subsection{Gerais}

Analisar, sob a perspectiva das hipóteses da necessidade ou do gargalo energético e da oportunidade, a manifestação do comportamento do uso de ferramentas de um grupo de macacos-prego (S. libidinosus) que habita um fragmento de manguezal no Maranhão. Além disso, estimar a densidade dos sítios de quebra e sua frequência de uso por meio das evidências indiretas encontradas na área de uso do grupo para inferirmos a relevância deste comportamento na alimentação e na sobrevivência dos macacos-prego que habitam em um ambiente sazonal e sujeita aos ritmos de maré.

\subsection{Específicos}

- Caracterizar os aspectos físicos das bigornas utilizadas pelos macacos-prego para a quebra dos alimentos encapsulados;

- Identificar os itens alimentares encapsulados quebrados com o auxílio de martelos;

- Mapear os sítios de quebra na área de estudo;

- Estimar a densidade dos sítios de quebra na área de estudo;

- Estimar a frequência mensal de uso dos sítios de quebra;

- Investigar se existe a influência da estação do ano (seca e chuvosa) na frequência de uso dos sítios de quebra;

- Investigar a relação entre a frequência mensal de uso das bigornas para a quebra de alimentos encapsulados e a disponibilidade de outros itens alimentares não-encapsulados. 


\section{HIPÓTESES}

Hipótese 1: Os macacos-prego utilizam com maior frequência bigornas que apresentam características que otimizam a quebra dos alimentos encapsulados.

Previsão (1): As bigornas com substrato reto e rugoso apresentam maior frequência de uso do que as inclinadas e lisas, pois estas características facilitam a quebra de alimentos encapsulados por minimizar as chances de deslocamento do alimento na bigorna.

Hipótese 2: A frequência do tipo de alimento encapsulado quebrado com o auxílio de martelos apresenta uma relação com seu tamanho e com o seu retorno energético.

Previsão (1): Os indivíduos utilizam martelos para acessar alimentos encapsulados de origem animal que apresentam maior tamanho e que possuem mais nutrientes do que recursos menos energéticos visando minimizar os custos do comportamento de quebra.

Hipótese 3: O uso de martelos para obtenção de carne apresenta uma correlação com a disponibilidade dos recursos alimentares e com o período seco/chuvoso do ano.

Previsão (1): Os indivíduos utilizam com maior frequência martelos para acessar recursos animais encapsulados no período do ano em que os recursos vegetais estão escassos. Neste caso, a expressão do comportamento de uso de ferramentas será corroborada pela hipótese da necessidade ou do gargalo energético.

Previsão (2): Os indivíduos utilizam martelos sempre que os recursos animais encapsulados estiverem abundantes no ambiente sem estar relacionado com a escassez de recursos vegetais como flores e frutos. Neste caso, a expressão do comportamento de uso de ferramentas será suportada pela hipótese da oportunidade. 


\section{MÉTODO}

\section{1. Área e grupo de estudo}

A pesquisa foi realizada em um fragmento de manguezal com área de 37 ha denominado Morro do Boi (2³7'21.7'S; 4241'18.5'W), situado à margem direita do rio Preguiças, localizado no município de Barreirinhas, nordeste do estado do Maranhão. Os indivíduos observados neste estudo pertencem a um grupo selvagem de macacos-prego ( $S$. libidinosus). A descrição mais detalhada sobre a área e o grupo de estudo encontra-se no Capítulo I.

\subsection{Coleta dos dados}

\subsubsection{Mapeamento, caracterização e densidade dos sítios de quebra}

No período de março de 2012 a março de 2013 foram realizados o mapeamento e a caracterização dos sítios de quebra. Esses processos ocorreram sempre que um local era descoberto por observação, ou seja, quando era detectada a presença de martelos e de conchas e carapaças de mariscos em cima das bigornas. Para o mapeamento dos sítios de quebra foi utilizado um GPS e através dessa marcação foi possível estimarmos a densidade de sítios utilizados durante esse período. Os martelos eram pedaços de madeira destacados ou dos galhos dos mangues ou mesmo do tronco desgastado pela ação do tempo e das marés que apresentavam sinais de quebra, como desgaste e resíduos de carapaças ao lado desses fragmentos. As bigornas eram troncos de mangues caídos e raízes aéreas do mangue vermelho (Rhizophora mangle). A caracterização dos sítios de quebra foi feita baseada no tipo de bigorna utilizada pelos macacos-prego e no tipo de alimento quebrado encontrado na bigorna.

A bigorna foi classificada quanto à parte da árvore de mangue que foi utilizada como substrato (tronco, raiz ou galho), quanto à inclinação (reto ou inclinado), quanto à textura do substrato (lisa ou rugosa). Além disso, o número de tipos de alimento encontrados na 
superfície da bigorna caracterizaram os sítios de quebra como simples (um tipo de alimento) ou mistos (mais de um tipo de alimento). Medidas referentes à altura e ao diâmetro das bigornas e ao comprimento e ao diâmetro dos martelos também foram coletadas com o auxílio de uma fita métrica e o peso dos martelos foi obtido através de uma balança de alta precisão eletrônica mod SF-400/CBR-01053.

\subsubsection{Evidências de quebra e frequência de uso de ferramentas}

O registro direto do comportamento de uso de martelos pelos macacos-prego $(S$. libidinosus) do grupo Morro do Boi não foi possível devido a dois fatores: 1) a não habituação completa de todos os indivíduos e 2) a dificuldade de locomoção no ambiente a fim de chegar o mais próximo possível para a visualização do comportamento. Mesmo não ocorrendo a observação visual direta desse comportamento, durante todo o período de coleta de dados foram ouvidos barulhos de quebra que usualmente eram seguidos de agonismo entre os indivíduos $(\mathrm{N}=46)$. Os barulhos de quebra consistiram no som produzido pela batida dos pedaços de madeira utilizados como martelos nas bigornas de madeira. Quando cessava o som produzido pelo atrito entre as madeiras, normalmente ouviam-se vocalizações agonísticas dos macacos-prego.

Sendo assim, foram feitos registros indiretos da quebra, baseados na metodologia de Mannu (2002). As evidências indiretas do uso de ferramentas de quebra eram a presença de fragmentos de itens alimentares encapsulados nas bigornas e também a presença de martelos (Figura 1).

Para estimar a frequência do uso de ferramentas pelos animais, era feita a limpeza mensal dos sítios de quebra, a qual consistia na retirada total dos fragmentos de carapaças de cima das bigornas (Mannu, 2002) com o auxílio de uma escova. Através dessa estimativa pudemos verificar através do teste de Mann-Witney se existiu influência da estação do ano (seca ou chuvosa) na frequência de uso dos sítios de quebra pelos macacos-prego.

Para mensurar o tamanho médio dos caranguejos quebrados com os martelos foram utilizadas as medidas obtidas com o auxilio de uma fita métrica dos cefalotórax intactos encontrados nos sítios de quebra junto aos resíduos de conchas ou das carapaças dos caranguejos (Figura 2).

Para a realização das análises estatísticas, as distribuições das variáveis envolvidas em 
cada teste foram comparadas com a distribuição normal padrão pelo teste "Goodness of Fit" de Shapiro-Wilk. Segundo o teste de normalidade, as amostras não apresentaram distribuição normal. Portanto, testes não-paramétricos foram utilizados para testar as hipóteses. O nível de significância foi de $\mathrm{p} \leq 0,05$.

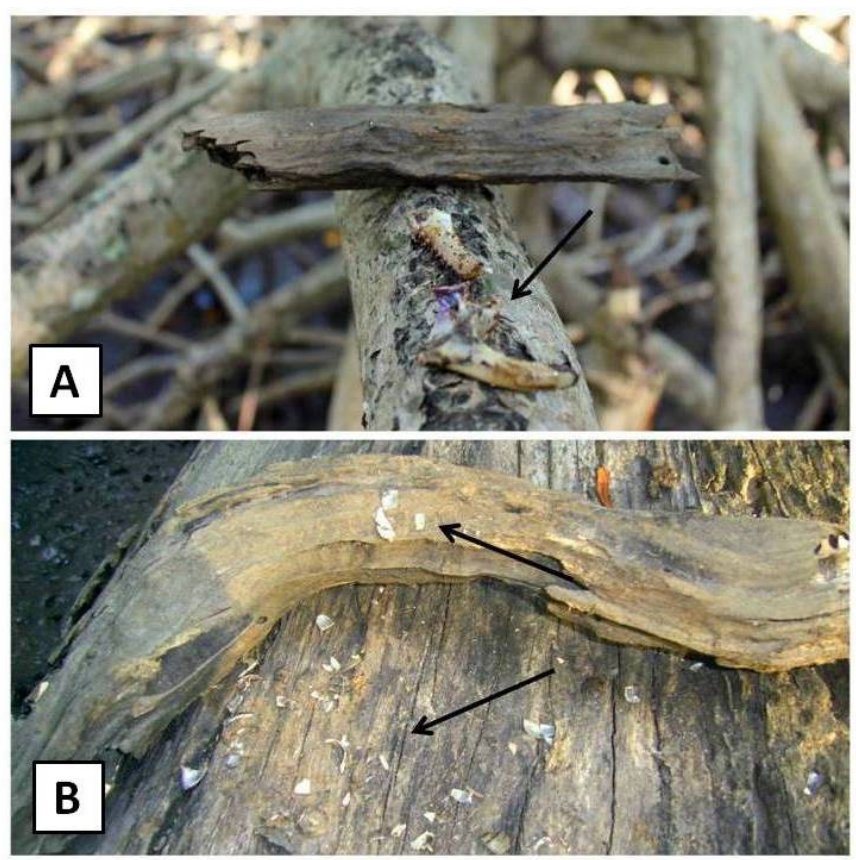

Figura 1. Evidências do uso de ferramentas por macacos-prego (S. libidinosus) do Morro do Boi. (A) Ocorrência de fragmentos das carapaças de caranguejos nas bigornas e (B) nos pedaços de pau utilizados como martelos.

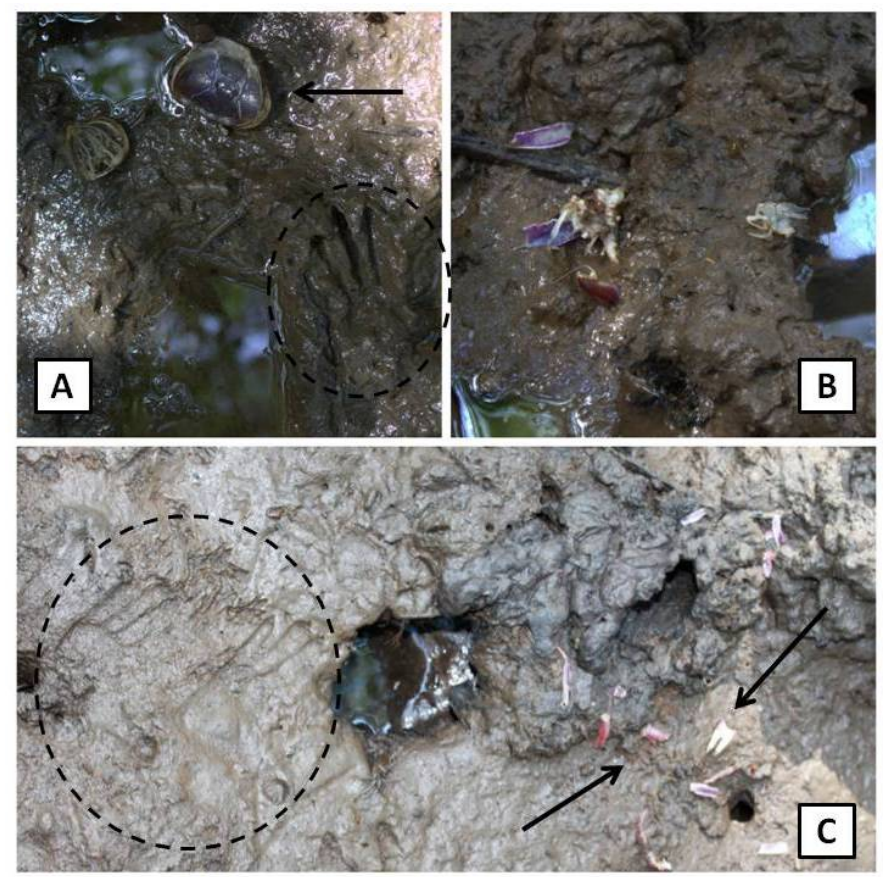

Figura 2. Vestígios de caranguejo com quebra recente. (A) cefalotórax superior intacto. (B) e (C) resíduos das carapaças de caranguejos quebradas com martelo. Destaque em círculo para a marca das mãos do macaco-prego (S. libidinosus). 


\section{RESULTADOS}

\subsection{Caracterização e densidade dos sítios de quebra}

Entre os meses de março de 2012 e março de 2013 foram identificados e mapeados 73 (setenta e três) sítios de quebra (1,97 sítios/ha) por meio da presença de um ou mais martelos com sinais de desgaste e vestígios das carapaças quebradas de caranguejos, conchas de gastrópodes e bivalves, além da presença de madeira quebrada para a extração dos turus. Os macacos-prego utilizaram como bigorna três substratos: os troncos de mangue caídos, com a maior proporção de uso $(52,86 \%, \mathrm{~N}=37)$, seguido das raízes aéreas do mangue vermelho (Rhizophora mangle) $(45,71 \%, \mathrm{~N}=32)$ e galhos dos mangues $(1,43 \%, \mathrm{~N}=1)$ (Figuras 3 e 4). Houve diferença significativa na ocorrência dos tipos de bigornas $\left(\chi^{2}=46,49 ; p=0,000\right)$. As bigornas de troncos eram encontradas sobre alguma raiz ou tronco caído ou estavam caídas sobre o solo e não houve diferença significativa $\left(\chi^{2}=0,656 ; p=0,417\right)$ entre elas na frequência de uso $(54,05 \%$ caídas sobre raízes ou outros troncos e $45,95 \%$ sobre o chão).

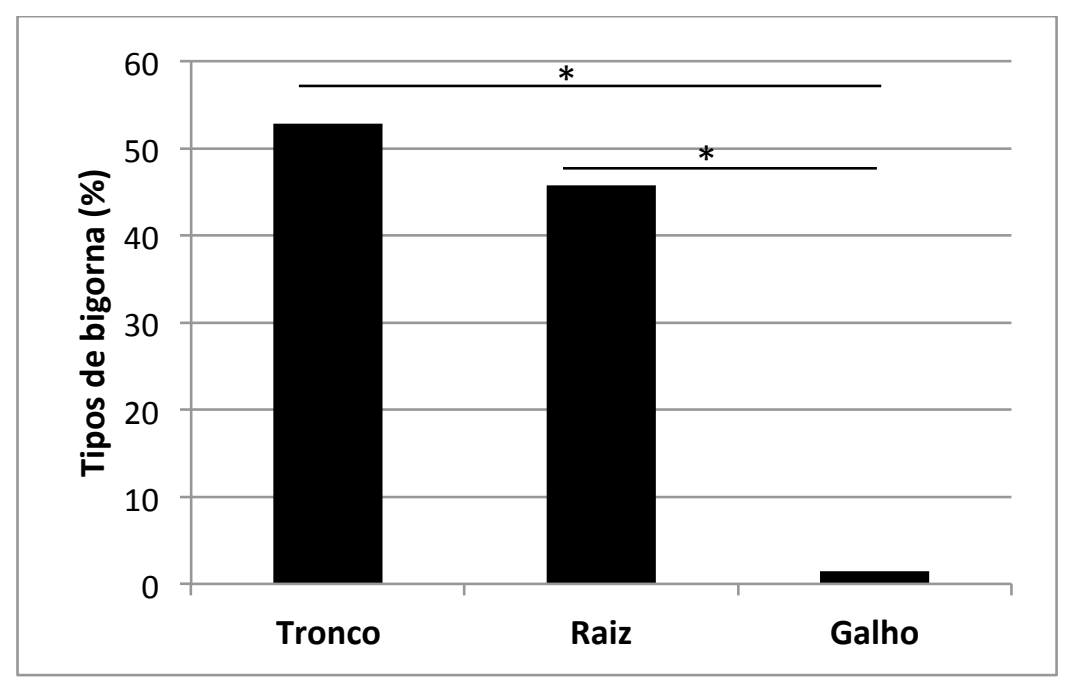

Figura 3. Tipos de bigorna utilizadas pelos macacos-prego (S. libidinosus) do Morro do Boi no período de março de 2012 a março de 2013.

Em relação às bigornas, a altura média em relação ao solo foi de 112,4 cm, sendo a maior apresentando $280 \mathrm{~cm}$ de altura e a menor apresentando $9 \mathrm{~cm}$ de altura. $\mathrm{O}$ diâmetro médio foi de $65,48 \mathrm{~cm}$, sendo o maior apresentando $130 \mathrm{~cm}$ de comprimento e o menor, 17 
cm. Já os martelos utilizados pelos macacos-prego foram pedaços de madeira proveniente dos galhos dos mangues ou pedaços de tronco apodrecido e apresentaram comprimento médio de $34 \mathrm{~cm}$, sendo o maior com $85 \mathrm{~cm}$ e o menor com $12 \mathrm{~cm}$. O diâmetro médio dos martelos foi de $14 \mathrm{~cm}$, com o maior apresentando $32 \mathrm{~cm}$ de diâmetro e o menor $5,5 \mathrm{~cm}$. O peso dos martelos variou de $50 \mathrm{~g}$ a $1598,5 \mathrm{~g}(\mathrm{~N}=76)$, com peso médio de $452 \mathrm{~g}(\mathrm{dp}=362,5 \mathrm{~g})$. (Tabela $1)$.
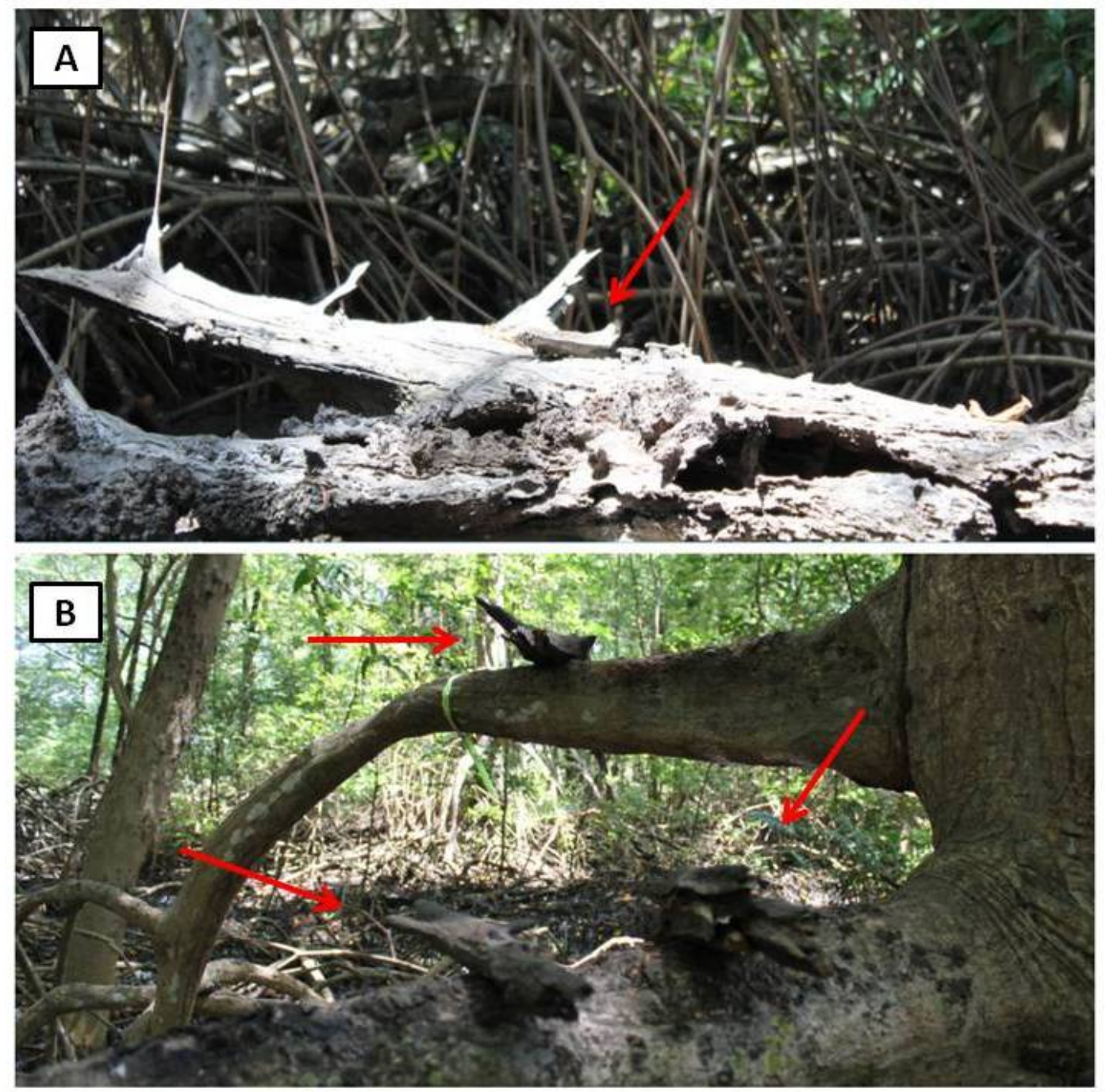

Figura 4. Caracterização dos sítios de quebra encontrados no Morro do Boi no período de março de 2012 a março de 2013: tipos de bigorna. (A) Bigorna do tipo tronco caída no chão (detalhe do martelo em cima da bigorna). (B) Bigorna do tipo raiz (Sítio com 3 (três) martelos, no detalhe). 
Tabela 1. Caracterização das bigornas e martelos utilizados pelos macacos-prego (S. libidinosus) do Morro do Boi para a extração de itens animais encapsulados no período de março de 2012 a março de 2013.

\begin{tabular}{|c|c|c|c|c|c|c|c|}
\hline & $\mathbf{N}$ & Média & Mediana & Mínimo & Máximo & Desvio padrão \\
\hline Altura da bigorna & 70 & 112.4714 & 93.5000 & 9.00000 & 280.000 & 68.0443 \\
\hline Diâmetro da bigorna* & 55 & 64.7545 & 59.0000 & 17.00000 & 151.000 & 29.6512 \\
\hline Comprimento do martelo & 76 & 34.0197 & 30.5000 & 12.00000 & 85.000 & 15.8269 \\
\hline Diâmetro do martelo & 76 & 14.0066 & 13.0000 & 5.50000 & 32.000 & 5.0335 \\
\hline Peso do martelo & 76 & 452.0760 & 326.6799 & 50.09554 & 1598.503 & 362.5728 \\
\hline
\end{tabular}

* Não foi possível medir o diâmetro das bigornas do tipo tronco que estavam caídas no chão, pois a madeira é muito pesada, inviabilizando o seu deslocamento. Nesse caso foi medida apenas a altura. Bigornas do tipo raiz e do tipo tronco que estavam sobre raízes tiveram sua altura e diâmetro medidos. Por isso, o número amostral da altura e do diâmetro das bigornas não foi o mesmo.

As bigornas do tipo raiz apresentaram altura média maior $(159 \mathrm{~cm})$ do que as do tipo tronco $(71 \mathrm{~cm})$, sendo esta diferença significativa $\left(\chi^{2}=33,66 ; p=0,000\right)$. As bigornas do tipo tronco apresentaram diâmetro médio significativamente maior $(80 \mathrm{~cm})$ quando comparadas às bigornas do tipo raiz $(54,6 \mathrm{~cm})\left(\chi^{2}=4,79 ; \mathrm{p}=0,028\right)$ (Figura 5).

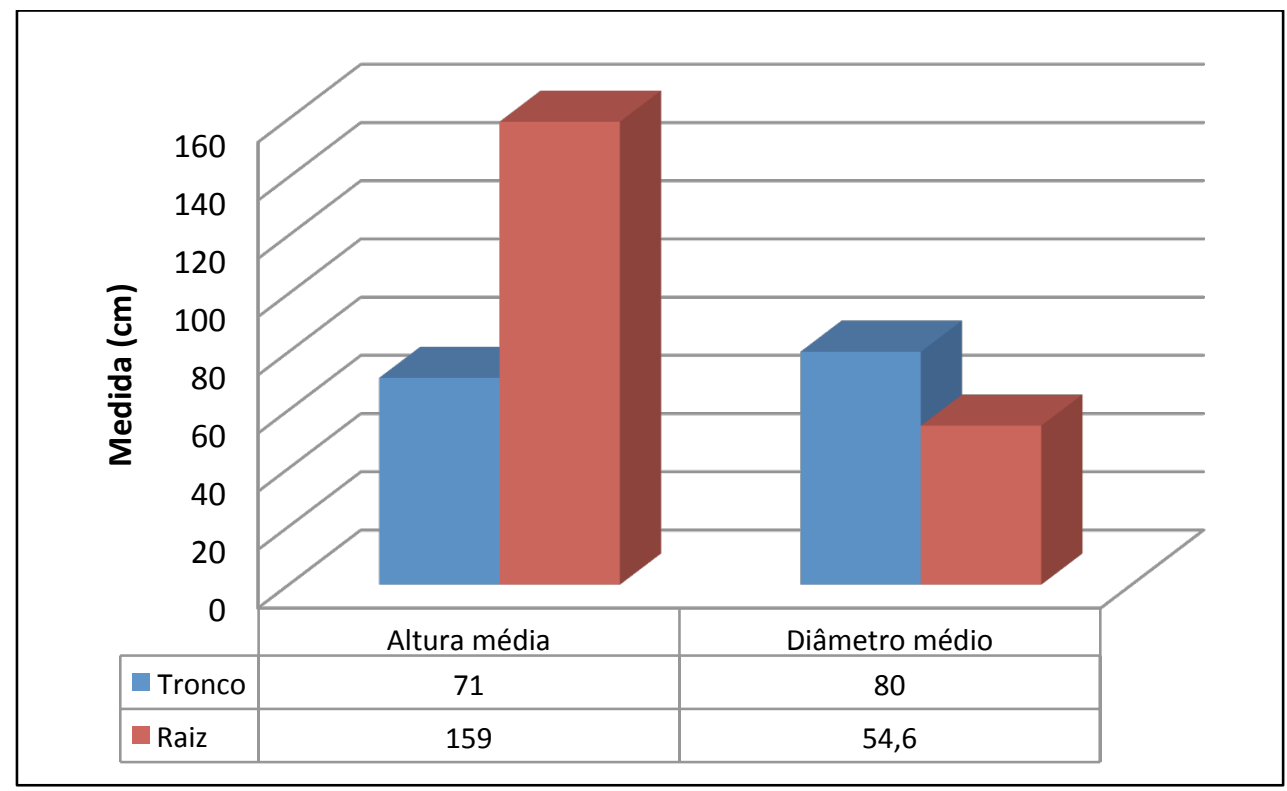

Figura 5. Caracterização das bigornas (altura e diâmetro) quanto ao tipo tronco e raiz utilizadas pelos macacos-prego (S. libidinosus) do Morro do Boi no período de março de 2012 a março de 2013. 
Houve diferença significativa na frequência de ocorrência de bigornas retas e inclinadas $\left(\chi^{2}=25,948 ; p=0,000\right)$ e de rugosas e lisas $\left(\chi^{2}=18,835 ; p=0,000\right)$. A maior proporção das bigornas foi reta $(75,47 \%)$ e rugosa $(71,7 \%)$ (Figuras 6 e 7).
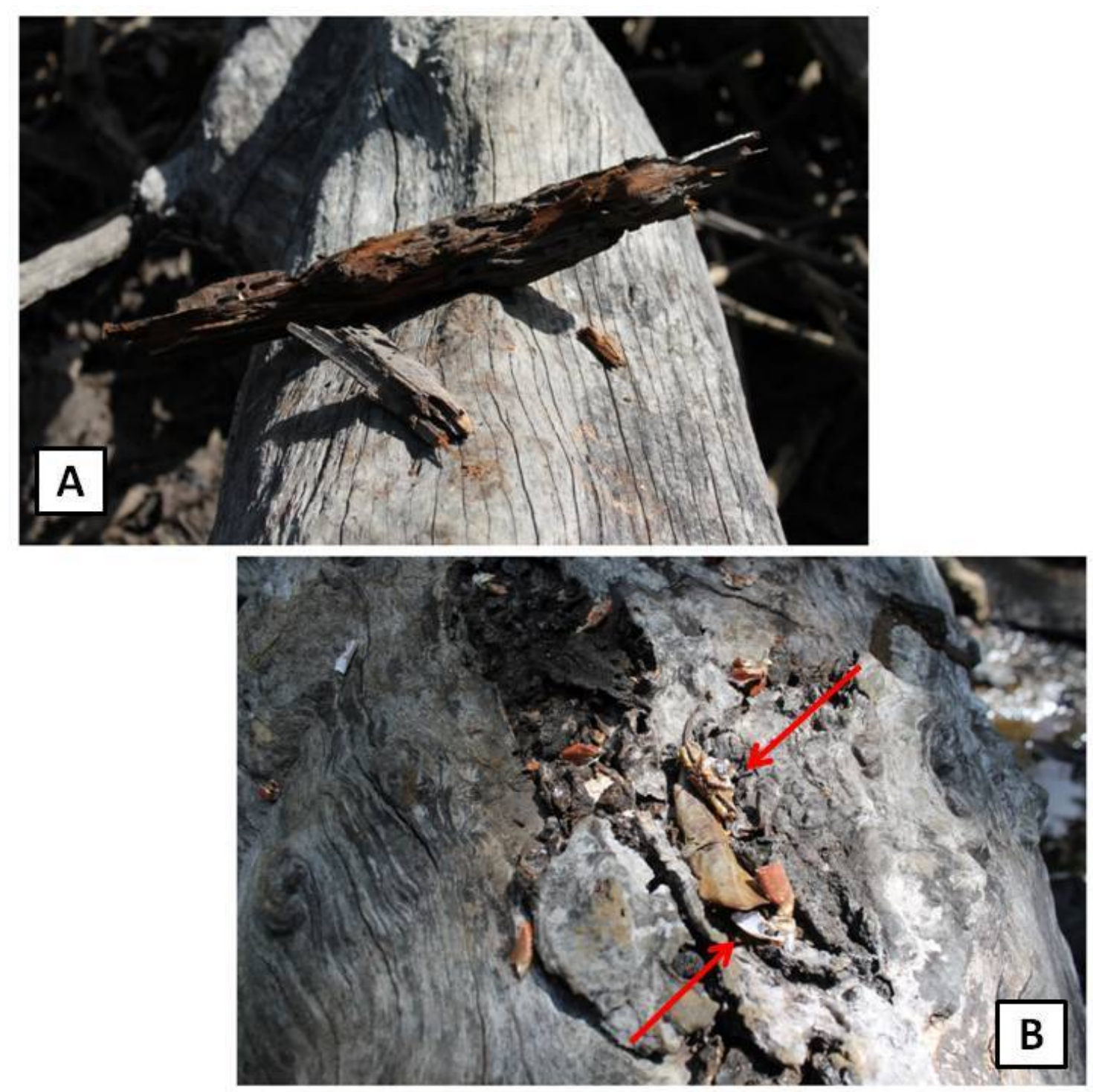

Figura 6. Caracterização das bigornas quanto ao substrato utilizadas pelos macacos-prego ( $S$. libidinosus) do Morro do Boi no período de março de 2012 a março de 2013. (A) Substrato liso. (B) Substrato rugoso. As setas indicam a presença de caranguejos quebrados. 


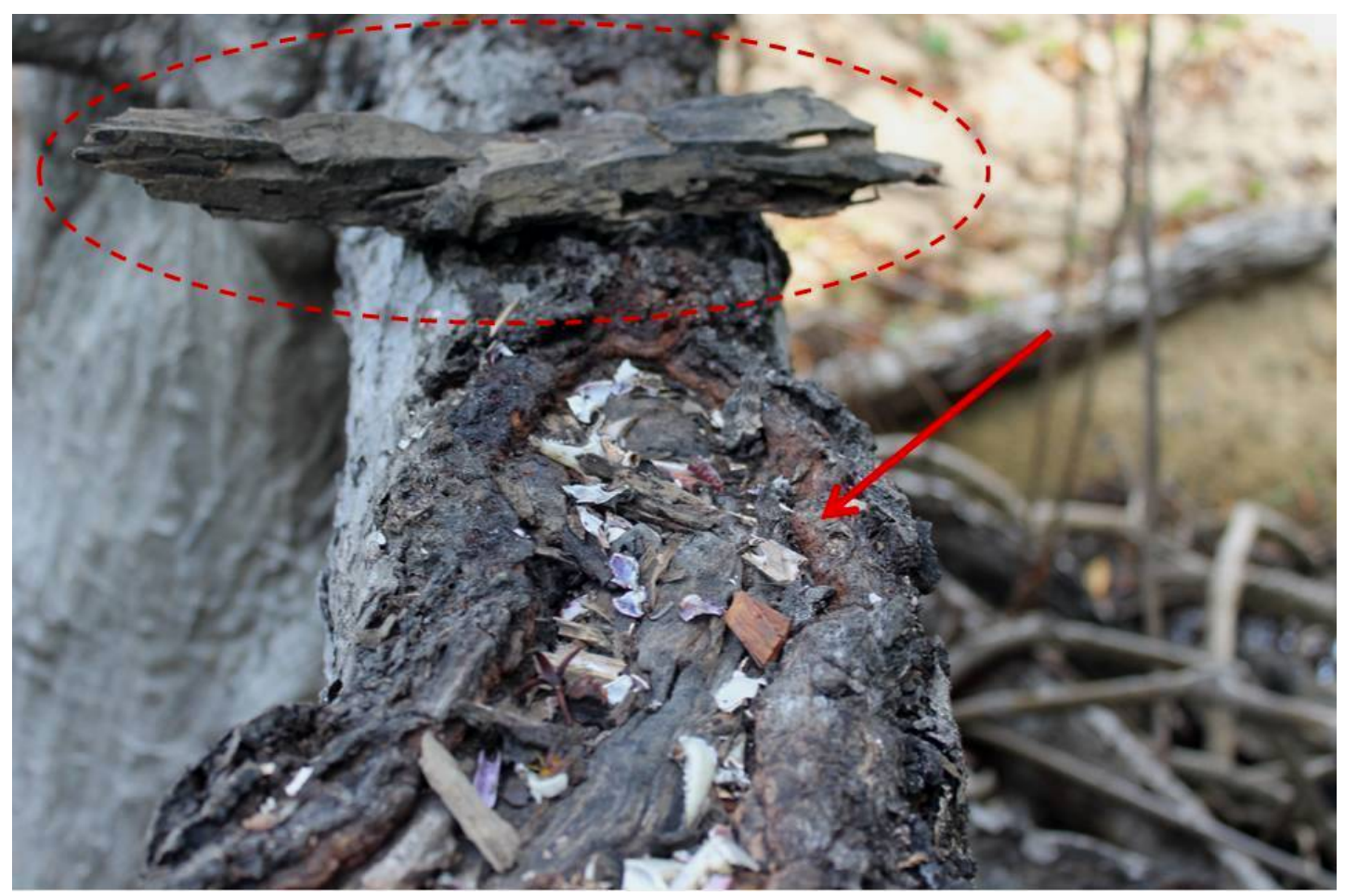

Figura 7. Bigorna de Rhizophora mangle do tipo raiz com substrato reto e rugoso utilizada pelos macacos-prego (S. libidinosus) do Morro do Boi no período de março de 2012 a março de 2013. Em vermelho destacam-se o martelo utilizado e os fragmentos das carapaças dos caranguejos que foram quebrados.

Os sítios mapeados apresentaram de 01 a 04 tipos de alimentos. A maioria dos sítios de quebra utilizados pelos macacos-prego foi do tipo simples $\left(82,19 \% ; \chi^{2}=41,447 ; \mathrm{p}=\right.$ 0,000), com a quebra exclusiva de caranguejos $(\mathrm{N}=60)$ (Figura 8). Os sítios mistos compreenderam $17,81 \%$, sendo os de maior frequência os de quebra de caranguejo e extração de turu $(8,21 \%, \mathrm{~N}=6)$, seguido dos de quebra de caranguejo e gastrópode $(6,85 \%, \mathrm{~N}=5)$. Os demais tipos de sítios mistos (caranguejo, gastrópode e turu/caranguejo, gastrópode, turu e outro bivalve) apresentaram a mesma proporção $(1,37 \%, \mathrm{~N}=1$, respectivamente). $\mathrm{O}$ item animal encontrado com maior frequência nos sítios de quebra foi o caranguejo $(82,14 \%)$, seguido do turu $(11,43 \%)$, do gastrópode $(5 \%)$ e do bivalve $(1,43 \%)$. Houve diferença significativa entre os tipos alimentares consumidos com o uso de martelos $\left(\chi^{2}=176,1868 ; \mathrm{p}=\right.$ $0,0000)$. 


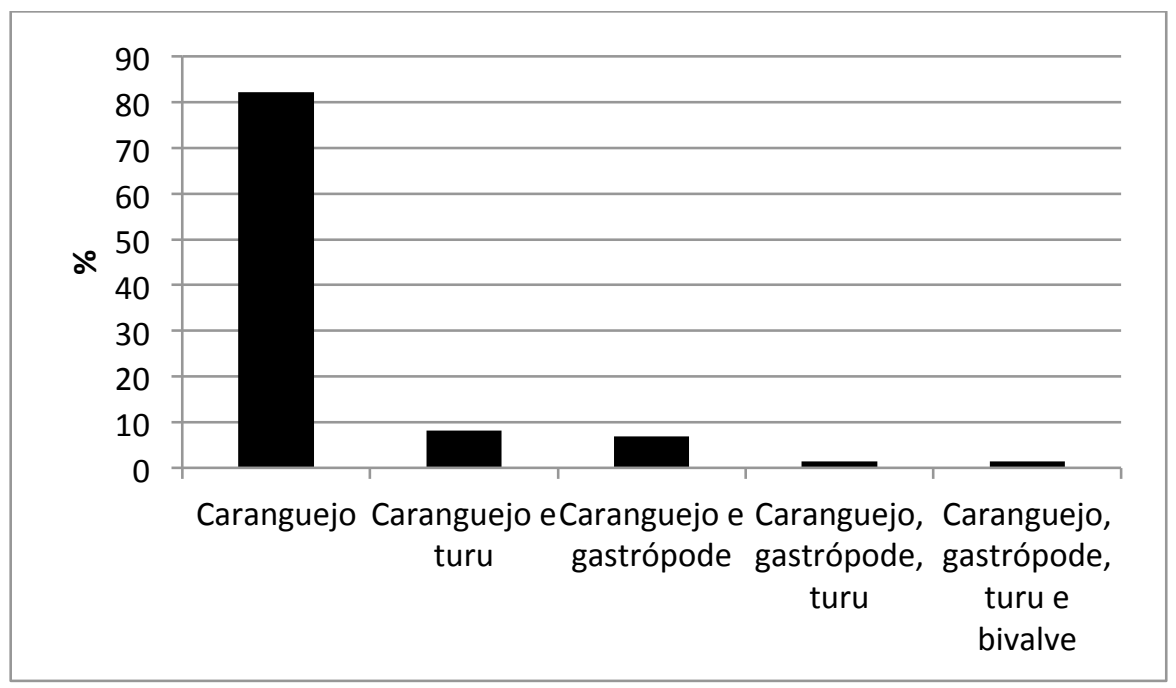

Figura 8. Caracterização dos sítios de quebra quanto ao tipo de alimento quebrado/extraído pelos macacos-prego (S. libidinosus) do Morro do Boi no período de março de 2012 a março de 2013.

Durante os 12 meses de coleta dos dados, 28 cefalotórax de caranguejos com a parte superior intacta foram encontrados nos sítios de quebra (Figura 9). O tamanho médio foi 6,5 cm de largura $(3 \pm 9 ; \mathrm{dp}=1,78)$ e 4,8 cm de comprimento $(2,5 \pm 6 ; \mathrm{dp}=0,94)$. Em relação aos demais recursos encapsulados, foi possível mensurar apenas um número reduzido de gastrópodes encontrados nas bigornas junto dos demais fragmentos $(\mathrm{n}=10)$. O tamanho médio dos gastrópodes foi de $1,8 \mathrm{~cm}$ de largura $(1,5 \pm 2 ; \mathrm{dp}=0,258)$ e $1,5 \mathrm{~cm}$ de comprimento $(1,3$ $\pm 1,7 ; \mathrm{dp}=0,198$ ) (Figura 10). Em geral, a quebra dos recursos encapsulados com os martelos fragmentava toda a carapaça do animal.
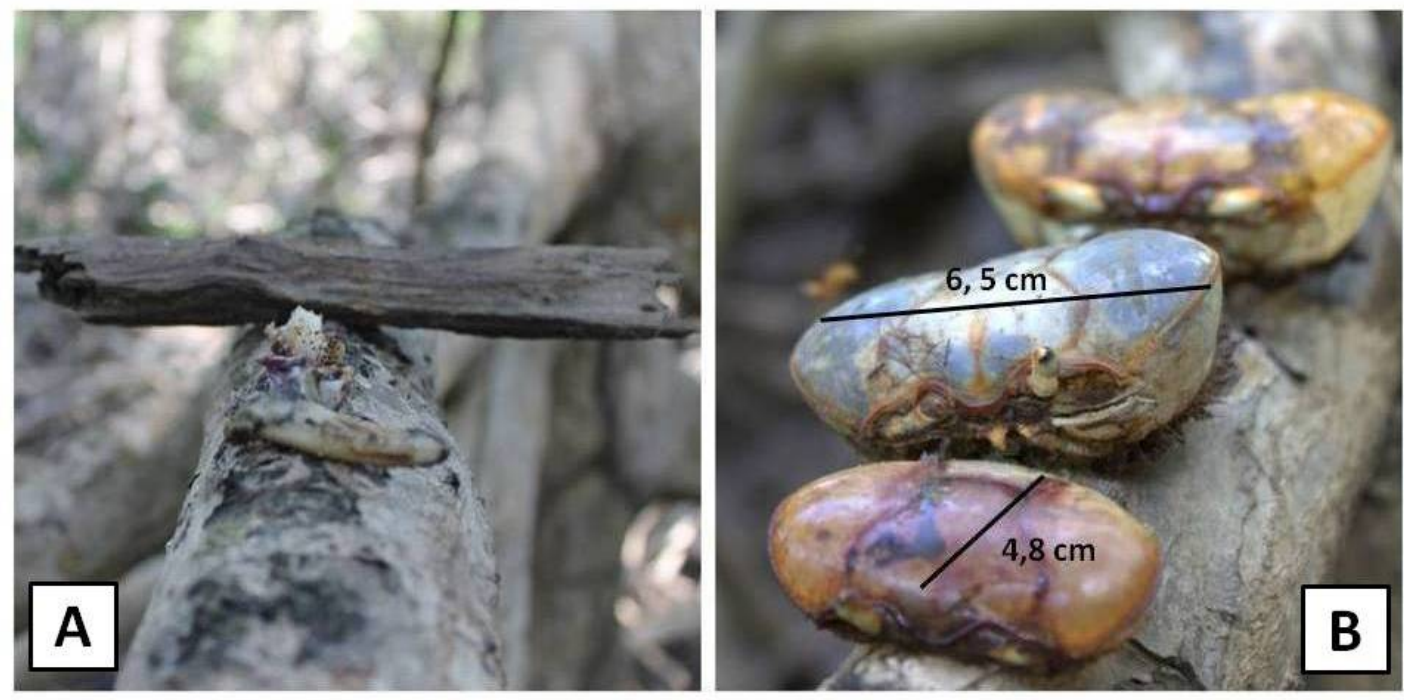

Figura 9. (A) Sítio de quebra com vestígios de quebra de caranguejo (Ucides cordatus) no Manguezal Morro do Boi em 2013. (B) Tamanho médio dos cefalotórax dos caranguejos encontrados intactos nos sítios de quebra. 

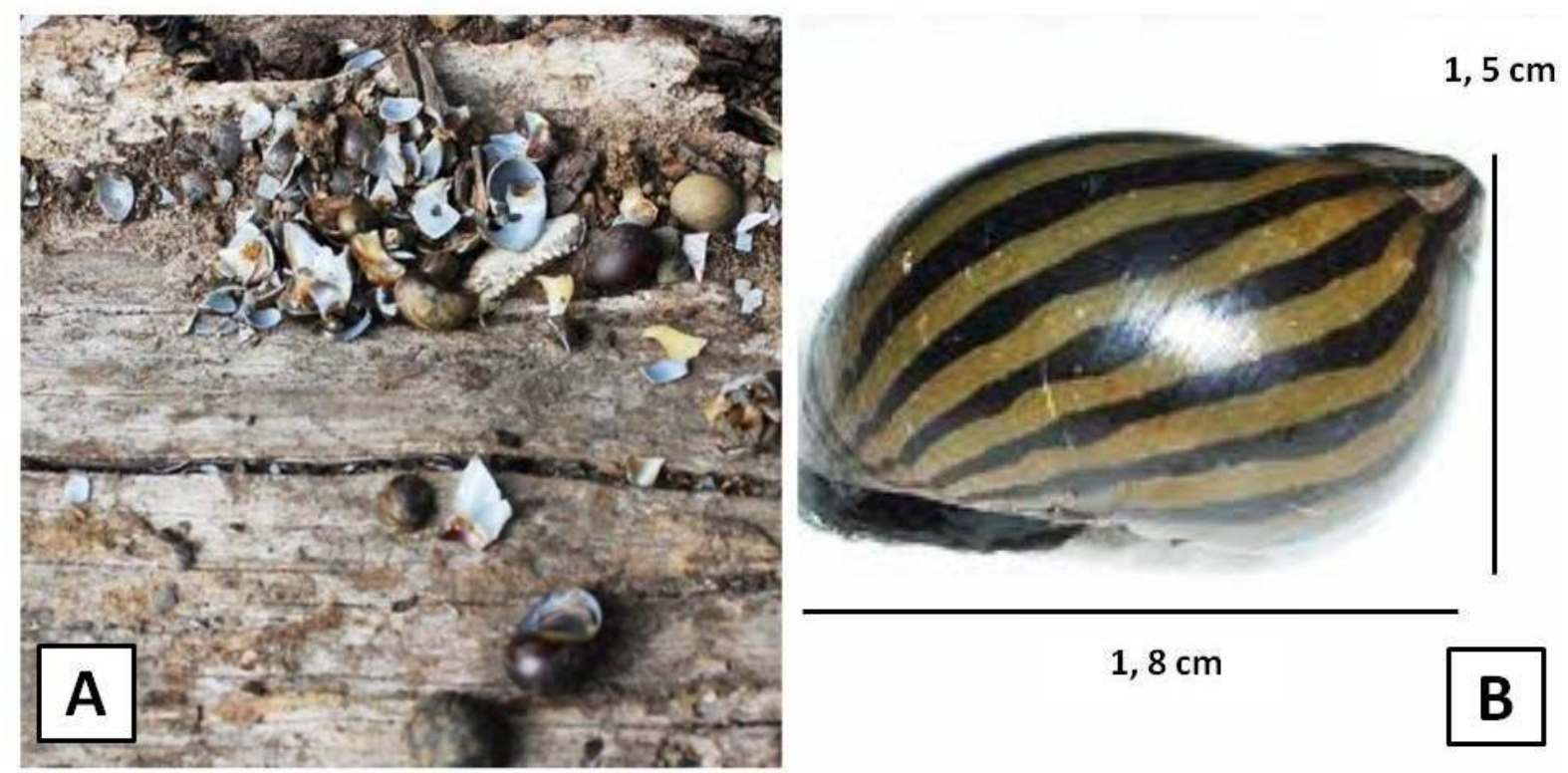

Figura 10. (A) Sítio de quebra com vestígios das conchas de gastrópodes (Neritina sp.) no manguezal Morro do Boi em 2012. (B) Tamanho médio dos gastrópodes encontrados nos sítios de quebra.

\subsection{Frequência de uso dos sítios de quebra}

O número de sítios de quebra utilizados mensalmente variou ao longo do período, sendo encontrados mais sítios com vestígios de quebra no mês de novembro $(\mathrm{N}=14)$ e menos nos meses de março e maio de $2012(\mathrm{~N}=4)$ (Figura 11). Segundo o teste de Mann-Whitney, não houve diferença significativa na frequência de uso de sítios de quebra entre as estações seca e chuvosa.

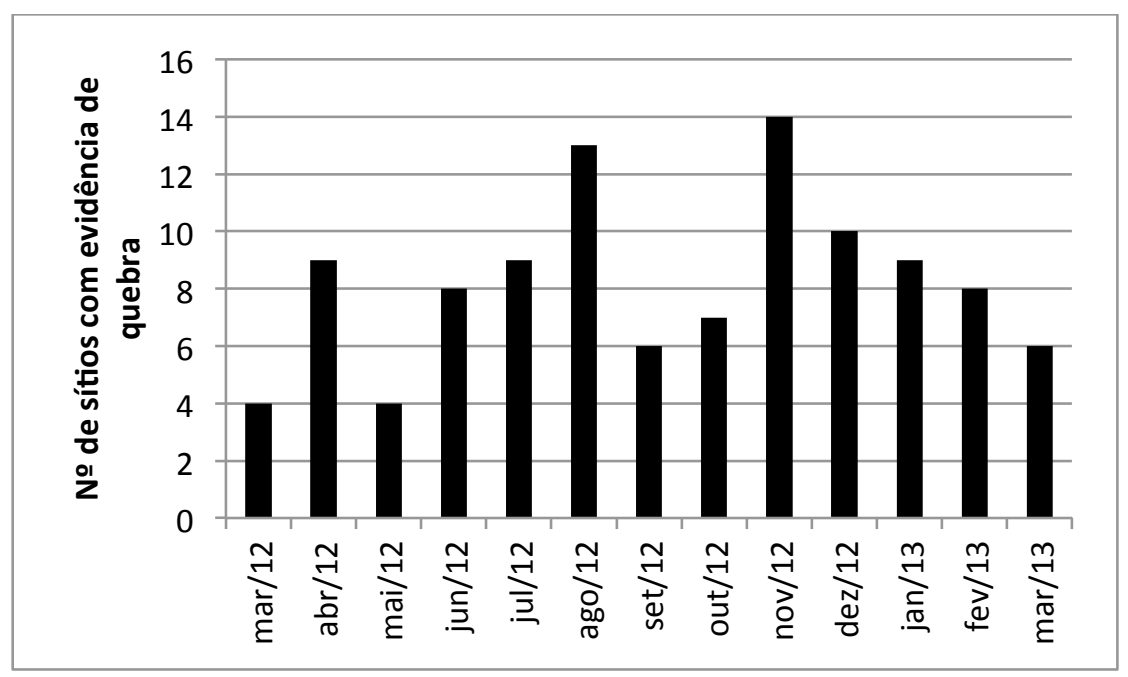

Figura 11. Número de sítios com vestígios de quebra de alimentos encapsulados no Morro do Boi no período de março de 2013 a março de 2013. 
Em relação ao tipo de alimento encontrado nos sítios de quebra, houve maior frequência de sítios com vestígios de quebra de gastrópodes, turus e outros bivalves na estação seca em comparação com os meses da estação chuvosa $\left(\chi^{2}=13,57186 ; p=0,0002\right)$. Em relação ao item caranguejo, não houve diferença significativa entre as estações $\left(\chi^{2}=\right.$ $0,655360 \mathrm{p}=0,79795)$ (Figura 12).

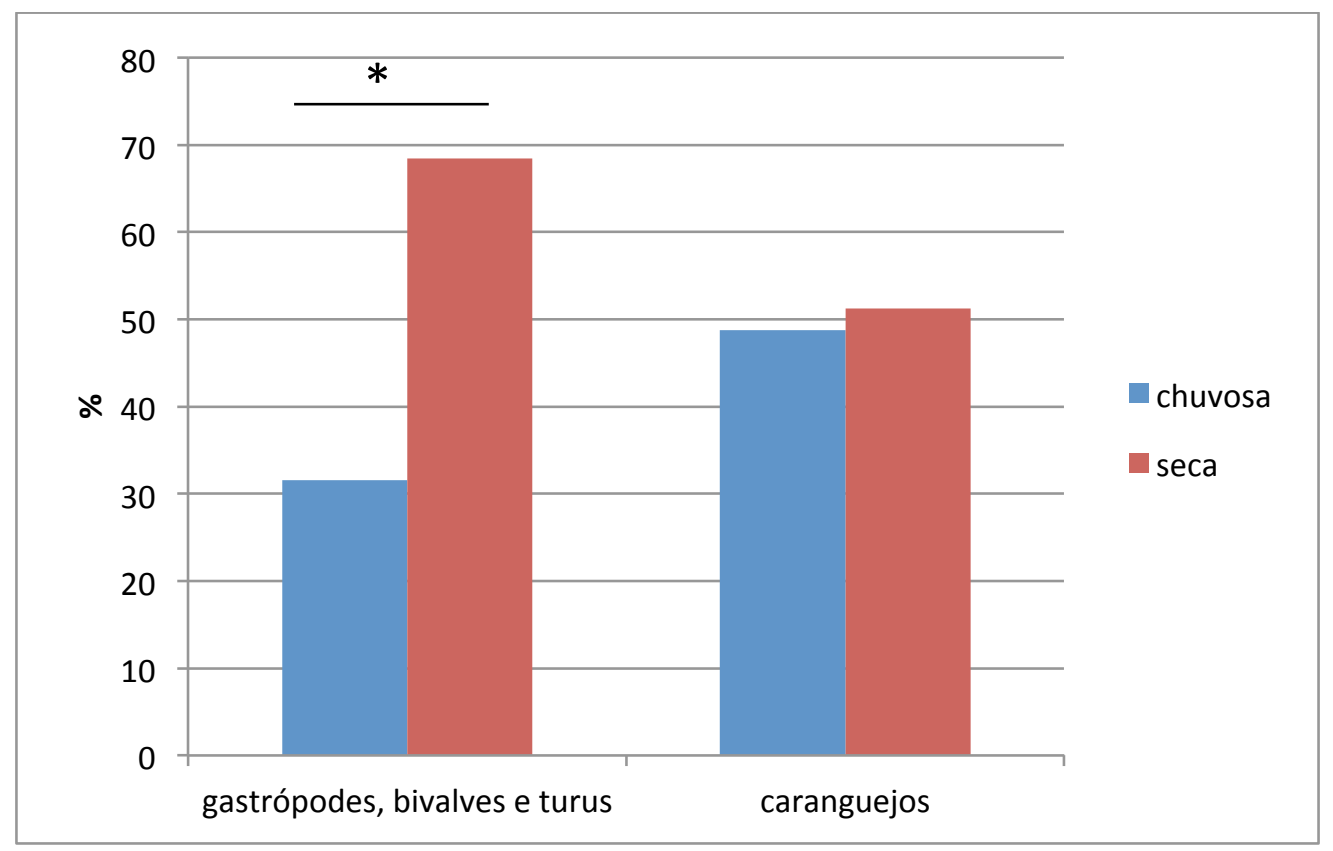

Figura 12. Tipo de alimento encapsulado encontrado nos sítios de quebra nas estações seca e chuvosa no Manguezal do Morro do Boi no período de março de 2012 a março de 2013.

A Figura 13 apresenta as localizações dos sítios de quebra na área de uso do grupo. Estes estão destacados conforme sua frequência de uso (01 (um) a 18 (dezoito) registros de quebra). Destes, quatro sítios de quebra apresentaram vestígios de uso durante todos os meses (numerados de 1 a 4). Outro sítio de quebra apresentou uso constante (03 meses consecutivos, destacado em azul escuro), porém devido às perturbações causadas por seres humanos na área, os macacos o abandonaram Este sítio margeava um igarapé (Figura 14), ou seja, um curso d'água constituído por um braço longo de rio ou canal onde os macacos-prego costumam forragear caranguejos.

O mapa do Morro do Boi foi dividido em aproximadamente 22 quadrados com área igual a $16.900 \mathrm{~m}^{2}$, ou seja, cada quadrado correspondendo a 1,69 ha (Figura 13). O número de sítios de quebra variou significativamente entre 0 e 13 em cada área amostral $\left(\chi^{2}=65,14894\right.$; $\mathrm{df}=21 ; \mathrm{p}=0,000002)$. 


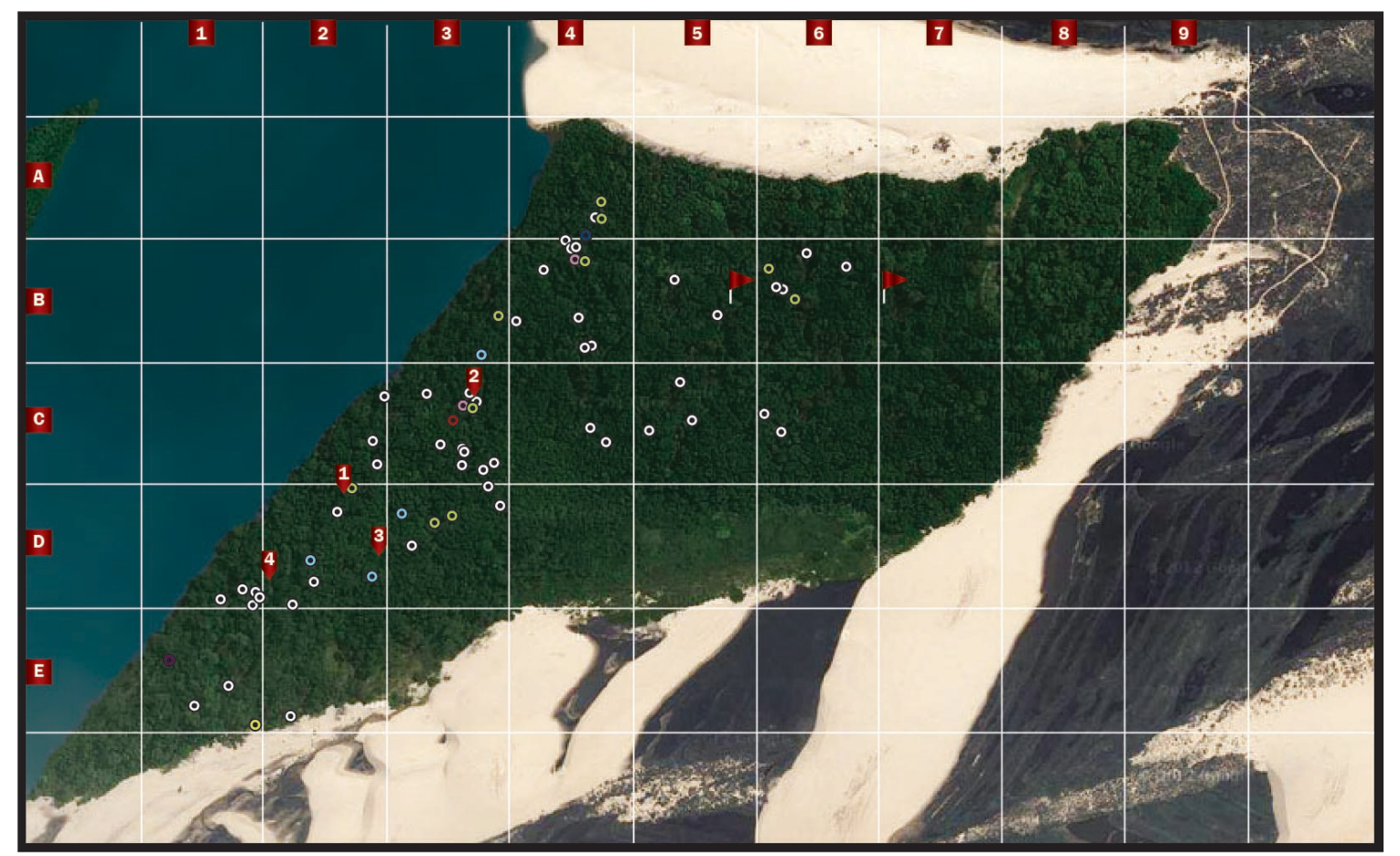

Figura 13. Localização dos sítios de quebra no fragmento de manguezal do Morro do Boi. Os sítios numerados de 1 a 4 foram os que apresentaram vestígios de uso durante todos os meses. Os dois sítios representados por bandeiras vermelhas apresentaram vestígios de quebra, porém nenhum martelo foi encontrado no local.
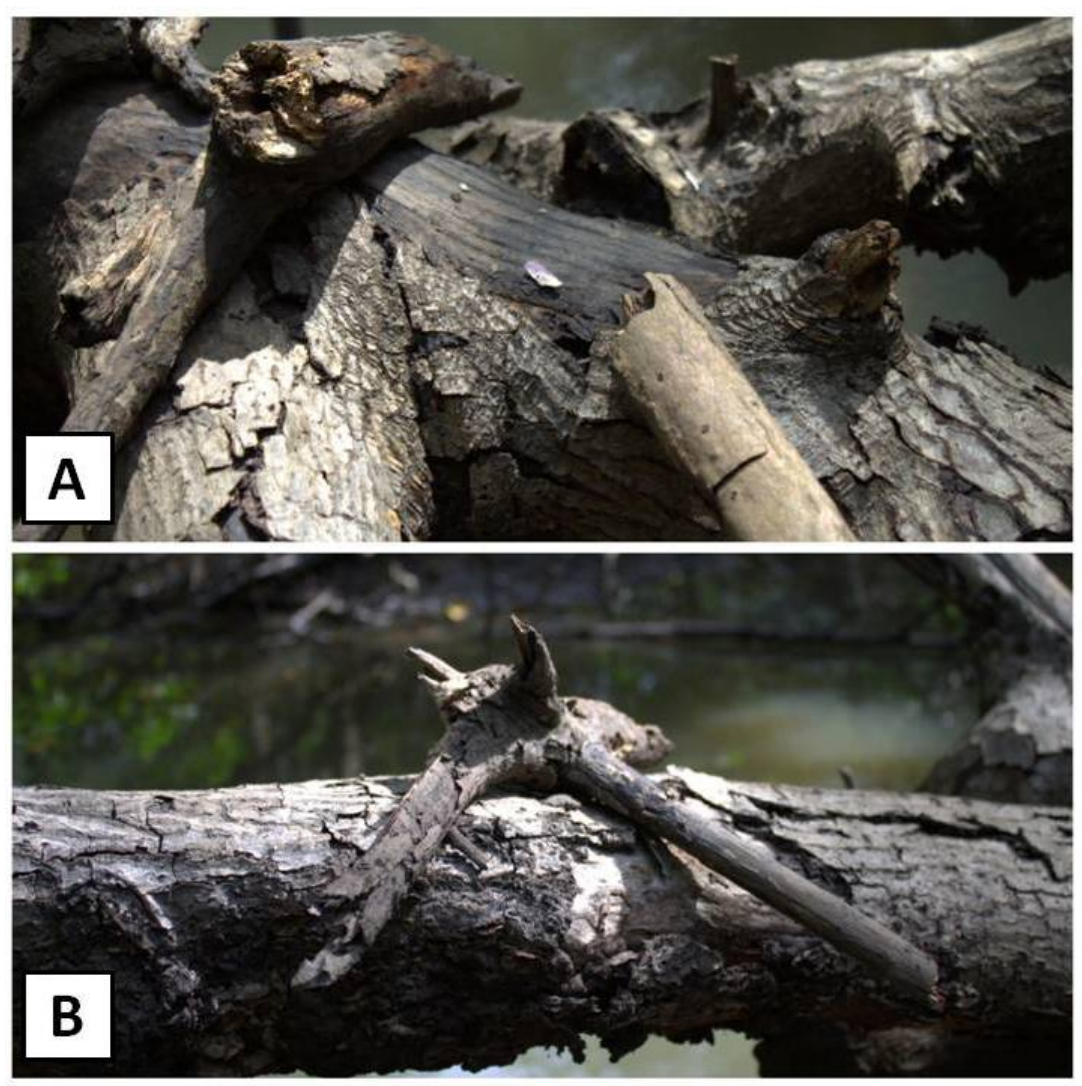

Figura 14. (A) e (B). Sítio de quebra com localização à margem de um igarapé (ao fundo) que foi abandonado pelos macacos-prego (S. libidinosus) do Morro do Boi devido às perturbações causadas por seres humanos no meio do estudo. 
Os sítios de quebra com repetição de uso após o mapeamento inicial (sítios ativos) foram em sua maioria com bigornas do tipo tronco $(66,67 \%)$, com superfície reta $(73,68 \%)$ e rugosa $(68,42 \%)$. Já os quatro mais frequentes foram todos com bigornas do tipo tronco, porém dois apresentaram superfície rugosa e dois superfície lisa. Bigornas ativas do tipo tronco apresentaram altura média de 77,3 $\mathrm{cm}(30 \pm 170 ; \mathrm{dp}=36,7)$ e diâmetro médio de 105,7 cm $(51,5 \pm 151 ; d p=29,41)$. Já as bigornas ativas do tipo raiz apresentaram altura média de 120,8 cm $(49 \pm 183 ; \mathrm{dp}=42,88)$ e diâmetro médio 47,5 cm $(25 \pm 88 ; \mathrm{dp}=20,95)$. Em relação aos quatro sítios com utilização mais frequente, a altura média foi de $101 \mathrm{~cm}(58 \pm 170 ; \mathrm{dp}=$ $52,59)$ e o diâmetro médio foi de $110,4 \mathrm{~cm}(83 \pm 130 ; \mathrm{dp}=20,57)$. 


\section{DISCUSSÃO}

Nossos dados mostram que os macacos-prego (S. libidinosus) que residem no fragmento de manguezal Morro do Boi, nos Pequenos Lençóis Maranhenses, utilizam martelos de madeira para quebrar conchas de crustáceos e moluscos. Discutiremos a seguir as características das bigornas mais utilizadas pelos indivíduos desse grupo e analisaremos a frequência do uso dos sítios de quebra ao longo das estações seca e chuvosa relacionando-a com a disponibilidade dos recursos alimentares. Além disso, avaliaremos os fatores que podem levar esses animais a utilizarem martelos de madeira para acessar recursos encapsulados de origem animal.

\subsection{Caracterização e densidade dos sítios de quebra utilizados pelos macacos-} prego do Morro do Boi

Nossa hipótese de que os macacos-prego do Morro do Boi utilizariam com maior frequência bigornas que apresentam características que otimizam a quebra dos alimentos encapsulados foi confirmada pelos resultados.

Nossa previsão de que as bigornas com substrato reto e rugoso apresentariam maior frequência de uso do que as inclinadas e lisas foi confirmada. Um substrato reto, sem muita inclinação e rugoso, ou seja, cheio de ondulações na superfície, permite que a presa seja manuseada sem correr o risco de escorregar/deslocar pela bigorna e provavelmente facilita a quebra através do atrito entre martelo, presa e bigorna. Tais ondulações nas bigornas do Morro do Boi podem ser comparadas às depressões encontradas nas bigornas escolhidas pelos macacos-prego da FBV. Na FBV, os macacos-prego escolhem bigornas que apresentam superfície horizontal com pouca inclinação e depressões (Visalberghi et al., 2007) e esse comportamento sugere que eles avaliam as características da bigorna, mais especificamente, a depressão encontrada na bigorna na qual eles colocam o coco (Liu et al., 2011). Segundo Liu et al. (2011), essa preferência por determinadas bigornas pode refletir a percepção das diferentes características das bigornas como potenciais sítios de quebra de coco. Portanto, esse argumento também pode ser utilizado para explicar a maior frequência de uso desse tipo de bigorna no manguezal do Morro do Boi. 
Os macacos-prego do Morro do Boi utilizaram principalmente bigornas de troncos e raízes de mangue vermelho (Rhizophora mangle), amplamente distribuídas na área de estudo. A densidade de sítios de quebra no Morro do Boi (1,97 sítio/ha) é bastante semelhante à encontrada na Fazenda Boa Vista, cuja densidade média é de 1,82 sítios/ha (Visalberghi et al., 2007).

Visalberghi et al. (2007) averiguaram as características das bigornas e martelos utilizados pelos macacos-prego da FBV e relataram que as bigornas eram em sua maioria pedras rochosas, formadas por silício e arenito e cimentadas com óxidos de ferro. De acordo com os autores, os macacos utilizam essas bigornas de pedra por serem abundantes na região e apresentarem estrutura forte e superfície horizontal, que são características que facilitam a quebra de frutos duros.

No manguezal não existem pedras e as bigornas só se apresentam na forma de troncos e raízes aéreas, principalmente de Rhizophora mangle, cuja madeira apresenta densidade entre 0,8 e $1,0 \mathrm{~g} / \mathrm{cm}^{3}$ (Richter \& Dallwitz, 2009). As poucas bigornas do tipo tronco de árvores utilizadas pelos macacos-prego da FBV variam de moderadamente pesadas e resistentes (densidade de $0,65 \mathrm{~g} / \mathrm{cm}^{3}$ ) a pesadas, muito resistentes e de difícil quebra, durável mesmo quando expostas ao tempo (densidade de $0,94 \mathrm{~g} / \mathrm{cm}^{3}$ ) (Visalberghi et al., 2007). Desta forma, as bigornas de madeira utilizadas pelos macacos-prego do manguezal Morro do Boi também se assemelham às bigornas de madeira da FBV no quesito densidade, pois são resistentes o suficiente para suportar a ação mecânica da dinâmica da quebra de alimentos encapsulados. Destacamos também que as bigornas escolhidas pelos macacos-prego do Morro do Boi ou partem diretamente do tronco de uma árvore com grande cobertura vegetal, no caso das bigornas de raiz, ou são bigornas de tronco que estão localizadas ou em cima das raízes aéreas ou no chão, porém próximos às árvores aumentando a segurança em relação aos possíveis predadores. Essa característica encontrada no Morro do Boi também se assemelha à FBV, cuja bigornas refletem um forte viés para evitar a predação, pois estão localizadas perto das árvores com maior cobertura vegetal, reduzindo desta forma a probabilidade de sua detecção por parte dos predadores aéreos.

Porém, nossos dados apontam duas diferenças em relação aos dados de Visalberghi et al. (2007): 1) as bigornas mais utilizadas pelos macacos-prego do Morro do Boi estão a uma altura média do chão significativamente superior à encontrada na FBV (MB: 112,4 cm; FBV: $83 \mathrm{~cm}$; t de Student: 6,64; $\mathrm{p}=0,04)$ e 2) os martelos do Morro do Boi foram pedaços de madeira com peso médio inferior aos daqueles da FBV (MB: 452g; FBV:1096g). A altura elevada da bigorna pode ter sido também uma estratégia contra a predação, visto que o campo 
visual na região dos sítios de quebra pode ser prejudicado pelo emaranhado de raízes aéreas. O peso inferior dos martelos do Morro do Boi pode ser reflexo do tipo de material de que é composto o martelo, pois estes são de madeira de Rhizophora mangle, que é menos densa do que o arenito e o basalto que compõem os martelos de pedra utilizados pelos macacos-prego da FBV(Visalberghi et al., 2007). Contudo, a pesquisa de Falótico (2011) no PNSC mostra que os macacos-prego utilizam pedras com peso médio inferior às do Morro do Boi para quebrar alimentos duros e para cavar o solo (PNSC: ferramenta de quebra $=213,85 \mathrm{~g}$; ferramenta para cavar $=126,10 \mathrm{~g})$.

O peso dos martelos utilizados pelos macacos-prego do Morro do Boi pode ser adequado ao tipo de alimento encapsulado que é encontrado e consumido, pois em Macaca fascicularis (Malaivijitnoud et al., 2007) e em Macaca fascicularis aurea (Gumert et al., 2009) que habitam zonas costeiras e manguezais, o peso médio dos martelos (pedras) utilizados para quebrar crustáceos e moluscos foi semelhante ao peso dos martelos de madeira do Morro do Boi (S. libidinosus do MB: 452g; Macaca fascicularis: 480g; Macaca fascicularis aurea: $422,6 \mathrm{~g})$.

A segunda hipótese levantada neste trabalho foi a de que a frequência do tipo de alimento encapsulado quebrado com o auxílio do martelo apresenta uma relação com seu tamanho e com o seu retorno energético. Nossa previsão de que os indivíduos utilizariam martelos para acessar alimentos encapsulados de origem animal que apresentam maior tamanho e que possuíssem mais nutrientes visando minimizar os custos do comportamento de quebra foi confirmada pelos resultados.

Os resultados apontam que os caranguejos do Morro do Boi apresentaram tamanho médio superior ao dos gastrópodes encontrados nos sítios de quebra. Gastrópodes e bivalves são menores e, conforme observado, disponíveis em grandes quantidades acima do solo lamoso e junto às raízes aéreas dos mangues. O turu, ao contrário desses últimos recursos, é encontrado dentro de pedaços de madeira desgastada pelo tempo, por isso não é um recurso facilmente detectado e extraído. De acordo com o maior tamanho dos caranguejos, a maioria dos resíduos encontrados nos sítios de quebra foi deste crustáceo em relação aos demais itens encapsulados. Segundo Son (2003), os macacos buscam proteínas e gorduras no mangue, uma vez que o teor desses itens nutricionais é maior nos caranguejos do que nos invertebrados dos galhos, das folhas e frutos de mangue. Além disso, os caranguejos possuem maior quantidade de minerais como o cálcio e fósforo do que os demais tipos de alimento (Son, 2003).

Conforme visto no Capítulo II, a disponibilidade de caranguejos na área de estudo não sofreu alteração significativa entre as estações. Essa disponibilidade contínua durante todo o 
ano associada ao maior tamanho em relação aos demais alimentos encapsulados pode explicar a maior frequência de caranguejos nos sítios de quebra.

Além disso, segundo dos Santos (2010), os macacos-prego só acessam a carne de gastrópodes e bivalves com o uso dos martelos, o que não acontece em relação ao caranguejo. Tanto no estudo de dos Santos (2010), quanto no presente estudo, foi observado o forrageio de caranguejos e o seu consumo sem o uso dos martelos. Os macacos-prego capturavam o caranguejo e se deslocavam com ele nas mãos ou boca até um local seguro na copa da árvore e lá desmembravam o caranguejo com as mãos e quebravam as cascas com os dentes. Nesse caso, o consumo de carne de caranguejo com o uso do martelo é facultativo, como forma de minimizar os custos do uso de ferramentas e maximizar o ganho energético.

O uso facultativo de martelos para obtenção de carne também pode ser visto em Macaca fascicularis e Macaca fascicularis aurea que habitam zonas costeiras sujeitas à variação de marés (Malaivijitnoud et al., 2007; Gumert \& Mallaivijitnond, 2012). Esses macacos utilizam pedras para processar principalmente invertebrados marinhos (bivalves, gastrópodes e crustáceos), mas também esmagam com pedras peixes, o molusco quitão e equinodermos, como o pepino-do-mar. Porém, o consumo de crustáceos não está restrito ao uso de ferramentas, pois quatro espécies de caranguejos podem ser consumidas sem o auxílio de pedras e são exploradas pelos macacos através do uso dos dentes e das mãos.

Já que a quebra e o consumo de gastrópodes e bivalves com o uso de martelos parece ser obrigatória, os macacos-prego podem avaliar os custos e benefícios de quebrar esses alimentos e parecem evitá-los. Veremos a seguir que a avaliação de usar ferramentas para a quebra de recursos com menor tamanho pode estar influenciando as tomadas de decisão dos macacos-prego do Morro do Boi de acordo com a disponibilidade dos outros recursos alimentares na área de uso do grupo.

\subsection{Frequência de uso dos sítios de quebra}

Sapajus libidinosus do Morro do Boi utiliza martelos para a quebra de crustáceos e moluscos, porém este não é um comportamento observado no orçamento de atividades do grupo, conforme visto no Capítulo II. Ainda assim, durante o período de um ano foi possível observar que os macacos-prego utilizaram bigornas e martelos em todos os meses do ano. Nossa previsão de que os indivíduos utilizariam com maior frequência os martelos para 
acessar recursos animais encapsulados no período do ano em que os recursos vegetais estão escassos foi parcialmente confirmada.

Conforme resultados apresentados no Capítulo II, houve variação na disponibilidade dos recursos vegetais entre as estações, mas não em relação aos recursos animais encapsulados, os quais estiveram sempre disponíveis ao longo do ano. De acordo com a previsão de que os indivíduos utilizariam martelos sempre que os recursos animais encapsulados estivessem abundantes no ambiente sem estar relacionado com a escassez de recursos vegetais como flores e frutos, não houve diferença significativa entre as frequências de uso dos sítios de quebra nos períodos seco e chuvoso. Neste caso, a expressão do comportamento de uso de ferramentas pelos macacos-prego do Morro do Boi está de acordo com a hipótese da oportunidade.

No entanto, a análise da frequência de quebra de tipos diferentes de presa animal revela um resultado paradoxal. A frequência de sítios de quebra com vestígios de caranguejos, que apresentam mais proteínas e minerais que os demais itens alimentares encontrados no manguezal (Son, 2003), não variou ao longo do ano. Mas a frequência dos sítios com vestígios de quebra dos recursos com maior relação custo/benefício de extração, gastrópodes, bivalves e turus, aumentou significativamente no período seco (julho a dezembro) em comparação com os meses da estação chuvosa. Assim, quando os recursos vegetais estiveram em menor disponibilidade na área, os macacos-prego investiram na quebra dos alimentos encapsulados, inclusive de gastrópodes e bivalves, que são recursos menores que os caranguejos e que demandam maior gasto de energia para a sua quebra, visto que o uso de martelos nesse caso parece ser obrigatório (dos Santos, 2010). Essa estratégia apresentada pelos macacos-prego do Morro do Boi pode ser explicada pelo consumo de alimentos alternativos como forma de complementar a dieta em períodos de diminuição de recursos alimentares.

O consumo de recursos alternativos quando os alimentos preferidos estão escassos é uma característica dos macacos-prego e caiararas (Brown \& Zunino, 1990; Taira, 2007; Izar, Verderane, Peternelli-dos-Santos, Mendonça-Furtado, Presotto, Tokuda et al., 2012; Mosdossy, 2013). Entende-se por alimento preferido aquele tipicamente sazonal (nem sempre disponível no ambiente), de alta qualidade, ou seja, com grande concentração de nutrientes, e facilmente processado, como por exemplo, os frutos (Marshall \& Wrangham, 2007; Marshall, Boyko, Feilen, Boyko \& Leighton, 2009). O alimento alternativo ("fallback food") constitui uma grande parte da dieta durante períodos de baixa abundância do alimento preferido (Harrison \& Marshall, 2011; Marshall \& Wrangham, 2007) e é muitas vezes uniformemente 
distribuído, mas de difícil processo e geralmente de baixa qualidade. Porém, alguns podem apresentar boa qualidade e bom retorno energético, complementando a dieta juntamente com os alimentos preferidos (Marshall \& Wrangham, 2007). A dificuldade de processamento de um alimento alternativo muitas vezes pode selecionar adaptações morfológicas ou comportamentais, como o forrageio extrativo e o uso de ferramentas (Marshall \& Wrangham, 2007; Taira, 2007; Makedonska, Wright \& Strait, 2012).

Para S. nigritus, durante os períodos de escassez de frutos a dieta é dominada pelo recurso disponível, como as bromélias (Brown \& Zunino, 1990). O mesmo já foi observado em S. nigritus no Parque Estadual Carlos Botelho (PECB), onde os macacos-prego estão sujeitos a uma baixa disponibilidade de frutos ao longo do ano, principalmente na estação seca. Neste caso, os macacos-prego do PECB consomem como alimentos alternativos, as bromélias (Taira, 2007; Peternelli-dos-Santos, 2009; Izar et al., 2012), que são recursos abundantes durante todo o ano, incluindo o período de escassez de frutos (Mosdossy, 2013) e o pecíolo da folha da palmeira Euterpe edulis (Taira, 2007). Nos caiararas (C. capucinus) também foi observado o maior consumo de bromélias em relação aos invertebrados no período de escassez geral de recursos alimentares e Mosdossy (2013) sugere que as bromélias funcionam como recurso alternativo na ausência dos alimentos preferidos. No Morro do Boi, nossos resultados parecem seguir essa mesma linha de raciocínio. A razão dos macacos-prego terem aumentado, na estação seca, o consumo de recursos menores e com maior relação custo/benefício do que os caranguejos pode ser a disponibilidade de gastrópodes e bivalves no solo do manguezal e nas raízes aéreas do mangue e também pela baixa mobilidade dessas presas. O caranguejo, por sua vez, apresenta maior mobilidade e, além disso, só sai da toca para se alimentar e reproduzir (Wunderlich, Pinheiro \& Rodrigues, 2008). Assim, para a sua captura é necessário que o macaco espere a presa sair da toca, o que reduz seu tempo disponível para alimentação e outras atividades, ou desça ao solo e introduza um braço na toca para sua busca, o que também gasta tempo e aumenta sua vulnerabilidade aos predadores. Portanto, o consumo de presas com menor retorno energético e que necessitam do uso de ferramentas para a sua obtenção quando os demais alimentos estão escassos ou demandam estratégias de forrageio complexas, indica que os macacos-prego do Morro do Boi utilizaram as ferramentas para complementar a dieta.

Nossos resultados também mostram que os sítios de quebra tenderam a se concentrar mais em uma determinada área do fragmento de manguezal. Da margem do rio até o centro do manguezal, a estrutura vegetal predominante é de mangue vermelho, cujos troncos e raízes foram úteis como bigornas. Na região oposta à margem fica uma área de restinga e dunas, e a 
vegetação predominante é de mangue branco e preto e de árvores frutíferas, as quais não apresentam raízes aéreas, sendo nesse caso necessária a presença de troncos de árvores caídos para servir de bigorna. Outro fator que também interfere na ausência de registros de bigornas nessa área da restinga e das dunas é que o solo do manguezal não é mais lamacento, ou seja, é duro e arenoso em decorrência da invasão das dunas, impedindo desta forma o estabelecimento dos caranguejos, gastrópodes e bivalves. Esse resultado também confirma a hipótese da oportunidade, pois a mudança das características do solo interfere na disponibilidade dos recursos encapsulados e consequentemente no consumo de presas que demandam o uso de ferramentas de quebra. Além disso, mostra que os macacos-prego do Morro do Boi consomem suas presas encapsuladas nos locais onde estas se encontram disponíveis, não havendo nem o transporte do alimento nem do martelo para essas áreas de restinga e de dunas que apresentam sedimento mais duro.

Diferentemente da FBV, no Morro do Boi os martelos e as bigornas se encontram amplamente distribuídos na zona com grande influência da maré, principalmente a de sizígia que ocorre nas luas nova e cheia, e os macacos-prego não enfrentam a escassez de martelos nem de bigornas. Por isso, o transporte de alimentos e de martelos para outros locais, que não onde o recurso se encontra, parece não ter sido uma estratégia utilizada pelos animais.

Diante do exposto, os resultados obtidos revelaram que os macacos-prego do Morro do Boi não estiveram expostos à escassez de alimentos durante o período do estudo, apenas a uma variabilidade periódica na disponibilidade dos recursos vegetais e que o uso de martelos ocorreu de modo oportunista, ratificando a hipótese da oportunidade.

O presente estudo buscou informações a respeito do uso de ferramentas de quebra por macacos-prego (Sapajus libidinosus) que vivem em um fragmento de Manguezal como forma de enriquecer o conhecimento a respeito da flexibilidade e adaptabilidade dessa espécie. Os resultados obtidos contribuem para o aumento do conhecimento sobre a espécie dentro de um contexto comparativo com populações de Sapajus libidinosus que vivem em outras condições ecológicas. O estudo abre novos questionamentos sobre a ecologia dessa espécie em florestas de mangue e sobre a importância do uso de ferramentas de quebra para a obtenção de alimento de origem animal em um ambiente sazonal, tornando necessária a execução de novos estudos para ampliar e aprimorar o conhecimento da Primatologia Brasileira. 


\section{CONCLUSÕES}

1- As bigornas de madeira utilizadas com maior frequência pelos macacos-prego do Morro do Boi apresentaram características facilitadoras de quebra, como substrato reto e rugoso. O substrato rugoso apresentou ondulações na sua superfície semelhantes às depressões encontradas nas bigornas de pedra utilizadas pelos macacos-prego de área de Caatinga/Cerrado.

2- As bigornas de madeira escolhidas pelos macacos-prego do Morro do Boi ou fizeram parte de uma árvore de mangue ou se localizaram próximas às árvores com maior cobertura vegetal, locais mais seguros em relação aos possíveis predadores.

3- Em comparação com S. libidinosus que apresentaram uso de ferramentas frequente em ambiente de Caatinga/Cerrado, os macacos-prego do Morro do Boi escolheram bigornas mais altas e seus martelos foram mais leves devido à diferença na composição material da ferramenta.

4- $\mathrm{O}$ alimento com maior frequência de quebra nos sítios foi o caranguejo, um recurso maior e de provável maior retorno energético do que aos demais recursos animais encapsulados, como os gastrópodes e bivalves.

5- A estação do ano não influenciou na frequência de uso dos sítios de quebra durante o período da pesquisa, corroborando a hipótese da oportunidade, ou seja, os macacosprego do Morro do Boi estiveram expostos aos recursos encapsulados, bigornas e martelos durante toda a pesquisa, usando-os sempre que tiveram oportunidade.

6- Na estação seca houve o aumento dos vestígios de quebra de gastrópodes, turus e outros bivalves nos sítios e isso pode ser um reflexo da baixa disponibilidade de recursos vegetais, o que levou os macacos-prego do Morro do Boi a utilizarem martelos para acessar também recursos encapsulados menores e com menor retorno energético, complementando sua dieta com alimentos alternativos.

7- Os sítios de quebra do Morro do Boi se concentraram na área mais influenciada pela variação da maré, não ocorrendo próximo às dunas e à vegetação de restinga. Esse resultado também confirma a hipótese da oportunidade, pois nessas áreas a invasão das dunas muda as características do solo, impedindo o estabelecimento das tocas dos caranguejos e a colonização de outros crustáceos e moluscos. 


\section{REFERÊNCIAS}

Alcântara-Filho, P. (1978). Contribuição ao estudo da biologia e ecologia do caranguejo-uçá Ucides cordatus cordatus (Linnaeus, 1763) (Crustacea, Decapoda, Brachyura), no manguezal do Rio Ceará (Brasil). Arq. Ciên. Mar, 18: 1-41.

Almeida, L. F, \& Mello, C. F. (1996). Estudo preliminar da biologia e ecologia do caranguejo-uçá, Ucides cordatus (Crustacea, Decapoda, Brachyura), no Município de Curuçá (PA) - Uma contribuição ao manejo de recursos em áreas de manguezais. In: Anais da $3^{a}$ Reunião Especial da SBPC, Ecossistemas Costeiros: do conhecimento à gestão, Florianópolis, SC. p. 499.

Altmann, J. (1974). Observational study of behaviour: sampling methods. Behaviour, 49:223265.

Altmann, J. \& Muruthi P. (1988). Differences in daily life between semi-provisioned and wild-feeding baboons. American Journal of Primatology, 15:213-222.

Altmann, S. A. (1998). Foraging for Survival. Chicago: University of Chicago Press.

Altmann, S. A. (2009). Fallback foods, electric omnivores, and packaging problem. American Journal of Physical Anthropology, 140:615-629.

Alves, R. R. N \& Nishida, A. K. (2004). Population structure of the mangrove crab Ucides cordatus (Crustacea: Decapoda; Brachyura) in the estuary of the Mamanguape River, Northeast Brazil. Tropical Oceanography. Recife, v. 32, n 1, p. 23-37.

Anapol F. \& Lee S. (1994). Morphological adaptation to diet in platyrrhine primates. Am. J. Phys. Anthropol. 94:239-261.

Biondi, L. C. M (2010). Comportamento posicional e uso de substratos em macacos-prego Cebus libidinosus Spix, 1823. Dissertação de Mestrado. Instituto de Psicologia, Universidade de São Paulo, São Paulo.

Boesch, C. \& Boesch, H. (1983). Optimisation of nut-cracking with natural hammers by wild chimpanzees. Behaviour, 83: 265-286. 
Boinski S., Quatrone R. P. \& Swartz, H. (2001). Substrate and tool use by brown capuchins in Suriname: ecological contexts and cognitive bases. American Anthropologist. 102: 741761.

Boyle, S. A. (2008). The effects of Forest fragmentation on primates in the Brazilian Amazon. $\mathrm{PhD}$. Thesis. Arizona State University.

Boyle, S. A.; Lourenço, W. C.; da Silva, S. R. \& Smith, A. T. (2009).Travel and spatial patterns change when Chiropotes satanas chiropotes inhabit forest fragments. International Journal of Primatology. 30:515-531.

Bronikowski, A. M. \& Altmann, J. (1996). Foraging in a variable environment: weather patterns and the behavioral ecology of baboons. Behavioral Ecology and Sociobiology. 39(1): 11-25.

Brown, A. D. \& Zunino, G. E. (1990). Dietary variability in Cebus apella an extreme habitats: evidence for adaptability. Folia Primatologica, 54(3-4):187-195.

Canale, G. R.; Guidorizzi, C. E.; Kierulff, M. C. M. \& Gatto, C. A. F. R. (2009). First record of tool use by wild populations of the yellow-breasted capuchin monkey (Cebus xanthosternos) and new records for the bearded capuchin (Cebus libidinosus). American Journal of Primatology, 71: 1-7.

Castro, A. C. L. (1986). Aspectos bio-ecológicos do caranguejo-uçá, Ucides cordatus cordatus (Linnaeus, 1763), no estuário do Rio dos Cachorros e Estreito do Coqueiro, São Luís, MA. Bol. Lab. Hidrob., São Luís, 7: 7-26.

Coussi-Korbel, S., Fragaszy, D. M. (1995). On the relation between social dynamics and social learning. Animal Behaviour, 50:1441-1453.

Denny, M. W. \& Gaines, S. D. (2007). Encyclopedia ODF tidepools and rock shores. In: Encyclopedias of the Natural World. $\mathrm{N}^{\mathrm{o}}$ 1. Barkeley and Los Angeles, California.University of California Press.

Di Bitetti, M. S. (2001). Home-range use by the tufted capuchin monkey (Cebus apella nigritus) in a subtropical rainforest of Argentina. Journal of Zoology, London 253:33-45.

Di Fiore, A. D., \& Rodman, P. S. (2001). Time allocation pattern on lowland woolly monkey (Lagothrix lagotricha poeppigii) in a Neotropical terra firma forest. International Journal of Primatology. 22: 449-480. 
Digby, L. J. \& Barreto, C. E. (1996). Activity and ranging patterns in common marmosets (Callithrix jacchus): implications for reproductive strategies, In: Adaptive Radiations of Neotropical Primates, edited by M. Norconk, A. Rosenberger \& P. Garber. Plenum Press, New York. 173-185.

dos Santos, R. R. (2010). Uso de ferramentas por macacos-prego em manguezais. Tese de Doutorado. Universidade Federal do Rio Grande do Norte. Natal, 107f.

Dunbar, R.I.M. (1988). Primate social systems. Chapman \& Hall, London.

Dunbar, R. I. M. (1992). Time: a hidden constraint on the behavioral ecology of baboons. Behavioural Ecology and Sociobiology. 31, 35-49.

Emidio, R. A. \& Ferreira, R. G. (2012). Energetic Payoff of Tool Use for Capuchin Monkeys in the Caatinga: Variation by Season and Habitat Type. American Journal of Primatology. 74:332-343.

Enstam, K. L. \& Isbell, L. A. (2004). Microhabitat preference and vertical use of space by patas monkeys (Erythrocebus patas) in relation to predation risk and habitat structure. Folia Primatologica. 75: 70-84.

Falótico, T. (2011). Uso de ferramentas por macacos-prego (Sapajus libidinosus) no Parque Nacional da Serra da Capivara - PI. Tese de Doutorado, Instituto de Psicologia, Universidade de São Paulo, São Paulo.

Fernandes, M. E. B. (1991). Tool Use and Predation of Oysters (Crassostrea rhizophorae) by the Tufted Capuchin, Cebus apella apella, in Brackish Water Mangrove Swamp. Primates, 32(4):529-531.

Fernandes, M. E. B. (1999). Phenological patterns of Rhizophora L., Avicennia L., and Laguncularia in Amazonian mangrove swamps. Hydrobiologia, 413:53-62.

Fernandes, M. E. B. \& Aguiar, N. O. (1993). Evidências sobre a adaptação de primatas neotropicais às áreas de mangue com ênfase em Cebus apella apella (Primates: Cebidae). A Primatologia no Brasil, IV, M. E. Yamamoto (Ed.). 67-80 pp.

Fernandes, M. E. B.; Virgulino, A. R. C.; Nascimento, A. A. M. \& Rodrigues, L. F. P. (2005). Padrões de floração e frutificação em Laguncularia racemosa (L.) Gaertn. F.: uma avaliação metodológica. Boletim do Laboratório de Hidrobiologia, 18: 33-38. 
Ferreira, R. G., Lee, P. C. \& Izar, P. (2008). Food competition in a semi-free-ranging Cebus apella group. Folia Primatologica, 79:463-475.

Ferreira, R. G.; Jerusalinsky, L.; Silva, T. C. F.; de Souza Fialho; M., de Araújo Roque, A.; Fernandes, A. et al. (2009). "On the occurrence of Cebus flavius (Schreber 1774) in the Caatinga, and the use of semi-arid environments by Cebus species in the Brazilian state of Rio Grande do Norte". Primates, 50 (4): 357-362.

Ferreira, R. G.; Emidio, R. A. \& Jerusalinsky, L. (2010). Three stones for three seeds: natural occurrence of selective tool use by capuchins (Cebus libidinosus) based on an analysis of the weight of stones found at nutting sites. American Journal of Primatology, 72(3): 270275.

Fisch, G.; Marengo, J. A. \& Nobre C. (1998). Uma revisão geral sobre o clima da Amazônia. Acta Amazônica, 28(2):101-126.

Fleagle, J. G \& Mittermeier, R. A. (1980). Locomotor behavior, body size, and comparative ecology of seven Surinam monkeys. American Journal of Physical Anthropology. 52:301 -314 .

Flores, A. V. V.; Abrantes, K. G. \& Paula, J. (2005). Estimating abundance and spatial distribution patterns of the bubble crab Dotilla fenestrata (Crustacea, Brachyura). Austral Ecology. 30 (1): 14-23.

Floriani, D. C.; Fernandes-Pinto, E. \& Fukuda, J. C. (2004). Parque Nacional dos Lençóis Maranhenses: o maior campo de dunas costeiras da América do Sul. Gerenciamento Costeiro Integrado, v. I, p. 62-64.

Ford, S. M. \& Hobbs, D. G. (1996). Species definition and differentiation as seen in the postcranial skeleton of Cebus. In: M. A. Norconk; A. L. Rosenberger; P. A. Garber (eds.) Adaptative radiations of neotropical primates. New York, Plenum Publishing Corporation. p. 229-249.

Fox, E. A., van Schaik, C. P., Sitompul, A. \& Wright, D. N. (2004). Intra and interpopulational differences in orangutan (Pongo pygmaeus) activity and diet: implications for the invention of tool use. American Journal of Physical Anthropology. 125: 162-174.

Fragaszy D. M.; Visalberghi, E. M. \& Fedigan, L. M. (2004a). The complete capuchin: the biology of the genus Cebus. Cambridge: Cambridge University Press. 
Fragaszy, D.M.; Visalberghi, E.; Fedigan, L. \& Rylands, A. B. (2004b). Taxonomy, distribution and conservation: where and what are they, and how did they get there? In: Fragaszy D,Fedigan L, Visalberghi E, editors. The complete capuchin: the biology of the genus Cebus. Cambridge: Cambridge University Press. p 13-35.

Fragaszy, D.; Izar, P.; Visalberghi, E.; Otonni, E. B. \& Oliveira, M. G. (2004c). Wild capuchin monkeys (Cebus libidinosus) use anvils and Stone pounding tools. American Journal of Primatology, 64: 359-366.

Fragaszy, D.; Pickering, T.; Liu Q.; Izar, P.; Ottoni, E. \& Visalberghi, E. (2010a). Bearded capuchin monkeys' and a human's efficiency at cracking palm nuts with stone tools: field experiments. Animal Behaviour, 79:321-332.

Fragaszy, D.M., Liu, Q., English, M. \& Simpson, K. (2010b). Energy expenditure and gain from nut-cracking in wild capuchin monkeys (Cebus libidinosus) in Piaui, Brazil.Presented at the XXIII Congress of the International Primatological Society, Kyoto, Japan.

Fragaszy, D. M.; Liu, Q.; Wright B.W.; Allen, A.; Brown, C. W. \& Visalberghi, E. (2013). Wild Bearded Capuchin Monkeys (Sapajus libidinosus) Strategically Place Nuts in a Stable Position during Nut-Cracking. PLoS ONE. 8(2): e56182. doi:10.1371/journal.pone.0056182.

Freese, C. H. \& Oppenheimer, J. R. (1981). The capuchin monkeys, genus Cebus. CoimbraFilho, A.F.; Mittermeier, R.A. Eds. Ecology and behavior of neotropical primates. Vol 1. Academia Brasileira de Ciências. Rio de Janeiro.

Garber, P. A. \& Rehg, J. A.(1999). The ecological role of the prehensile tail in white-faced capuchins (Cebus capucinus). Am. J. Phys. Anthropol. 110: 325-340.

Goren-Inbar, N.; Sharon, G.; Melamed, Y. \& Kislev, M. (2002). Nuts, Nut Cracking, and Pitted Stones at Gesher Benot Ya`aqov, Israel. Proceedings of the National Academy of Sciences, U. S. A. 99:2455-2460.

Groves, C. P. (2001). Primate taxonomy. Washigton, D. C. Smithsonian Institution Press.

Gumert, M. D.; Kluck, M. \& Malaivijitnond, S. (2009). The Physical Characteristics and Usage Patterns of Stone Axe and Pounding Hammers Used by Long-Tailed Macaques in the Andaman Sea Region of Thailand. American Journal of Primatology, 71:594-608. 
Gumert, M. D. \& Malaivijitnond, S. (2012). Marine prey processed with stone tools by Burmese Long-Tailed Macaques (Macaca fascicularis aurea) in intertidal habitats. American Journal of Physical Anthropology. 149:447-457.

Gursky, S.L. (2000). Effect of Seasonality on the Behavior of an Insectivorous Primate. International Journal of Primatology. 21:477-495.

Harrison, M. E. \& Marshall, A. J. (2011). "Strategies for the Use of Fallback Foods in Apes.” International Journal of Primatology. 32 (3): 531-565.

IBAMA. (2003). Plano de manejo do Parque Nacional dos Lençóis Maranhenses. Ministério do Meio Ambiente, Instituto Brasileiro do Meio Ambiente e Recursos Naturais Renováveis. São Luís, MA. 499p.

Isbell, L. A. (1991). Contest and scramble competition: patterns of female aggression and ranging behaviour among primates. Behavioral Ecology, 2(2):143-155.

Isbell, L. A. \& Young, T. P. (1993). Social and ecological influences on activity budgets of vervet monkeys, and their implications for group living. Behavioral Ecology and Sociobiology. 32: 377-385.

Izar, P. (2004). Female social relationship of Cebus apella nigritus in a Southeastern Atlantic forest: an analysis through ecological models of primate social evolution. Behaviour, 141:71-99.

Izar, P. \& Resende, B. D. (2007). Métodos para o estudo do comportamento de primatas em vida livre. Lógicas Metodológicas: trajetos de pesquisa em psicologia (Org. Maria Margarida Pereira Rodrigues \& Paulo Rogério Meira Menandro). Vitória - UFES, PP. 93-117.

Izar, P.; Verderane, M. P.; Peternelli-dos-Santos, L.; Mendonça-Furtado, O.; Presotto, A.; Tokuda, M. et al. (2012). Flexible and Conservative Features of Social Systems in Tufted Capuchin Monkeys: Comparing the Socioecology of Sapajus libidinosus and Sapajus nigritus. American Journal of Primatology, 73:1-17.

Iwamoto, T. \& Dunbar, R. I. M. (1983). Thermoregulation, habitat quality and the behavioural ecology of gelada baboons. Journal of Animal Ecology, 52(2):357-66.

Izawa K. (1979). Foods and feeding behavior of wild black-capped capuchins (Cebus apella). Primates. 20:57-76. 
Janson, C. H. \& van Schaik, C. P. (1993). Ecological risk aversion in juvenile primates: Slow and steady wins the race. In: M Pereira and LA Fairbanks (eds.): Juvenile Primates: Life History, Development, and Behavior. Chicago: The University of Chicago Press. 57-85.

Jolly, A.; Dobson, A.; Rasamananina, H.; Walker, J.; O`Conner, S.; Salberg, M. et al. (2002). Demography of Lemur catta at Berenty Reserve: Effects of troop size, rainfall, and habitat. International Journal of Primatology, 23: 327-353.

Jones, C. (2005). Behavioural flexibility in primates: Causes and consequences. Chicago: Springer Press.

Kay R. F. (1981). The nut-crackers -- a new theory of the adaptations of the ramapithecines. Am. J. Phys. Anthropol. 55:141-151.

Lacerda, L. D. \& Schaeffer-Novelli, Y. (1999). Mangroves of Latin America: the need for conservation and sustainable utilization. In: A. Yáñez-Aranciba \& A. L. Lara Dominguez [Eds.]. Ecosistemas de manglar en America Tropical. Instituto de Ecologia, A.C. México, UICN/ORMA, Costa Rica, NOAA/NMFS Silver Springer MD USA. 5-8.

Lehmann, J.; Korstjens, A. H. \& Dunbar, R. I. M. (2007). Fission-Fusion social systems as a strategy for coping with ecological constraints: a primate case. Evolutionary Ecology. 21:613-63.

Lewis, M. C. \& O'Riain, M. J. (2009). Fish and chips: marine foraging and raiding in a troop of chacma baboons on the Cape Peninsula. 50 years of Zoological Research: reflection and insights. 34-35.

Lourenço, R.; Paula, J. \& Henrique, M. (2000). Estimating the size of Uca tangeri (Crustacea, Ocypodidae) without massive crab capture. Scientia Marina. 64 (4): 437-439.

Liu, Q.; Fragaszy, D.; Wright, B.; Whright, K., Izar, P. \& Visalberghi, E. (2011). Wild bearded capuchin monkeys (Cebus libidinosus) place nuts in anvils selectively. Animal Behaviour. 81: 297-305.

Lynch Alfaro, J. W. (2007). Subgrouping patterns in a group of wild Cebus apella nigritus. International Journal of Primatology. 28(2): 271-289. 
Lynch Alfaro, J. W.; Boubli, J. P.; Olson, L. E.; Di Fiore, A.; Wilson, B.; Gutiérrez-Espeleta, G. A. et al. (2012a). Explosive Pleistocene range expansion leads to widespread Amazonian sympatry between robust and gracile capuchin monkeys. Journal of Biogeography, 39(2):272-288.

Lynch Alfaro, J. W.; Silva Jr., J. S. \& Rylands, A. B. (2012b). How Different Are Robust and Gracile Capuchin Monkeys? An Argument for the use of Sapajus and Cebus. American Journal of Primatology, 00:1-14.

Macintosh, D. J. \& Ashton, E. C. (2002). A Review of Mangrove Biodiversity Conservation and Management Centre for Tropical Ecosystems Research, University of Aarhus, Denmark.

Makedonska, J.; Wright, B. W. \& Strait, D. S. (2012). "The Effect of Dietary Adaption on Cranial Morphological Integration in Capuchins (Order Primates, Genus Cebus).” Edited by Sharon Gursky-Doyen. PLoS ONE 7 (10) (October 26): e40398.

Malaivijitnoud, S.; Lekprayoon, C.; Tandavanittj, N.; Panha, S.; Cheewatham, C \& Hamada, Y. (2007). Stone-Tool Usage by Thai Long-Tailed Macaques (Macaca fascicularis). American Journal of Primatology, 69:227-233.

Mannu, M. (2002). O uso espontâneo de ferramentas em um grupo de macacos-prego em condições de semi liberdade: descrição e demografia. Dissertação (Mestrado em Psicologia (Psicologia Experimental) - Universidade de São Paulo.

Mannu, M. \& Ottoni, E. B. (2009). The enhanced tool-kit of two groups of wild bearded capuchin monkeys in the Caatinga: tool making, associative use, and secondary tools. American Journal of Primatology, 71:242-251.

Marshall, A. J. \& Wrangham, R. W. (2007). "Evolutionary Consequences of Fallback Foods." International Journal of Primatology. 28 (6): 1219-1235.

Marshall, A. J.; Boyko, C. M.; Feilen, K. L.; Boyko, R. H. \& Leighton, M. (2009). "Defining Fallback Foods and Assessing Their Importance in Primate Ecology and Evolution." American Journal of Physical Anthropology 140 (4): 603-614.

Massaro, L.; Liu, Q.; Visalberghi, E. \& Fragaszy, D. (2012). Wild bearded capuchin (Sapajus libidinosus) select hammer tools on the basis of both stone mass and distance from the anvil. Anim Cogn. 15(6):1065-1074. 
Matthews, L. J. (2009). Activity patterns, home range size, and intergroup encounters in Cebus albifrons support existing models of capuchin socioecology. International Journal of Primatology. 30:709-728.

Mehlig, U. (2006). Phenology of the red mangrove, Rhizophora mangle L., in the Caeté Estuary, Pará, equatorial Brazil. Aquat. Bot. 84:158-164.

Ménard N. (2002). Ecological plasticity of Barbary macaques (Macaca sylvanus). Evolutionary Anthropology, 11:95-100.

Menezes, M. P. M; Berger, U. \& Mehlig, U. (2008). Mangrove vegetation in Amazonia: a review of studies from coast of Pará and Maranhão states, north Brazil. Acta Amazonica, 38:403-420.

Milton, K. (1980). Physiological ecology of Howlers (Allouata): Energetic and Digestive considerations and comparison with the Colobinae. International Journal of Primatology, 19(3):513-548.

Milton, K. (1998). Physiological ecology of howlers (Alouatta): energetic and digestive considerations and comparison with the Colobinae. International Journal of Primatology. 19:513-548.

Morris, P. (2009). Life: Primates. [Filme-vídeo]. Produção de Patrick Morris. BBC. BBC One. Reino Unido. 1 DVD, 59 min.

Mosdossy, K. N. (2013). Insect Abundance In Relation To Capuchin (Cebus capucinus) Foraging: Fallback Foods In A Costa Rican Tropical Dry Forest. Dissertation of Master's degree. University of Calgary. Calgary, Alberta. 112p.

Moura, A. C. A. (2004). The capuchin monkey and the Caatinga dry forest: a hard life in harsh habitat. Tese de doutorado. University of Cambridge, Cambridge (UK).

Moura, A. C. A. \& Lee, P. (2004). Capuchin stone tool use in Caatinga dry forest. Science, 306:1909.

Muruthi, P.; Altmann, J. \& Altmann, S. A. (1991). Resource base, parity and reproductive condition affect female feeding time and nutrient intake within and between groups of a baboon population. Oecologia. 87:467-472. 
Nadia, T. L.; Morellatto, L. P. C. \& Machado, I. C. (2012). Reproductive phenology of a northeast Brazilian mangrove community: Environmental and biotic constraints. Flora, 207:682-692.

Nakai, E. S. (2007). Fissão-fusão em Cebus nigritus: flexibilidade social como estratégia de ocupação de ambientes limitantes. Dissertação de Mestrado, Instituto de Psicologia, Universidade de São Paulo, São Paulo.

Ottoni, E. B. \& Mannu, M. (2001). Semifree-ranging tufted capuchin monkeys (Cebus apella) spontaneously use tools to crack open nuts. International Journal of Primatology, $22: 347-358$

Ottoni, E. B. \& Izar, P. (2008). Capuchin Monkey Tool Use: Overview and Implications. Evolutionary Anthropology, 17:171-178.

Pereira, M. E. \& Fairbanks, L. A. (1993). Juvenile Primates. Oxford University Press, New York.

Peres, C. A. (1993). Structure and spatial organization of an Amazonian terra firme forest primate community. Journal of Tropical Ecology, 9(3):259-276.

Peternelli-dos-Santos, L. C. (2009). Diferenças sexo/etárias no forrageamento de Cebus nigritus em Área de Mata Atlântica. Dissertação de Mestrado. Instituto de Psicologia, Universidade de São Paulo, São Paulo.

Phillips, K. A. (1998). Tool use in wild capuchin monkeys (Cebus albifrons trinitatis). American Journal of Primatology, 46: 259-261.

Port-Carvalho, M.; Ferrari, S. F.; Magalhães, C. (2004). Predation of crabs by tufted capuchins (Cebus apella) in Eastern Amazonia. Folia Primatologica, 75: 154-156.

Resende, B. D. (2004). Ontogenia de comportamentos manipulativos em um grupo de macacos-prego (Cebus apella) em situação de semiliberdade. Tese de Doutorado, Instituto de Psicologia, Universidade de São Paulo, São Paulo.

Rímoli, J. (2001). Ecologia de macacos-prego (Cebus apella nigritus, Goldfuss, 1809) na Estação Biológica de Caratinga (MG): Implicações para a conservação de fragmentos de Mata Atlântica. Dissertação de Mestrado. Universidade do Pará. 
Rímoli, J., Strier, K. B. \& Ferrari, S. F. (2008). Seasonal and longitudinal variation in the behavior of free-ranging black tufted capuchins Cebus nigritus (Goldfuss, 1809) in a fragment of Atlantic Forest in Southeastern Brazil. In: A Primatologia no Brasil - 9 (S.F. Ferrari \& J. Rímoli, Eds.) Aracaju, Sociedade Brasileira de Primatologia, Biologia Geral e Experimental - UFS. 130-146.

Robinson, J. G. (1986). Seasonal variation in use of time and space by the wedge-capped capuchin monkey, Cebus olivaceus: Implications for foraging theory. Smithsonian Contributions to Zoology, 431. Washington, DC: Smithsonian Institution Press.

Rocha, V. J.; Reis, N. R. \& Sekiama, M. L. (1998). Uso de ferramentas por Cebus apella (Linnaeus) (Primates, Cebidae) para obtenção de larvas de coleoptera que parasitam sementes de Syagrus romanzoffianum (Cham.) Glassm. (Arecaceae). Rev. Bras. Zool. 15(4): 945-950.

Sabbatini, G.; Stammati, M.; Tavares, M. C. H. \& Visalberghi, E. (2008). Behavioral flexibility of a group of bearded capuchin monkeys (Cebus libidinosus) in the National Park of Brasília (Brazil): consequences of cohabitation with visitors. Brazilian Journal of Biology, 68(4): 685-69.

Sanz, C. M. \& Morgan, D. B. (2009). Flexible and persistent tool-using strategies in honeygathering by wild chimpanzees. International Journal of Primatology, 30: 411-427.

Sanz, C., Call, J. \& Morgan, D. (2009). Design complexity in termite-fishing tools of chimpanzees (Pan troglodytes). Biology Letters, 5: 293-296.

Sanz, C. M., Schoening, C. \& Morgan, D. B. (2010). Chimpanzees prey on army ants with specialized tool set. American Journal of Primatology, 72: 17-24.

Sastry, A. N. (1983). Ecological aspects of reproduction. In: W. B.Vernberg (ed.), The biology of Crustacea: environment adaptations. 8: 179-270 (Academic Press, New York).

Schaeffer-Novelli, Y. (1995). Manguezal: ecossistema entre a terra e o mar. São Paulo, Caribbean Ecological Research.

Schaeffer-Novelli, Y.; Cintrón-Molero, G.; Adaime, R. R. \& Camargo, T. M. (1990). Variability of mangrove ecosystems along the Brazilian coast. Estuaries, 13:204-218.

Seed, A. \& Byrne, R. (2010). Animal Tool-Use. Current Biology, 20:1032-1039. 
Silva, G. M. M.; Veríssimo, K. C. S. \& Oliveira, M. A. B. (2011). Orçamento das atividades diárias de dois grupos de Callithrix jacchus em área urbana. Revista de Etologia, 10 (2): 57-63.

Silva Jr, J. S. (2001). Especiação nos macacos-prego e caiararas, gênero Cebus Erxleben, 1777 (Primates, Cebidae). Tese (Doutorado), Universidade Federal do Rio de Janeiro. p. 292.

Sirianni, G. \& Visalberghi, E. (2013).Wild Bearded Capuchins Process Cashew Nuts Without Contacting Caustic Compounds. American Journal of Primatology. 75:387-393.

Skov, M.W. \& Hartnoll, R. G. (2001). Comparative suitability of binocular observation, burrow counting and excavation for the quantification of the mangrove fiddler crab Uca annulipes (H. Milne Edwards). Hydrobiologia. 449: 201-212.

Skov, M. W.; Vaninni, M.; Shunula, J. P.; Hartnoll, R. G. \& Cannicci, S. (2002). Quantifying the density of mangrove crabs: Ocypodidae and Grapsidae. Marine Biology. 141 (4): $725-$ 732 .

Snaith, T. V. \& Chapman, C. A. (2007). Primate group size and socioecological models: do folivores really play by different rules? Evolutionary Anthropology.16: 94-106.

Son, V. D (2003a). Diet of Macaca fascicularis in a Mangrove Forest, Vietnam. Laboratory Primate Newsletter. Vol 42, n 4:1-5.

Son, V. D. (2003b). Morphology of Macaca fascicularis in a mangrove forest, Vietnam. Laboratory Primate Newsletter, 4(2): 9-11.

Son, V. D. (2004). Time Budgets of Macaca fascicularis in a Mangrove Forest, Vietnam. Laboratory Primate Newsletter. Vol 43, n 3:1-4.

Souto, A; Bione, C. B. C.; Bastos, M.; Bezerra, B. M.; Fragaszy, D. \& Schiel, N. (2011). Critically endangered blond capuchins fish for termites and use new techniques to accomplish the task. Bioloy Letters. doi: 10.1098/rsbl.2011.0034.

Souza-Filho, P. W. (2005). Costa de manguezais de macromaré da Amazônia: cenários morfológicos, mapeamento e quantificação de áreas usando dados de sensores remotos. Revista Brasileira de Geofísica, 23(4):427-435. 
Spagnoletti, N.; Visalberghi, E.; Ottoni, E.; Izar, P. \& Fragaszy, D. (2011). Stone tool use by adult wild bearded capuchin monkeys (Cebus libidinosus). Frequency, efficiency and tool selectivity. Journal of Human Evolution, 61:97 - 107.

Spagnoletti, N.; Visalberghi, E.; Verderane, M.P.; Ottoni, O.; Izar, P. \& Fragaszy, D. (2012). Stone tool use in wild bearded capuchin monkeys, Cebus libidinosus. Is it a strategy to overcome food scarcity? - Anim. Behav. 83: 1285-1294

Spironello, W. R. (2001). The brown capuchin monkey (Cebus apella). Ecology and home range requirements in Central Amazonia. In: Lessons from Amazonia: The ecology and conservation of a fragment forest (R.O. Bierregaard, C. Gascon Jr., T. E. Lovejoy \& R Mesquita, eds). Yale University Press, New Haven \& London. 271-283.

St. Amant, R., and Horton, T. E. (2008). Revisiting the definition of tool use. Animal Behaviour, 75(4):1199-1208.

Steenbeck, R. \& van Schaik, C. P. (2001). Competition and group size in Thomas's langurs (Presbytis thomasi): the folivore paradox revisited. Behavioral Ecology and Sociobiology. 49:100-110.

Taira, J.T.; Verderane M.P., Ottoni, E. B. \& Izar, P. (2002). Exploração das palmeiras Euterpe edulis e Archontophoenix canninghamiana por duas populações de macacosprego (Cebus apella). Anais XX Encontro Anual de Etologia: 326-326.

Taira, J. T. (2007). Consumo do palmito Juçara (Euterpe edulis) por macacos-prego (Cebus nigritus): Estratégia de forrageamento ótimo ou requinte de um gourmet? Dissertação de mestrado apresentada ao Instituto de Psicologia de São Paulo.

Teichroeb, J. A. \& Sicotte, P. (2009). Test of the ecological-constraints model on ursine colobus monkeys (Colobus vellerosus) in Ghana. American Journal of Primatology, 71: 49-59.

Terborgh, J. (1983). Five New World Monkeys: a study in comparative ecology. Princeton University Press, Princeton, New Jersey, p. 260.

Umapathy, G. \& Kumar, A. (2000). Impacts of the habitat fragmentation on time budget and feeding ecology of lion-tailed macaque (Macaca silenus) in rain forest fragments of Anamali Hills, South India. Primate Report, (58): 67-82. 
van Schaik, C. P.; van Noordwijk, M. A.; de Boer, R. J. \& den Tonkelaar, I. (1983). The effect of group size on time budgets and social behavior in wild long-tailed macaques (Macaca fascicularis). Behavioral Ecology and Sociobiology.13:173-181.

van Schaik, C. P., Deaner, R. O. \& Merrill, M. Y. (1999). The conditions for tool use in primates: implications for the evolution of material culture. Journal of Human Evolution, $36(6), 719-741$.

van Schaik, C. \& Knott, C. D. (2001). Geographic variation in tool use on Neesia fruits in Orangutans. American Journal of Physical Anthropology. 11: 331-342.

van Schaik, C. P.; Fox, E. A. \& Fechtman, L. T (2003). Individual variation in the rate of use of tree-hole tools among wild orangutans: implications for hominin evolution. Journal of Human Evolution. 44 (1): 11 - 23.

Verderane, M. P. (2010). Socioecologia de macacos-prego (Cebus libidinosus) em área de ecótono Cerrado/Caatinga. Tese de Doutorado, Instituto de Psicologia, Universidade de São Paulo, São Paulo.

Verderane, M. P.; Izar, P.; Visalberghi, E. \& Fragaszy, D. M. (2013). Socioecology of wild bearded capuchin monkeys (Sapajus libidinosus): an analysis of social relationships among female primates that use tools in feeding. Behaviour. 150: 659-689.

Visalberghi, E. (1990). Tool use in Cebus. Folia Primatologica, 54: 146-154.

Visalberghi, E. \& McGrew, W. C. (1997). Cebus meets Pan. International Journal of Primatology, 18(5):677- 681.

Visalberghi, E.; Fragaszy, D.; Izar, P.; Ottoni, E. B. (2005). Terrestriality and Tool use. Letter. Science, v. 308, p. 951-952.

Visalberghi, E.; Fragaszy, D. M.; Ottoni, E. B.; Izar, P.; Oliveira, M. G. \& Andrade, F. R. D. (2007). Characteristics of hammer Stones and anvils used by wild bearded capuchin monkeys (Cebus libidinosus) to crack open palm nuts. American Journal of Physical Anthropology, 132:426-444.

Visalberghi, E.; Addessi, E.; Truppa, V.; Spagnoletti, N.; Ottoni, E.; Izar, P. \& Fragaszy D. (2009a). Selection of effective stone tools by wild capuchin monkeys. Current Biology, 19:213 - 217. 
Visalberghi, E.; Spagnoletti, N.; da Silva, E. D. R.; Izar, P. \& Fragaszy, D. (2009b). Distribution of potential suitable hammers and transport of hammer tools and nuts by wild capuchin monkeys. Primates. 50 (2): 95-104.

Wainwright, M. (2002). The Natural History of Costa Rican Mammals. Zona Tropical. pp. 135-139.

Whitten, P. L. (1983). Diet and dominance among female vervet monkeys (Cercopithecus aethiops). American Journal of Primatology. 5(2): 139-59.

Wright B. W. (2005). Craniodental biomechanics and dietary toughness in the genus Cebus. J. Hum. Evol. 48(5):473-492.

Wright, B. W.; Wright, K. A.; Chalk, J.; Verderane, M. P.; Fragaszy, D. M.; Visalberghi, E.; et al. (2009). Fallback foraging as a way of life: using dietary toughness to compare the fallback signal among capuchins and implications of interpreting morphological variation. American Journal of Primatology, 140:687-699.

Wunderlich, A. C.; Pinheiro, M. A. A. \& Rodrigues, A. M. T. (2008). Biologia do caranguejo-uçá, Ucides cordatus (Crustacea: Decapoda: Brachyura), na Baía da Babitonga, Santa Catarina, Brasil. Revista Brasileira de Zoologia. 25 (2): 188-198. 